\title{
ADRIANO ZAGER
}

A ativação imune materna e os efeitos sobre a imunidade, neuroinflamação e desenvolvimento da encefalomielite autoimune experimental na prole de camundongos

São Paulo

2013 


\section{ADRIANO ZAGER}

\section{A ativação imune materna e os efeitos sobre a imunidade, neuroinflamação e desenvolvimento da encefalomielite autoimune experimental na prole de camundongos}

Tese apresentada ao Programa de PósGraduação em Patologia Experimental e Comparada da Faculdade de Medicina Veterinária e Zootecnia da Universidade de São Paulo para a obtenção do título de Doutor em Ciências

Departamento:

Patologia

Área de concentração:

Patologia Experimental e Comparada

Orientador:

Prof. Dr. João Palermo Neto

São Paulo

2013 
Autorizo a reprodução parcial ou total desta obra, para fins acadêmicos, desde que citada a fonte.

DADOS INTERNACIONAIS DE CATALOGAÇÃO-NA-PUBLICAÇÃO

(Biblioteca Virginie Buff D’Ápice da Faculdade de Medicina Veterinária e Zootecnia da Universidade de São Paulo)

Zager, Adriano

A ativação imune materna e os efeitos sobre a imunidade, neuroinflamação e desenvolvimento da encefalomielite autoimune experimental na prole de camundongos. / Adriano Zager. -- 2013.

146 f. : il.

Tese (Doutorado) - Universidade de São Paulo. Faculdade de Medicina Veterinária e Zootecnia. Departamento de Patologia, São Paulo, 2013.

Programa de Pós-Graduação: Patologia Experimental e Comparada.

Área de concentração: Patologia Experimental e Comparada.

Orientador: Prof. Dr. João Palermo-Neto.

1. Ativação imune materna. 2. Imunidade mediada por células. 3. Citocinas Th1/Th2/Th17. 4. Neuroinflamação. 5. Encefalomielite autoimune experimental. I. Título. 


\section{CERTIFICADO}

Certificamos que o Projeto intitulado "Kfeitos da exposiça pré-natal ao LPS sobre a resposta neuroimune da prole de camundongos estressados quando adultos", protocolado sob o n $1683 / 2009$, utlizando 250 (duzentos e cincuenta) camundongos, sob a responsabilidade do Prof. Dr. Joāo Palermo Neto, esta de acordo com os principios éticos de experimentaça animal da Comissão de Bicética da Faculdade de Medicina Veterinária e Zootecnia da Universidade de Stro Pauls e foi aprovado em reunia de 09 de setembro de 2009 .

We certify that the Research "Effects of maternal exposure to LIS during pregnancy on stress response of a mice offspring", utilizing 250 (two hundred fifty) mice, protocol number $1633 / 2009$, under the responsibility Prof. Dr. João Palermo Neto, agree with Ethical Principles in Animal Research adopted by Bioethic Commission of the School of Veterinary Medicine and Animal Science of University of Stio Paulo and was approved in the meeting of day $09 / 09 / 09$.

Siso Paulo, 22 de setembro de 2009

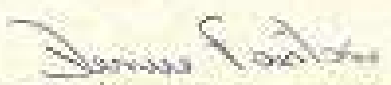

Profa Dra Denise Tabacchi Fantoni

Presidente da Comissīo de Bioética FMVZ/USP 


\section{FOLHA DE AVALIAÇÃO}

Autor: ZAGER, Adriano

Título: $A$ ativação imune materna e os efeitos sobre a imunidade, neuroinflamação e desenvolvimento da encefalomielite autoimune experimental na prole de camundongos

Tese apresentada ao Programa de Pós-Graduação em Patologia Experimental e Comparada da Faculdade de Medicina Veterinária e Zootecnia da Universidade de São Paulo para a obtenção do título de Doutor em Ciências

Data:

1

\section{Banca Examinadora}

Prof. Dr.

Instituição: Julgamento:

Prof. Dr.

Instituição: Julgamento:

Prof. Dr.

Instituição: Julgamento:

Prof. Dr. Instituição: Julgamento:

Prof. Dr. Instituição: Julgamento: 
Esta tese foi realizada no Departamento de Patologia da Faculdade de Medicina Veterinária e Zootecnia - Universidade de São Paulo no período de agosto/09 a agosto/13, com apoio financeiro da Fundação de Amparo à Pesquisa do Estado de São Paulo, processos \#09/51998-6 e \#09/51886-3 (Projeto Temático). 


\section{Agradecimentos}

- Um agradecimento especial ao meu orientador e mestre Prof. João Palermo Neto, um exemplo de profissionalismo e comprometimento com a ciência, por me receber em seu grupo de pesquisa, me dando a oportunidade e as ferramentas para a realização de uma tese bem sucedida, além dos ensinamentos que levarei para a vida toda;

- À toda minha família, em especial aos meus pais, pelo entusiasmo e apoio incondicional, me ajudando e incentivando de todas as formas possíveis para a conclusão de mais essa jornada;

- À minha namorada Sandra que, além de colaborar com esse trabalho, esteve ao meu lado, me apoiando e aconselhando em todos os momentos;

- Aos meus amigos e colaboradores Jean Pierre e Gregory, sem os quais as idéias e experimentos dessa tese não seriam viáveis;

- À todos os membros do grupo de pesquisa em neuroimunomodulação, pelas colaborações e momentos compartilhados durante as referatas;

- Aos professores do Departamento de Patologia, em especial Cristina Massoco, Paulo Maiorka, Frederico Costa-Pinto, Luciano Felício e Martha Bernardi por estarem sempre disponíveis para contribir com o trabalho;

- À todos os colegas de pós-graduação, em especial Daniel Cohn, Thiago Aloia, Luciana Cunha, Thiago Reis, Adriana, Atílio, Milena e Thalita, pela amizade construída ao longo dos anos;

- Aos técnicos do laboratório de Farmacologia Vágner, Herculano e Nicolle, pela ajuda indispensável e apoio técnico durante os experimentos; 
- À todos os funcionários do Biotério, em especial Cláudia, Idalina e Nelsinho, pelo cuidado com os animais, sem os quais esse trabalho não seria possível;

- À todos os funcionários do departamento de Patologia pela boa vontade durante toda a realização dessa tese. 


\section{RESUMO}

ZAGER, A. A ativação imune materna e os efeitos sobre a imunidade, neuroinflamação e desenvolvimento da encefalomielite autoimune experimental na prole de camundongos. [Maternal immune activation and the effects on immunity, neuroinflammation and development of experimental autoimmune encephalomyelitis in the offspring]. 2013. $146 \mathrm{f}$. Tese (Doutorado em Ciências) - Faculdade de Medicina Veterinária e Zootecnia, Universidade de São Paulo, São Paulo, 2013.

Experiências vivenciadas durante o período pré-natal são determinantes para a saúde do feto. A ocorrência de infecções maternas e a consequente ativação do sistema imune da mãe ocasionam uma série de alterações estruturais e funcionais no cérebro da prole, podendo predispor o indivíduo a transtornos psiquiátricos na vida pós-natal, como esquizofrenia e autismo. No entanto, estudos que investigam as alterações imunes na prole ainda são escassos na literatura. Dessa forma, o objetivo do presente estudo foi avaliar, na prole, o impacto da ativação imune materna sobre a atividade imune periférica, a resposta imune-inflamatória no sistema nervoso central (SNC), e sobre o desenvolvimento da encefalomielite autoimune experimental (EAE), o modelo murino de Esclerose Múltipla. Camundongos fêmeas prenhes receberam uma administração de salina ou lipopolissacarídeo (LPS) ao final da gestação (dia gestacional 17) e, quando adulta, a prole foi submetida a 3 experimentos principais, analisando: (1) produção de citocinas, atividade de células da periferia e desenvolvimento da hipersensibilidade do tipo tardia; (2) produção de mediadores inflamatórios por células residentes do SNC e; (3) desenvolvimento dos sintomas clínicos e da resposta imune no decorrer da EAE. Nossos resultados mostraram que a ativação imune materna provocou na prole alterações imunes periféricas, como aumento da produção de Interleucina(IL)12 e exacerbação da resposta de hipersensibilidade do tipo tardia; potencialização da produção das citocinas IL-1 $\beta$ e IL-6 em cultura primária de células residentes do SNC e; piora na severidade dos sintomas clínicos causados pela EAE, que coincide com aumento do infiltrado de linfócitos e macrófagos no SNC e ativação imuneinflamatória das células da glia. Tomados em seu conjunto, os dados do presente trabalho sugerem que condições inflamatórias durante a gestação, particularmente 
durante o final da gestação, podem predispor o feto a distúrbios autoimunes e neurodegenerativos na vida adulta.

Palavras-chave: Ativação imune materna. Imunidade mediada por células. Citocinas Th1/Th2/Th17. Neuroinflamação. Encefalomielite autoimune experimental. 


\section{ABSTRACT}

ZAGER, A. Maternal immune activation and the effects on immunity, neuroinflammation and development of experimental autoimmune encephalomyelitis in the offspring. [A ativação imune materna e os efeitos sobre a imunidade, neuroinflamação e desenvolvimento da encefalomielite autoimune experimental na prole de camundongos]. 2013. 146 f. Tese (Doutorado em Ciências) - Faculdade de Medicina Veterinária e Zootecnia, Universidade de São Paulo, São Paulo, 2013.

Prenatal period experiences are crucial for the fetal health. The occurrence of maternal infections and subsequent maternal immune system activation cause a number of structural and functional changes in the brain of the offspring that may predispose individuals to psychiatric disorders in post-natal life, such as schizophrenia and autism. However, studies investigating offspring's immune alterations are still scarce in the literature. The aim of this study was to evaluate, in mice offspring taken from LPS-treated dams, the impact of maternal immune activation on peripheral immune cell activity, central nervous system (CNS) inflammatory response, and development of experimental autoimmune encephalomyelitis $(E A E)$, the murine model of multiple sclerosis. Pregnant female mice received a dose of either saline or lipopolysaccharide (LPS) during late gestation (gestational day 17), and offspring were used in three experiments to analyze: (1) cytokine production and activity by peripheral immune cells and development of delayed type hypersensitivity, (2) production of inflammatory mediators by resident CNS cells and, (3) development of clinical symptoms and immune response during the course of EAE. Our results showed that maternal immune activation resulted in immune alterations in the offspring, such as increased peripheral production of interleukin (IL) -12 and exacerbated response of delayedtype hypersensitivity; enhancement of IL-1 $\beta$ and IL-6 productions in primary CNS resident cells culture and; increased severity of EAE clinical symptoms, which is positively correlated with the increased lymphocytes and macrophages infiltration within the CNS and also with the immune-inflammatory activation of glial cells. Taken together, the data from this study suggest that inflammatory conditions during pregnancy, especially during the late pregnancy, may predispose the fetus to autoimmune and neurodegenerative disorders in adulthood. 
Keywords: Maternal immune activation. Cell-mediated immunity. Th1/Th2/Th17 cytokines. Neuroinflammation. Experimental autoimmune encephalomyelitis. 


\section{LISTA DE ABREVIATURAS}

6-OHDA - 6-hidroxidopamina

APC - Célula apresentadora de antígeno

BHE - Barreira hematoencefálica

BSA - Albumina bovina sérica

CBA - Cytometric Bead Array

CFA - Adjuvante completo de Freund

Con-A - Concanavalina-A

DA - Doença de Alzheimer

DAMPS - Danger-associated molecular patterns

DCFH - Diclorofluoresceína

DG - Dia gestacional

DP - Doença de Parkinson

DPN - Dia pós-natal

DTH - Delayed-type hipersensitivity

EAE - Encefalomielite Autoimune Experimental

EDTA - Ácido etilenodiamino tetra-acético

EM - Esclerose Múltipla

GFAP - Glial fibrillary acidic protein

HPA - hipotálamo-pituitária-adrenal

Iba-1 - lonized calcium binding adaptor molecule 1

IFN- $\gamma$ - Interferon-gama

IL - Interleucina

IP - Intraperitoneal

IRF-3 - Fator Regulador de Interferon tipo 3

LPS - Lipopolissacarídeo

MAP-2 - Microtubule-Associated Protein 2

MFI - Intensidade média de fluorescência

MHC II - Complexo de histocompatibilidade principal tipo II

MOG - Myelin Oligodendrocyte Glycoprotein

$\mathrm{NFKB}$ - Fator nuclear $\mathrm{kB}$

OVA - Ovalbumina 
PAMPs - Pathogen-associated molecular patterns

PMA - Phorbol myristato acetato

Polyl:C - Ácido polyriboinosinico:polyribocytidilico

SAPI - S. aureus marcado com iodeto de propídio

SC - Subcutânea

SDS - Dodecil sulfato de sódio

SFB - Soro fetal bovino

SNC - Sistema Nervoso Central

TGF- $\beta$ - Fator de transformação do crescimento beta

Th1 - Linfócito T helper 1

Th2 - Linfócito T helper 2

Th17 - Linfócito T helper 17

TNF - Fator de necrose tumoral

Treg - Linfócito $\mathrm{T}$ regulador 


\section{SUMÁRIO}

1 INTRODUÇÃO

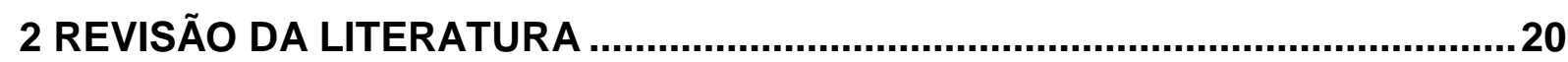

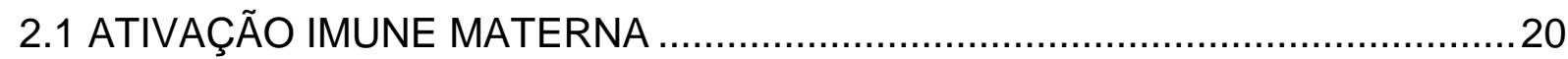

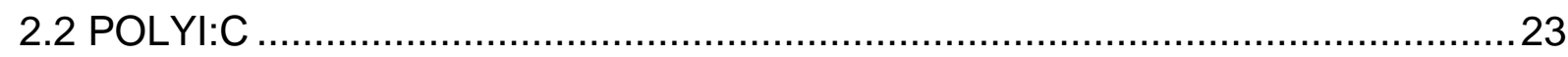

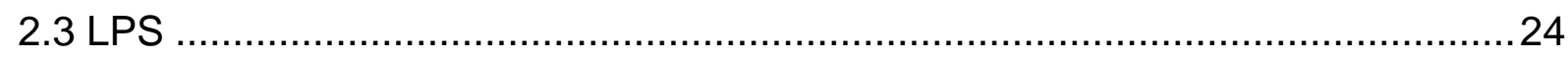

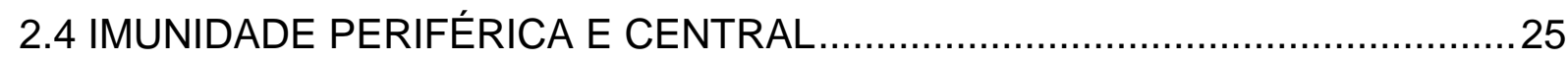

2.5 ESCLEROSE MÚLTIPLA E ENCEFALOMIELITE AUTOIMUNE

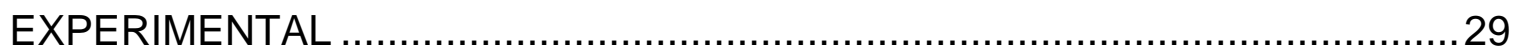

3 OBJETIVOS

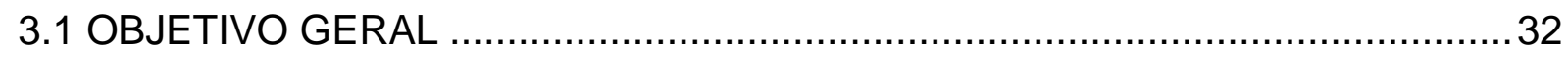

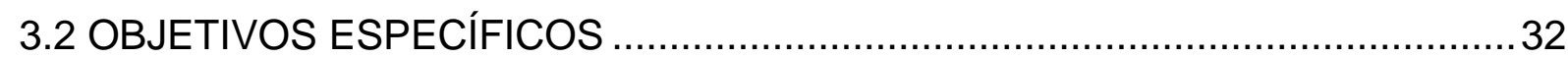

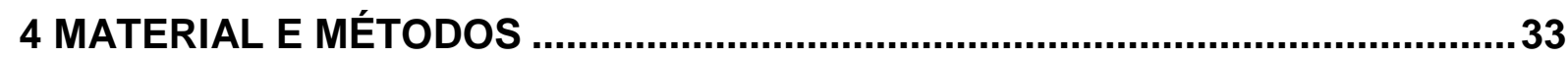

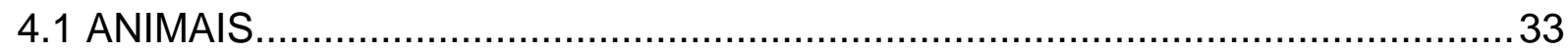

4.2 TRATAMENTO E PROCEDIMENTOS PRÉ-NATAIS .......................................33

4.3 AVALIAÇÃO DO BURST OXIDATIVO E DA FAGOCITOSE POR

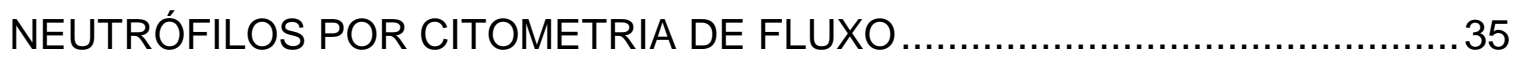

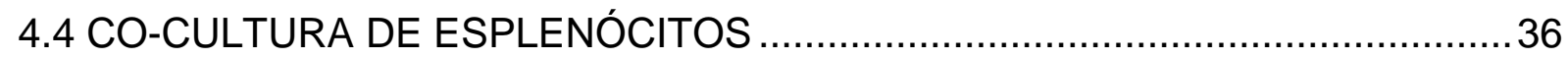

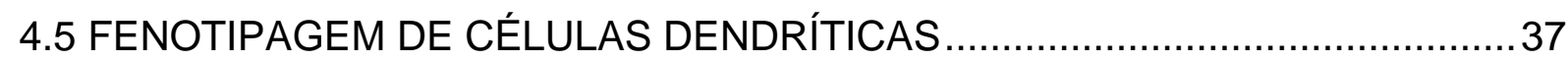

4.6 HIPERSENSIBILIDADE DO TIPO TARDIA (DELAYED-TYPE

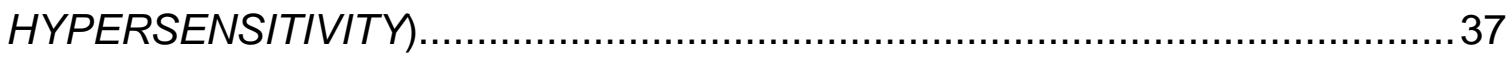

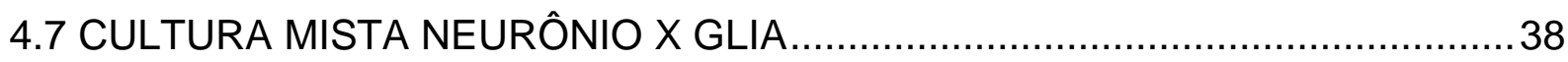

4.8 CARACTERIZAÇÃO DOS TIPOS CELULARES DA CULTURA MISTA

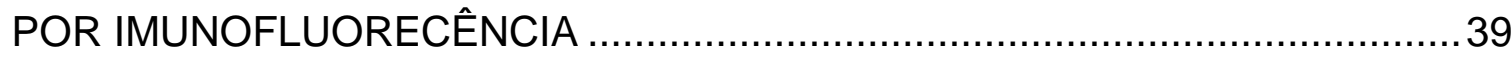

4.9 QUANTIFICAÇÃO DE NITRITOS PELA REAÇÃO DE GRIESS .........................39 
4.10 INDUÇÃO DA ENCEFALOMIELITE AUTOIMUNE EXPERIMENTAL...............40

4.11 MEDIDA DA ATIVIDADE LOCOMOTORA NO CAMPO ABERTO....................40

4.12 OBTENÇÃO DE CÉLULAS MONONUCLEARES DO SNC E

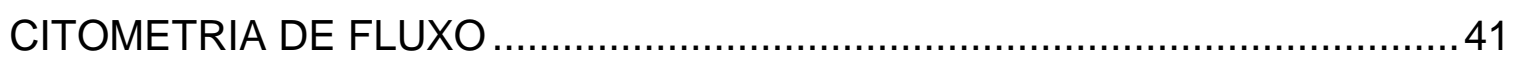

4.13 OBTENÇÃO DE CÉLULAS DO BAÇO E LINFONODOS E CITOMETRIA

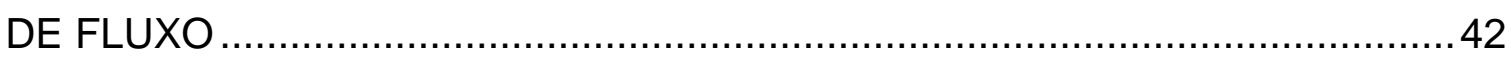

4.14 QUANTIFICAÇÃO DE CITOCINAS NO SOBRENADANTE ............................42

4.15 RT-PCR

4.16 DETERMINAÇÃO DA EXPRESSÃO PROTÉICA POR WESTERN

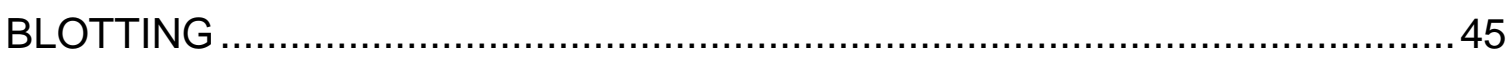

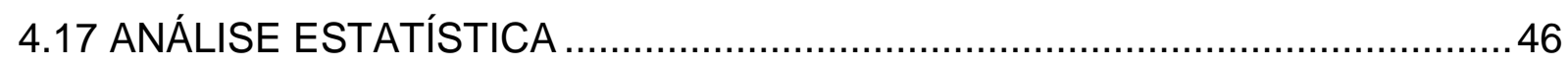

5 DELINEAMENTO EXPERIMENTAL E RESULTADOS.........................................47

5.1 EXPERIMENTO 1: AVALIAÇÃO DAS ALTERAÇÕES IMUNES

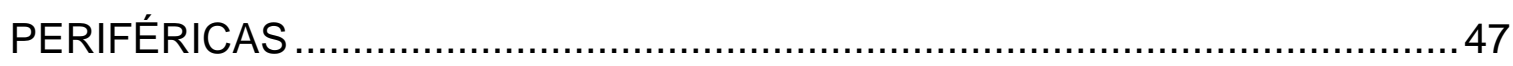

5.1.1 Avaliação do burst oxidativo e da fagocitose por neutrófilos ....................48

5.1.2 Quantificação de citocinas no sobrenadante das culturas .......................49

5.1.2.1 Células não aderentes estimuladas com con-A ........................................49

5.1.2.2 Células aderentes estimuladas com LPS .............................................50

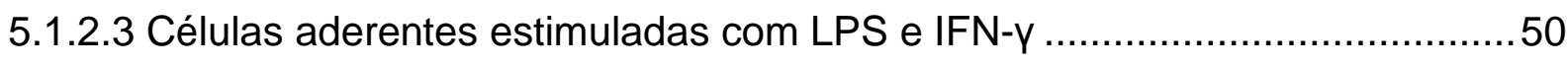

5.1.3 Fenotipagem de células dendríticas ........................................................51

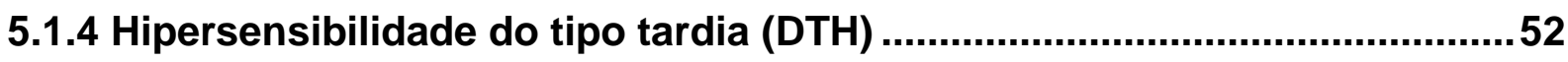

5.2 EXPERIMENTO 2: PRODUÇÃO DE MEDIADORES INFLAMATÓRIOS

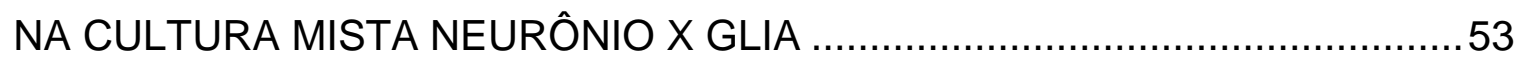

5.2.1 Caracterização celular por imuno-fluorecência.........................................54

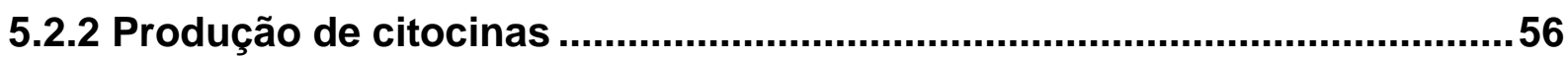


5.2.3 Produção de nitritos

5.3 EXPERIMENTO 3: DESENVOLVIMENTO DA ENCEFALOMIELITE

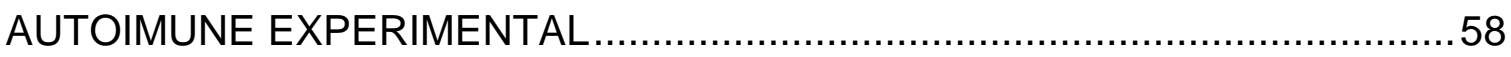

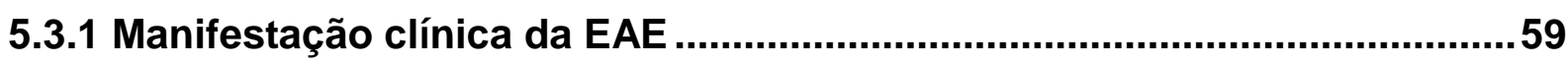

5.3.2 Atividade locomotora no campo aberto .......................................................60

5.3.3 Caracterização do infiltrado celular do SNC durante o pico da EAE.........61

5.3.4 Fenotipagem de células mononucleares …............................................62

5.3.5 Quantificação de citocinas no SNC por RT-PCR ........................................65

5.3.6 Quantificação proteica por Western Blotting ............................................66

5.3.7 Alterações imunes periféricas durante o início da EAE .............................68

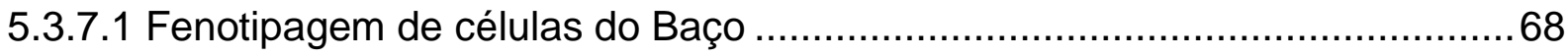

5.3.7.2 Fenotipagem de células dos Linfonodos ................................................69

5.3.7.3 Produção de citocinas no Baço …………….......................................... 70

5.3.7.4 Produção de citocinas nos Linfonodos ................................................... 71

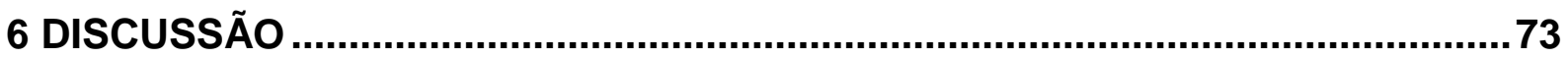

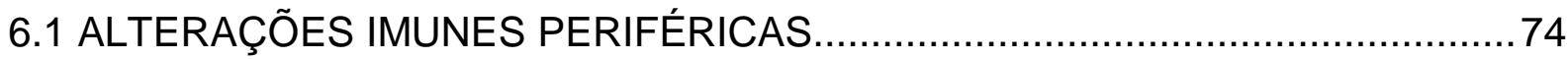

6.2 PRODUÇÃO DE MEDIADORES INFLAMATÓRIOS POR CÉLULAS

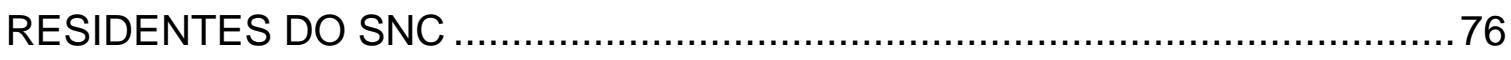

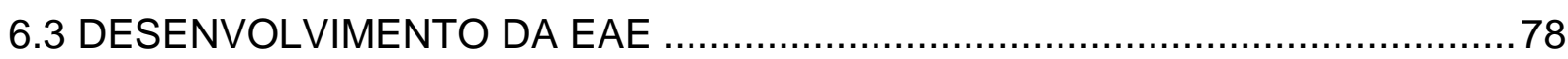

6.4 INFILTRADO DE CÉLULAS IMUNES PERIFÉRICAS DURANTE O PICO DA EAE

6.5 PARTICIPAÇÃO DAS CÉLULAS RESIDENTES DO SNC NA EAE …...............81

6.6 ATERAÇÕES IMUNES PERIFÉRICAS DURANTE O INÍCIO DA EAE ...............82

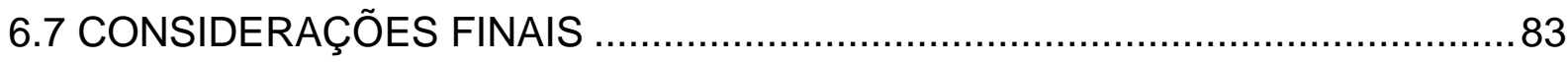

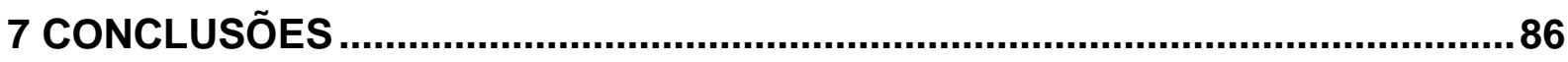




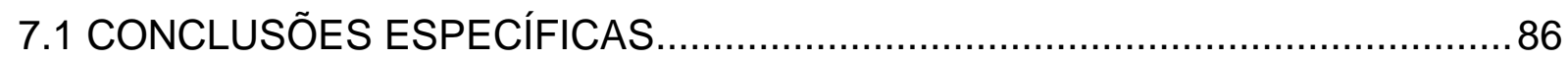

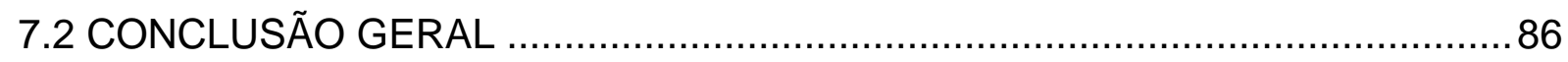

REFERÊNCIAS

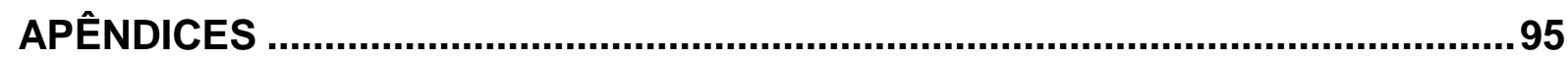




\section{INTRODUÇÃo}

Desde a primeira descrição da síndrome da adaptação geral, feita por Hans Selye em 1936, e da introdução do termo "estresse" em medicina, ficou evidente que estados mentais afetam a fisiologia de um organismo, particularmente o sistema imune. A partir daí, evidências crescentes indicaram que essa interação entre os sistemas nervoso e imune é recíproca, fornecendo as bases da neuroimunomodulação.

Atualmente sabe-se que existe uma interação bi-direcional entre o sistema nervoso e o sistema imune que se manifesta através de um equilíbrio dinâmico tanto em condições fisiológicas como, principalmente, patológicas. Por um lado, mediadores produzidos por células imunes, como citocinas e prostaglandinas, agem no sistema nervoso central (SNC), modulando a atividade de neurônios e causando alterações na neurotransmissão e no comportamento.

Por outro lado, a ativação do sistema nervoso autônomo simpático assim como do eixo hipotálamo-pituitária-adrenal (HPA) modulam a atividade do sistema imune de maneira dependente da intensidade e da duração do estímulo estressor. Levando-se em consideração que orgãos linfóides como baço, linfonodo e timo possuem inervações simpáticas e também respondem aos glicocorticóides, estressores, quando aplicados de forma aguda, estimulam a atividade de certas células, melhorando a resposta imune; por outro lado, estressores crônicos prejudicam a imunidade, principalmente o perfil de citocinas Th1. Não obstante, esse fenômeno pode ser modulado também por receptores de outros neurotransmissores presentes em células imunes como, por exemplo, receptores glutamatérgicos, colinérgicos e adrenérgicos.

Apesar das evidências crescentes indicarem que os sistemas nervoso e imune estão intrisecamente conectados, podendo um controlar e regular a função do outro, essa relação não está muito esclarecida no que diz respeito ao período gestacional. Modelos animais em que estressores ou desafios imunes são aplicados nas mães prenhes são uma importante ferramenta para o estudo das interações neuroimunes; em especial, mostram a importância do ambiente gestacional para a 
fisiologia do feto, mesmo após seu nascimento. Nesse sentido, ainda são escassos os estudos que correlacionam a ativação imune pré-natal com o aparecimento de distúrbios imunológicos e doenças neurodegenerativas na vida adulta, como a esclerose múltipla, sendo o foco do presente trabalho. 


\section{REVISÃO DA LITERATURA}

Nas últimas décadas tornou-se evidente que o desenvolvimento e o comportamento posterior de um organismo imaturo não é determinado somente por fatores genéticos e pelo ambiente pós-natal, mas também pelas condições maternas vivenciadas durante a gestação (KYLE; PICHARD, 2006). É de conhecimento geral que experiências vivenciadas durante a vida perinatal (período que consiste da concepção até o desmame) são capazes de desencadear profundas conseqüências no organismo e na saúde da prole mesmo na vida adulta (PAINTER et al., 2005). Particularmente, a vida e o ambiente intra-uterino desempenham um papel fundamental no desenvolvimento do feto, uma vez que diversos estímulos aplicados sobre a mãe afetam a homeostasia fisiológica do mesmo. Essas alterações observadas na prole, jovem e/ou adulta podem ser decorrentes, entre outros, da ação de fatores nutricionais, farmacológicos e ambientais (ZHANG et al., 2005; VILTART; VANBESIEN-MAILLIOT, 2007; RITZ; WILHELM, 2008).

\subsection{ATIVAÇÃO IMUNE MATERNA}

A exposição da mãe a estímulos imune-inflamatórios representa uma importante comorbidade durante a gravidez, uma vez que o feto é reconhecido pelo organismo da mãe como um tipo de antígeno, o que exige um balanço imunológico muito delicado por parte da mãe para a continuidade da gestação. É sabido que em condições de inflamação sistêmica intensa, o organismo da mãe pode não mais tolerar a presença do feto ocorrendo rejeição e, consequente aborto (DENNEY; CULHANE, 2009; AISEMBERG et al., 2010).

Em condições de inflamação aguda ou de processos inflamatórios em menores proporções, a ativação imune aumenta a liberação de glicocorticóides e, a produção de citocinas pró-inflamatórias, principalmente de Interleucina(IL)-1 $\beta$, IL-6 e Fator de necrose tumoral (TNF) por células do sistema imune da mãe e do feto. Essas citocinas têm a capacidade de atravessar a barreira placentária e 
hematoencefálica, modulando diversas funções em desenvolvimento, como por exemplo, aquelas ligadas ao SNC e ao sistema imune do feto. Ainda, os patógenos podem ser reconhecidos por células do trofoblasto (porção fetal da placenta), que por sua vez também produzem citocinas que vão agir no feto (MEYER et al., 2007), como ilustrado na figura 1.

Figura 1 - Resposta imune e de liberação de citocinas durante a gravidez

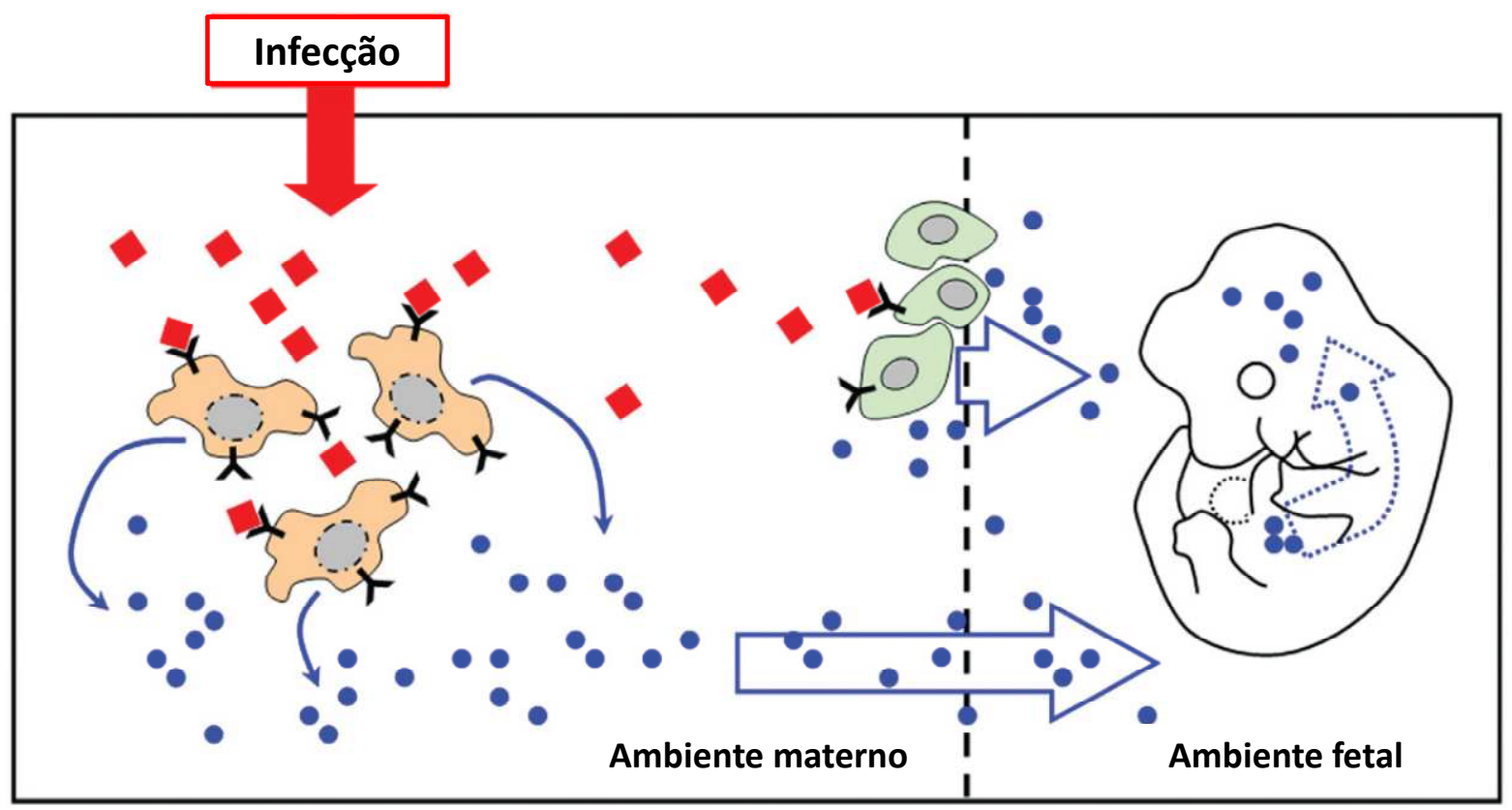

Legenda: Patógenos (em vermelho) são reconhecidos pelo sistema imune materno (em laranja) e por células da placenta, que produzem e liberam citocinas pró-inflamatórias (em azul) no organismo da mãe e no ambiente intra-uterino. Esses mediadores inflamatórios agem no SNC do feto e podem afetar o desenvolvimento neural, dependendo do estágio gestacional e da especificidade dessas citocinas.

Fonte: modificado de Meyer et al. (2007).

No entanto, essas alterações dependem da duração e do estágio gestacional da exposição. Por exemplo, exposição a processos inflamatórios durante o início da gestação (em humanos, o primeiro trimestre; em roedores, até o sétimo dia de prenhez) afetam principalmente a proliferação e diferenciação neural, assim como a maturação sináptica. As conseqüências da inflamação pré-natal são mais funcionais quando ocorrem durante os estágios tardios da gestação (em humanos, o terceiro trimestre; em roedores, a partir do dia 14 de prenhez), modificando principalmente a migração e a organização neural, a maturação sináptica e o crescimento axonal, como ilustrado na figura 2 (MEYER et al., 2007). 
Figura 2 - Efeito diferenciado de desafios pré-natais em diferentes estágios da prenhez sobre o desenvolvimento do SNC
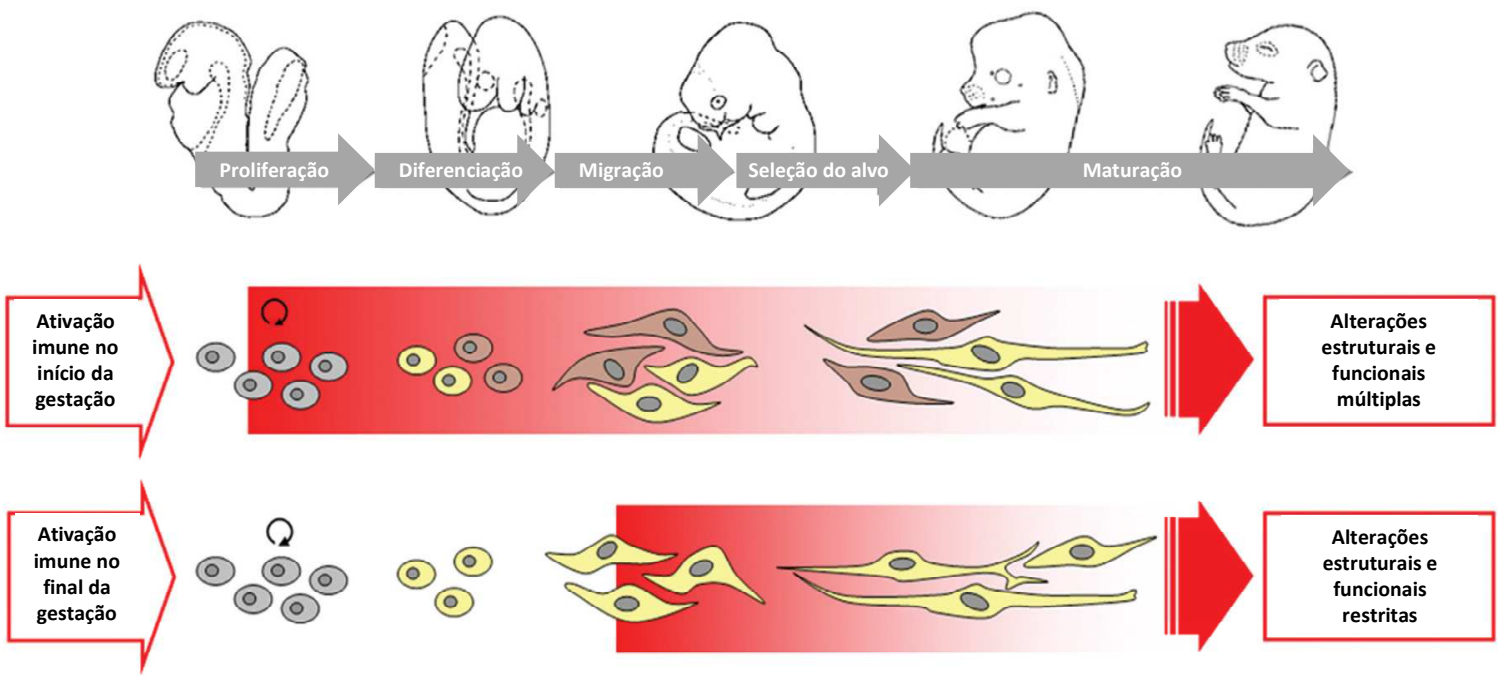

Fonte: modificado de Meyer et al. (2007).

Alguns modelos experimentais têm sido usados para mimetizar as condições de infecções na mãe como, por exemplo, os produzidos por bactérias Gram negativas (Escherichia coll) e Gardinerella vaginalis, que representam as infecções de ocorrência mais comum durante a gravidez (FARO; FENNER, 1998). Nesse sentido, é importante destacar que as infecções por $E$. coli representam cerca de $90 \%$ de todas as infecções no trato urinário de mulheres em idade fértil (FARO; FENNER, 1998).

Conforme descrito por Ashdown et al. (2006), as alterações advindas de inflamação materna descritas na literatura são atribuídas à ativação imune da mãe, e não à uma ação direta do estímulo imune, uma vez que esse estímulo não atravessa a barreira placentária. Por essa razão, experimentos dessa natureza são considerados modelos de Ativação Imune Materna ou Pré-natal. Na tentativa de se estudar de que forma a ativação imune materna influencia o desenvolvimento do feto, diversas abordagens foram criadas, como por exemplo a exposição da mãe à patógenos específicos como por exemplo, à bactéria $E$. coli e ao vírus influenza.

Em contrapartida à administração de patógenos vivos, a ativação imune também pode ser induzida pela administração de proteínas bacterianas e análogos sintéticos virais, o que apresenta vantagens sobre modelos que utilizam agentes patogênicos, uma vez que é possível estabelecer uma curva dose-resposta com o uso desses compostos, além da facilidade de manipulação sem medidas de biosegurança tão restritas. 
Os dois modelos de ativação imune materna mais utilizados na literatura consistem na exposição da mãe a compostos como 0 ácido polyriboinosinico:polyribocytidilico (Polyl:C), considerado um modelo de infecção viral e o lipopolissacarídeo (LPS), um modelo de infecção bacteriana.

\subsection{POLYI:C}

O Polyl:C, um análogo sintético de RNA viral, é reconhecido primeiramente pelo receptor Toll-like 3 das células imunes, que por sua vez ativa fatores de transcrição como o fator nuclear KB (NFKB); esta ativação é responsável pela síntese e liberação de citocinas pró-inflamatórias (principalmente IL-1 $\beta$, IL-6 e TNF- $\alpha$ ) e do Fator Regulador de Interferon tipo 3 (IRF-3). Este fator é responsável pela liberação de interferons $\alpha$ e $\beta$ do tipo 1 que, por sua vez, juntamente com as citocinas, atravessam a barreira placentária exercendo seus efeitos sobre o desenvolvimento fetal (MEYER et al., 2009).

Diversas consequências são relatadas no SNC da prole após a exposição ao Polyl:C; dentre elas, podemos citar diminuição da neurogênese no hipocampo e da expressão dos receptores D1 e D2 no cortéx pré-frontal, e o aumento da expressão de tirosina hidroxilase no mesencéfalo, estridado e núcleo accumbens (MEYER et al., 2008b; 2008c; WINTER et al., 2009; MEYER et al., 2010). Ainda, esse tipo de manipulação afeta também a expressão cerebral de diversos genes responsáveis pelo desenvolvimento de áreas dopaminérgicas (MEYER et al., 2008a).

Quanto ao comportamento da prole, é relatado que o Polyl:C reduz, nos filhotes de mães tratadas, o reconhecimento de objetos, a interação social e o reflexo de startle, aumentando a resposta locomotora à anfetamina; esses dois últimos achados podem ser revertidos pela administração de neurolépticos (antagonistas dopaminérgicos) (ZUCKERMAN et al., 2003; OZAWA et al., 2006; SMITH et al., 2007; MEYER et al., 2008d).

Recentemente, um elegante trabalho publicado na revista Science relatou que um estressor aplicado durante a puberdade foi capaz de desencadear uma série de efeitos provocados pela exposição pré-natal ao Polyl:C, como, por exemplo, a 
resposta comportamental, neuroquímica e neuroinflamatória da prole (GIOVANOLI et al., 2013).

Em contrapartida aos efeitos já conhecidos de desafios imunes durante 0 desenvolvimento, pesquisas recentes já relacionam a ativação imune pré-natal com o aparecimento de doenças neurodegenerativas na vida adulta, como Doença de Alzheimer (DA). Um estudo recente mostrou que a administração de Polyl:C a camundongos wild type no final da gestação (dia gestacional DG17) foi capaz de induzir agregados da proteína $\beta$-amilóide em regiões cerebrais na prole avaliada quando adulta. Nesse mesmo estudo, foi também demonstrado que esse efeito é exacerbado em camundongos triplos transgênicos para a DA, o 3xTg-AD, e que esses achados correlacionam-se com neuroinflamação e morte neuronal aumentadas na prole proveniente de mães desafiadas com Polyl:C (KRSTIC et al., 2012).

\subsection{LPS}

O LPS, uma endotoxina presente na parede celular de bactérias gramnegativas, liga-se, quando administrado, aos receptores de superfície Toll-like 4 e CD40 de macrófagos que induzem ativação de mediadores intracelulares, como o NFkB. Essa ativação induz a síntese e liberação de citocinas pró-inflamatórias produzindo seus efeitos sobre o desenvolvimento fetal (MEYER et al., 2009).

Como exemplo desses efeitos, mostrou-se que a administração única ou repetida de LPS de E. coli no período pré-natal provoca alterações principalmente no sistema dopaminérgico central, incluindo-se aumento da transmissão dopaminérgica no núcleo accumbens (ROMERO et al., 2007) e aumento da locomoção induzida por anfetamina assim como da resposta de sobressalto (FORTIER et al., 2004).

Estudos do nosso laboratório demonstraram que a administração de LPS na metade da gestação de ratas foi capaz de afetar não só a neurotransmissão central, mas também o comportamento da prole, como diminuição da atividade exploratória, comportamento de brincar, interação social e comportamento sexual da prole (BERNARDI et al., 2010; KIRSTEN et al., 2010a; 2010b). 
Não obstante, uma série de estudos correlacionou a ativação imune materna com a perda neuronal em modelos da doença de Parkinson (DP). De fato, a administração de LPS per se foi capaz de reduzir o número de neurônios dopaminérgicos mesencefálicos em ratos, fenômeno esse correlacionado com a expressão aumentada de TNF-a nessa região cerebral (LING et al., 2002; CARVEY et al., 2003). Interessante observar que essa perda neuronal foi progressiva e culminou no $16^{\circ}$ mês de vida do rato, mimetizando a progressão lenta da DP em humanos e representando, portanto, um modelo interessante para o estudo desta patologia.

Mais recentemente, esse mesmo grupo de pesquisadores demonstrou que a exposição pré-natal ao LPS potencializou a perda neuronal provocada por infusões intracerebroventricular de 6-hidroxidopamina (6-OHDA) e rotenona, neurotoxinas que são bem estabelecidas como modelos de DP (LING et al., 2004a; LING et al., 2004b). Tomados em seu conjunto, esses trabalhos indicam que a ativação imune não só age como causa, mas também como fator de risco em modelos animais da DP, e que sua interação na vida adulta com toxinas ambientais como a rotenona (agrotóxico usado até os dias de hoje) deve ser considerada extremamente importante.

Além disso, alterações induzidas pela ativação imune materna durante a fase pré-natal também repercutem na resposta imune da prole, como, por exemplo, desenvolvimento tardio da imunidade inata e aumento da concentração plasmática basal de IL-2, IL-6 e TNF- $\alpha$ (HODYL et al., 2007; ROMERO et al., 2007).

No entanto, estudos que descrevem alterações imunes na prole ainda são escassos na literatura, principalmente no que diz respeito à imunidade adquirida. Dessa forma, fica evidente a necessidade de trabalhos que traçem um perfil imune periférico mais detalhado na prole de mães desafiadas.

\subsection{IMUNIDADE PERIFÉRICA E CENTRAL}

Atualmente sabe-se que os mecanismos efetores da imunidade adquirida dependem de dois eventos principais: da apresentação de antígeno e produção de 
citocinas pelas células apresentadoras de antígeno (APCs, macrófagos e células dendríticas) e da diferenciação dos lintócitos T efetores em subtipos Th1 ou Th2, dependendo do perfil de citocinas secretadas pelas APCs. Citocinas como a IL-12 induzem diferenciação das células T para Th1, a imunidade mediada por células, distinguida principalmente pela produção de IFN- $\gamma$; enquanto a liberação de IL-4 estimula a diferenciação para linfócitos Th2, mediadores da imunidade humoral e produtores de IL-4, IL-5 e IL-13. Recentemente, descobriu-se um novo subtipo de linfócitos $T$ efetores, as células Th17, conhecidas principalmente pela produção de IL-17, em resposta à polarização induzida por IL-23, TGF- $\beta$ e IL-6; e estão relacionadas à reações de hipersensibilidade e autoimunidade (ABBAS et al., 2007).

Mesmo antes da apresentação do antígeno, os macrófagos também se diferenciam em dois subtipos, M1 (de caráter pró-inflamatório) e M2 (de caráter antiinflamatório), de acordo com a presença de ligantes exógenos (padrões moleculares associados a patógenos; pathogen-associated molecular patterns, PAMPs) e endógenos (padrões moleculares associados a perigo; danger-associated molecular patterns, DAMPS) dos receptores do tipo toll. O macrófago M1 caracteriza-se principalmente pela produção das citocinas de perfil Th1 como IL-12, IFN- $\gamma$ e TNF; ao passo que o macrófago M2 produz citocinas de perfil Th2, como IL-4 e IL-13.

Não obstante à resposta imune periférica, atualmente pesquisas indicam que no SNC, também ocorrem eventos característicos de resposta imune, como apresentação de antígeno, produção de citocinas e migração celular. Inicialmente considerado um orgão "imunoprivilegiado" por possuir a barreira hematoencefálica (BHE), acreditou-se que os mediadores inflamatórios presentes no SNC não poderiam ser produzidos in situ e só poderiam vir da periferia. No entanto, evidências crescentes indicam uma participação crucial das células da glia nesses fenômenos (CARSON et al., 2006). Originalmente atribuídas à dar suporte e nutrição aos neurônios, sabe-se, hoje, que as células gliais participam da produção de fatores neurotróficos e da resposta imune no SNC. Neste sentido, a microglia é o maior expoente imune, uma vez que trata-se de uma célula da linhagem hematopoética que é considerada um macrófago residente do SNC.

Sabe-se que as doenças neurodegenerativas possuem um caráter inflamatório bastante pronunciado, com participação de células imunes e citocinas da periferia (GLASS et al., 2010). Evidências sugerem que a progressão de doenças 
degenerativas correlaciona-se com a neuroinflamação provocada e perpetuada pela glia, que é capaz de reconhecer o perfil pró-inflamatório da periferia e secretar diversos mediadores inflamatórios, como citocinas, espécies reativas de oxigênio e prostaglandinas, assim aumentando a permeabilidade da BHE e propagando a perda neuronal (GLASS et al., 2010).

Atualmente sabe-se que progenitores da linhagem mielóide provenientes da medula óssea adentram o SNC durante o desenvolvimento fetal (a partir do DG 14 em roedores), colonizando diversas regiões cerebrais para depois se diferenciar na célula imunocompetente do SNC, a microglia. Assim como proposto para os macrófagos periféricos, sugere-se que a microglia também possa se diferenciar em subtipos M1 (de caráter pró-inflamatório) e M2 (de caráter anti-inflamatório) de acordo com as citocinas secretadas (CUNNINGHAM, 2013). Interessante observar que essa colonização ocorre de forma distinta de acordo com o sexo, idade gestacional e região encefálica, além de ser influenciada por desafios imunes perinatais. Nesse sentido, Bilbo et al. $(2009,2011)$ demonstraram que uma infecção experimental por E. coli em neonatos foi capaz de reprogramar a microglia de forma a torná-la hiper-reativa a desafios subsequentes, aumentando a expressão de complexo de histocompatibilidade principal tipo II (MHC II) e a produção de IL-1 por essas células. Esses achados corroboram com a hipótese de que a microglia seja passível de influência dos fatores ambientais (principalmente infecções) durante o período perinatal alterando suas características morfológicas de um estado ramificado (em repouso e estática) para uma conformação amebóide (ativa e móvel), como ilustrado na figura 3 (BILBO; SCHWARZ, 2009; BILBO et al., 2011). 
Figura 3 - llustração representando o infiltrado de precursores mononucleares no SNC durante o período perinatal e como um desafio imune pode modular a ativação microglial de forma a torná-la hiper-reativa (amebóide e móvel) a desafios subsequentes na vida adulta

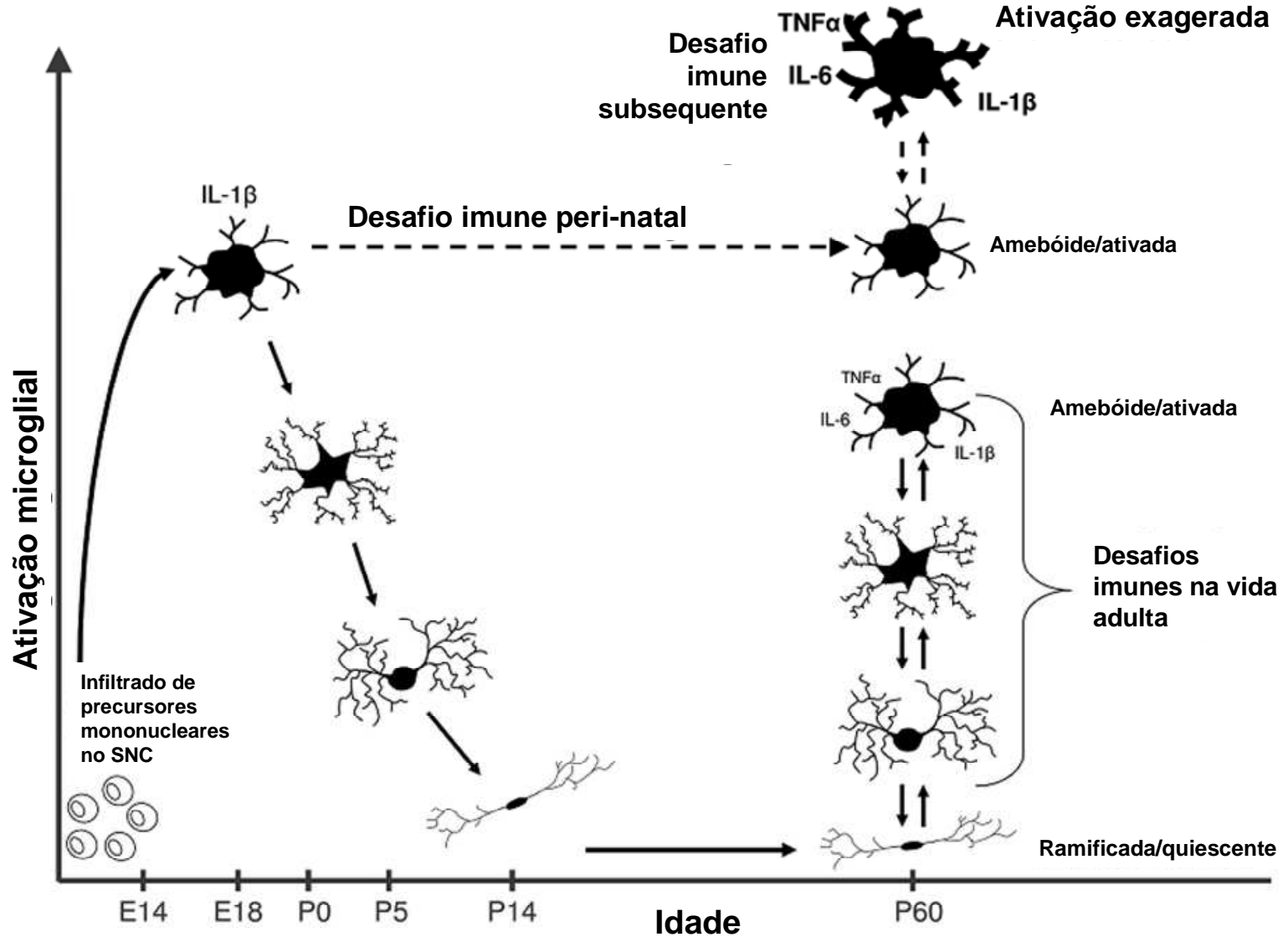

Fonte: Modificado de Bilbo e Schwarz (2009).

A participação dos astrócitos em distúrbios neuroinflamatórios também é fundamental, principalmente em condições autoimunes do SNC como a esclerose múltipla. O astrócito pode ser a principal fonte de IL-6 no SNC (GIRALT et al., 2013) e atuar conjuntamente com as células apresentadoras de antígeno no decorrer da Encefalomielite Autoimune Experimental (EAE) (YANG et al., 2012), o modelo murino da esclerose múltipla

No entanto, a susceptibilidade das células da glia a uma ativação imune prénatal permanece inexplorada, uma vez que esse período é considerado crítico para o desenvolvimento de fenótipo inflamatório da glia e para o aparecimento de doenças neurodegenerativas na vida adulta, como a esclerose múltipla. 


\subsection{ESCLEROSE MÚLTIPLA E ENCEFALOMIELITE AUTOIMUNE EXPERIMENTAL}

A Esclerose Múltipla (EM) é uma doença progressiva e desmielinizante do SNC, de prevalência crescente em países desenvolvidos, afetando aproximadamente de 0,05 a $0,15 \%$ da população caucasiana (NOSEWORTHY et al., 2000). A doença é classificada em duas formas principais: a EM remissivaremitente (cerca de $85 \%$ dos casos) é a mais frequente e afeta duas vezes mais mulheres do que homens, sendo que a maior parte dos casos evolui para a doença secundária-progressiva; e a EM primária-progressiva, que acomete cerca de $15 \%$ dos pacientes e caracteriza-se por início insidioso e progressão constante (KORNEK; LASSMANN, 2003). Ainda não está bem estabelecido quais fatores estão envolvidos em cada forma da doença, mas acredita-se que o background genético, aliado à susceptibilidade individual e às influências ambientais atuem em conjunto para o estabelecimento da EM (GIOVANNONI; EBERS, 2007; HANDEL et al., 2010).

A EM é caracterizada pela perda na capacidade de reconhecimento de antígenos próprios e consequente destruição da mielina pelo sistema imune; diversos tipos celulares estão envolvidos na progressão da doença, como os macrófagos, os linfócitos $\mathrm{B}$ e T CD8 ${ }^{+}$. A participação das células $\mathrm{TCD} 4^{+}$é tida como tendo fundamental importância, uma vez que é o infiltrado desse tipo celular no SNC uma das principais características da doença (SOSPEDRA; MARTIN, 2005). Embora a EM seja considerada uma doença mediada pela resposta Th1, o papel das células Th17 vem se mostrando fundamental como descrito nos últimos anos (SOSPEDRA; MARTIN, 2005).

Grande parte das pesquisas que envolvem a EM são provenientes de modelos animais. A Encefalomielite Autoimune Experimental (EAE), o modelo murino da $E M$, consiste na imunização de camundongos com antígenos de mielina derivados do SNC, emulsificados em adjuvante completo de Freund (CFA). Tal procedimento desencadeia intensa ativação imune, produção de citocinas inflamatórias e quimiocinas, rompimento da barreira hematoencefálica e consequente inflamação do orgão alvo (SNC). Ainda, a participação das células da 
glia nesses processos tem se tornada cada vez mais estudada, uma vez que a ativação de astrócitos e microglia é capaz de potencializar a neuroinflamação e propagar a perda neuronal, como ilustrado na figura 4 (GLASS et al., 2010).

Figura 4 - Ilustração representando a resposta imune no SNC durante a progressão da EM. Destacase a participação dos linfócitos Th17 e dos plasmócitos infiltrantes, além das células Th1. Não obstante, ilustra-se a participação das células da glia na apresentação de antígeno e produção de mediadores inflamatórios

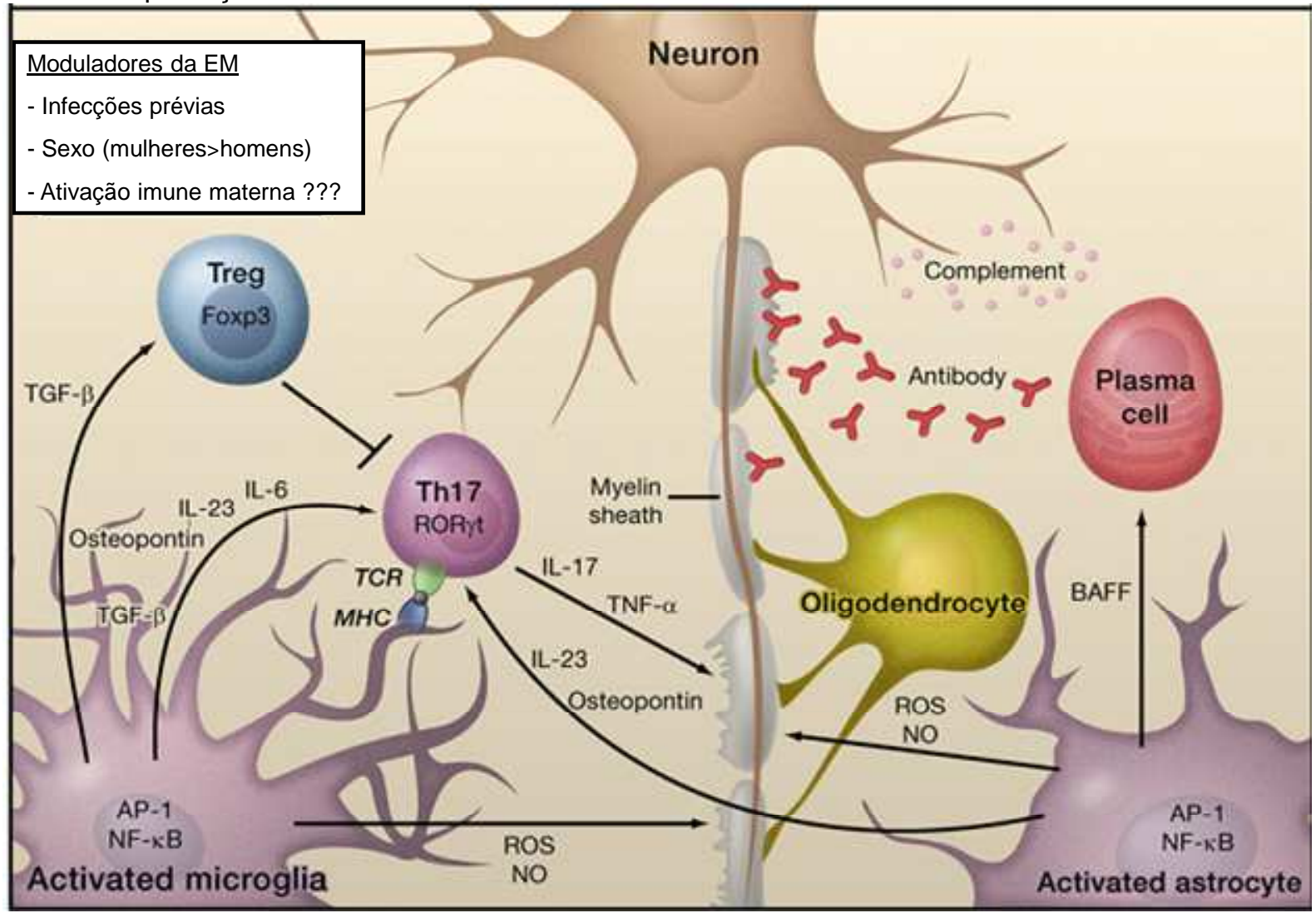

Fonte: modificado de Glass et al. (2010).

Com relação aos fatores predisponentes da $E M$, sabe-se que a influência do ambiente e de infecções prévias contribuem para o surgimento da doença. Nesse sentido, a prevalência aumentada da doença em latitudes extremas levanta a hipótese de uma correlação entre a menor insidência solar e a maior prevalência da EM (FERNANDES DE ABREU et al., 2011). A ocorrência de infecções virais (vírus Herpes e Eppstein-Barr) e bacterianas (Chlamydia pneumoniae) prévias também parece estar relacionada com o desencadeamento da EM, podendo acontecer de duas formas distintas: reatividade cruzada entre o patógeno e antígenos próprios provocada por peptídeos e determinantes antigênicos compartilhados e, ativação 
imune secundária, em que mediadores inflamatórios durante a resposta imune normal, como citocinas e espécies reativas de oxigênio, desencadeiam reação contra antígenos próprios (SOSPEDRA; MARTIN, 2005).

Não obstante, é evidente que fatores ambientais modulam a resposta imune e o consequente desenvolvimento da $\mathrm{EM}$, uma vez que experiências prévias e hábitos de vida influenciam o desencadeamento da doença (HANDEL et al., 2010). Especula-se que toxinas ambientais e infecções prévias representam fatores de risco para o desencadeamento da autoimunidade por atuar justamente na mudança de perfil de citocinas secretadas (LIBBEY et al., 2010). Mandal et al. (2010a, b) demonstraram que a ativação imune materna causada pelo Polyl:C é capaz de influenciar a imunidade da prole de modo a promover a polarização preferencial das células T para o subtipo Th17, indicando uma provável susceptibilidade às doenças auto-imunes.

Nesse sentido, evidências crescentes apóiam a hipótese de que experiências vividas durante o período perinatal, como a ativação imune materna, podem levar à pertubações na imunidade periférica e ao desenvolvimento do SNC. Dessa forma, tornam-se necessários estudos que envolvam a ativação imune da mãe durante a gestação, a resposta imune periférica e neuroinflamatória e o desenvolvimento na vida adulta do modelo murino da EM, a Encefalomielite Autoimune Experimental. 


\section{OBJETIVOS}

\subsection{OBJETIVO GERAL}

Investigar os efeitos da ativação imune pré-natal provocada pela administração de LPS no final da gestação sobre a resposta imune periférica e do SNC da prole de camundongos, assim como a susceptibilidade desta prole à Encefalomielite Autoimune Experimental (EAE).

\subsection{OBJETIVOS ESPECÍFICOS}

A presente tese dividiu-se em três experimentos principais, cujos objetivos foram avaliar os efeitos da ativação imune pré-natal sobre:

- Alterações imunes periféricas na prole adulta; como produção de citocinas e atividade de células imunes;

- A resposta de hipersensibilidade do tipo tardia pela prole adulta, o modelo in vivo para avaliação da imunidade mediada por células;

- A produção de mediadores inflamatórios por células do SNC da prole, através de cultura primária de neurônios e células da glia;

- O desenvolvimento da EAE pela prole, o modelo murino de Esclerose Múltipla.

- O infiltrado de linfócitos e macrófagos no SNC durante o pico dos sintomas da EAE na prole adulta;

- A ativação das células da glia durante o pico dos sintomas da EAE na prole adulta;

- A frequência de células e produção de citocinas em orgão imunes periféricos da prole durante o início da EAE. 


\section{MATERIAL E MÉTODOS}

\subsection{ANIMAIS}

Foram utilizados camundongos da linhagem Swiss e C57BL/6J machos com 70 dias de idade, e fêmeas virgens das mesmas linhagens com 50 dias, provenientes do biotério do Departamento de Patologia da Faculdade de Medicina Veterinária e Zootecnia (FMVZ-USP). O estudo foi conduzido em condições de ventilação/exaustão, luz (claro das 7 às 19 horas) e temperatura $\left(22 \pm 2^{\circ} \mathrm{C}\right.$ ) controladas automaticamente. Ração e água foram mantidos à vontade nas gaiolas padrão de polipropileno.

Os experimentos foram conduzidos seguindo princípios éticos relativos ao uso de animais de experimentação e sob aprovação do Comitê de Bioética da FMVZUSP (protocolo \#1683/2009). O máximo de esforço foi desprendido para minimizar possíveis desconfortos causados aos animais. Além disso, em todos os experimentos do presente trabalho foi empregada a filosofia dos "3Rs" (do inglês replace, reduce e refine), que tem como objetivo reduzir o tamanho da amostra sem comprometer as análises estatísticas e a interpretação dos resultados.

\subsection{TRATAMENTO E PROCEDIMENTOS PRÉ-NATAIS}

Lipopolissacarídeo (LPS derivado de Escherichia coli sorotipo 0127:B8, Sigma, St. Louis, EUA) foi dissolvido em salina estéril 0,9\% e aplicado intraperitonealmente (ip) na dose de $120 \mu \mathrm{g} / \mathrm{kg}$ de peso do animal. Salina estéril foi usada como veículo no volume de $10 \mathrm{ml} / \mathrm{kg}$. Essa dose de LPS foi escolhida 
baseada em dados da literatura que comprovam sua capacidade de ativar o sistema imune da mãe sem induzir aborto ou parto prematuro (GOLAN et al., 2005).

Para obtenção dos filhotes, foram utilizados em cada experimento camundongas com 50 dias de idade, virgens e com ciclo estral sincronizado, acasaladas com machos da mesma linhagem. O número total de animais por caixa $\mathrm{i}$ de 3, sendo 2 fêmeas para cada macho experiente.

Para sincronização do ciclo das fêmeas, foi utilizado uma divisória de acrílico separando o macho das fêmeas, impedindo contato físico mas permitindo contato olfatório entre os animais e consequente sincronização do ciclo das fêmeas na presença do macho, conforme descrito por Meyer et al. (2009). Após 3 dias, a divisória foi retirada permitindo-se, assim, o contato físico dos animais. Esse procedimento está ilustrado na figura 5.

Figura 5 - Ilustração do procedimento de sincronização do ciclo das fêmeas Swiss através da separação de um machos e de duas fêmeas durante o período de três dias
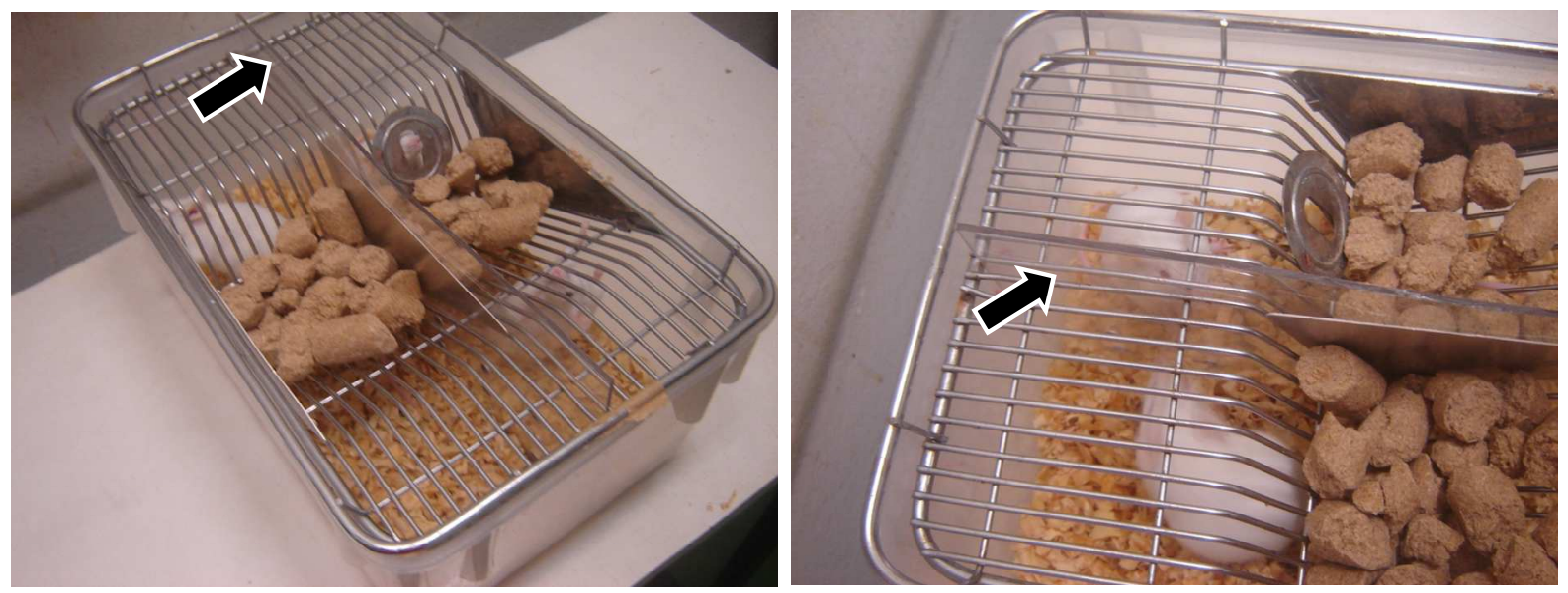

Legenda: Os bebedouros foram retirados para ilustração. As setas pretas indicam as divisórias de acrílico.

Nos dias subsequentes, realizou-se a observação da presença do tampão vaginal no começo da manhã e ao final da tarde, sendo a presença deste considerada como indicativa de acasalamento e dia gestacional zero (DG 0). As fêmeas foram matidas em pares até o dia do tratamento (DG 17), sendo então colocadas em caixas-moradia individuais, onde permaneceram até o desmame dos filhotes, que foi realizado aos 21 dias de vida.

No DG 17, as fêmeas receberam uma única injeção ip de salina ou LPS. Após o desmame no dia pós-natal 21, os filhotes foram distribuídos em grupos distintos de 
4 filhotes por gaiola, respeitando-se o tratamento pré-natal. Evitou-se que filhotes da mesma ninhada fossem alocados em uma mesma gaiola, com o intuito de minimizar variáveis genotípicas eventualmente presentes.

\subsection{AVALIAÇÃO DO BURST OXIDATIVO E DA FAGOCITOSE POR NEUTRÓFILOS POR CITOMETRIA DE FLUXO}

Após a eutanásia dos animais, o sangue foi individualmente coletado em tubos contendo heparina; uma bateria de 5 tubos foi, então, montada para cada animal sendo enumerada de "A" até "E". Cada tubo (de acordo com a letra) recebeu uma substância diferente, obedecendo-se sempre a uma mesma ordem.

Desta forma, todos os tubos de "A" a "E" receberam alíquotas, que correspondiam a $2 \times 10^{5} \mathrm{cel} / 100 \mu \mathrm{l}$ de sangue. Os tubos com as letras "B", "D" e "E"

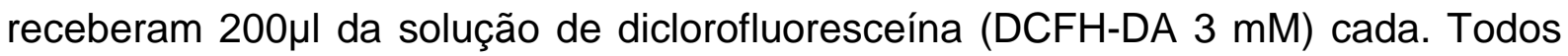
os tubos de letra "C" e "D" receberam $100 \mu l$ da solução de S. aureus marcado com iodeto de propídio (SAPI 100ng). Os tubos de letra "E", por sua vez, receberam $100 \mu \mathrm{l}$ de phorbol myristato acetato (PMA 100 ng). Para que todas as amostras tenham um volume final de $1100 \mu$, todos os tubos foram completados com PBS.

Em seguida, os tubos foram incubados em banho-maria a $37^{\circ} \mathrm{C}$ por 30 minutos. Depois da incubação, foram adicionados $2 \mathrm{ml}$ de EDTA $3 \mathrm{mM}$ nos tubos "C" e " $D$ " para interromper a reação de fagocitose, sendo os mesmos centrifugados posteriormente a $200 \times \mathrm{g}$ por 5 minutos. Desprezou-se o sobrenadante após a centrifugação; as células foram, então, ressuspensas por agitação manual, realizando-se, a seguir, a lise hipotônica das amostras com soluções de $\mathrm{NaCl}$ a $0,2 \%$ e $1,6 \%$. Primeiramente, foi colocado em cada tubo $2 \mathrm{~mL}$ de solução de $\mathrm{NaCl}$ $0,2 \%$, imediatamente após 20 segundos, colocou-se mais $2 \mathrm{~mL}$ de solução de $\mathrm{NaCl}$ $1,6 \%$ para tornar a solução isotônica novamente. Após centrifugação foi realizada uma nova lise hipotônica. Após a segunda lise, os tubos foram centrifugados novamente e os sobrenadantes desprezados; as células resultantes foram ressuspensas em $200 \mu \mathrm{L}$ de PBS gelado. 
Após completar o procedimento para obtenção das amostras, realizou-se a leitura destas no citômetro de fluxo (FACScalibur Becton Dickinson, Immunocytometry Sistem, San Jose, EUA). Os tubos "C" e "D" foram utilizados para a avaliação da fagocitose, enquanto que os tubos "B" e "E" foram utilizados na avaliação do burst oxidativo. Cada amostra passou pelo citômetro apenas 1 vez, e de cada uma delas, foram adquiridos 10.000 eventos (células). A fluorescência foi obtida padronizando-se o número de eventos para cada tubo $A, B, C, D$ e E. Os valores referentes ao burst oxidativo das amostras foram avaliados por meio da média geométrica da intensidade de fluorescência emitida pela população de neutrófilos. O valor da média geométrica foi fornecido pelo software sendo utilizado para indicar a intensidade de fluorescência das células. Com relação à atividade fagocítica, verificou-se a porcentagem de fagocitose, ou seja, o número de neutrófilos que fagocitaram o $S$. aureus marcado com PI e, conseqüentemente que emitiam fluorescência vermelha, divididos pelo número total destas células multiplicadas por 100. Foi avaliada, também, a intensidade de fagocitose (quantidade de bactérias fagocitadas) por meio da média geométrica da intensidade de fluorescência.

\subsection{CO-CULTURA DE ESPLENÓCITOS}

Cada baço foi coletado e macerado em $5 \mathrm{~mL}$ de RPMI-1640 estéril formando uma suspensão de células. Esta suspensão foi centrifugada a $200 \mathrm{xg}$ por 5 minutos e ressuspensa em $9 \mathrm{~mL}$ de cloreto de amônio estéril para a lise das hemácias, sendo centrifugado novamente em seguida. Este procedimento foi repetido mais uma vez para a lise completa das hemácias. Em seguida, as células foram ressuspensas em $5 \mathrm{~mL}$ de meio RPMI completo ( $5 \%$ soro fetal bovino, SFB) estéril, ajustadas para $1 \times 10^{7}$ célula/mL e cultivadas em placas de 6 poços em estufa a $37^{\circ} \mathrm{C}\left(5 \% \mathrm{CO}^{2}\right)$ por duas horas.

Após o período de incubação, as células não aderentes (linfócitos) e aderentes (macrófagos, neutrófilos e células dendríticas) foram separadas, ajustadas novamente para $1 \times 10^{6}$ célula/mL e co-cultivadas em meio RPMI 
completo ( $5 \%$ SFB) por 24 horas na presença de diferentes estímulos. As células não aderentes (linfócitos) foram estimuladas com Concanavalina-A (Con-A 10 $\mu \mathrm{g} / \mathrm{ml}$ ), enquanto as células aderentes (células apresentadoras de antígeno) foram estimuladas com LPS $(1 \mu \mathrm{g} / \mathrm{ml})$ ou LPS mais IFN- $\gamma(50 \mathrm{U} / \mathrm{ml})$. Após o período de 24 horas de incubação, o sobrenadante das culturas foi coletado, centrifugado a $200 \times \mathrm{g}$ por 5 minutos e congelado a $-80^{\circ} \mathrm{C}$ até o dia das análises.

\subsection{FENOTIPAGEM DE CÉLULAS DENDRÍTICAS}

Após as 24 horas de incubação, as células aderentes estimuladas com LPS ou LPS+IFN- $\gamma$ foram ressuspensas e centrifugadas a $200 \times \mathrm{g}$ por 5 minutos. As células remanescentes foram marcadas com anticorpos específicos: CD80-PE, CD86-FITC, IA ${ }^{\text {b}}$-PE and CD11c-FITC (Becton Dickison Biosciences, San Jose, EUA). Após incubação por 60 minutos à temperatura ambiente no escuro, as células foram lavadas duas vezes em PBS (100 $\mu$ l/tubo) e ressuspendidas em $150 \mu \mathrm{L}$ de PBS. A seguir as amostras foram submetidas à leitura em citômetro de fluxo, analisando-se 5.000 eventos do gate selecionado para células dendríticas. Para a aquisição dos resultados foi utilizado o software CellQuest Pro (Becton Dickison Biosciences, San Jose, EUA). Para a análise dos resultados foi utilizado o software FlowJo (Tree Star, Ashland, EUA).

\subsection{HIPERSENSIBILIDADE DO TIPO TARDIA (DELAYED-TYPE HYPERSENSITIVITY}

Vinte camundongos machos adultos foram usados para induzir uma resposta de DTH à ovalbumina (OVA grau V, Sigma-Aldrich $\AA$, St. Louis, EUA), empregando um protocolo descrito anteriormente (RIBEIRO et al., 2010). Resumidamente, os animais foram injetados com 50 ug de OVA emulsionada em $100 \mathrm{uL}$ de adjuvante completo de Freund (CFA, Sigma-Aldrich, St. Louis, EUA) por via subcutânea (sc) na 
base da cauda. Sete dias depois, os animais foram desafiados sc na pata traseira esquerda com 20 ul de uma solução de OVA 4\% agregada em solução salina. A espessura da pata foi medida 1, 4, 6, 24 e 48 horas após o desafio. O aumento relativo na espessura da pata foi calculado subtraindo a espessura inicial, e foi apresentado como a porcentagem de aumento da espessura da pata em relação ao basal.

\subsection{CULTURA MISTA NEURÔNIO X GLIA}

Para esse experimento, neonatos foram sacrificados por decapitação de 1 a 3 dias após o nascimento. Os cérebros foram coletados da maneira mais asséptica possível, dissecados com auxílio de lupa para retirada das meninges e masserados com auxílio de peneira (cell strainer, $70 \mu \mathrm{m}$ ) em meio Dulbecco's Modified Eagle Medium (DMEM F12). Após esses procedimentos, foram agrupados 3 cérebros por placa, obedecendo-se um limite máximo de 1 filhote de cada mãe por cultura e respeitando-se o tratamento pré-natal.

Após a dissociação mecânica dos tecidos, as células foram submetidas à um pré-plaqueamento de 45 minutos para a remoção de fibroblastos. Após essa etapa, as células foram mantidas em garrafas de cultura de $25 \mathrm{~cm}^{2}$ revestidas com Poly-LLisina (Sigma-Aldrich, St. Louis, EUA), trocando-se o meio DMEM F12 a cada 3 dias, onde permaneceram por aproximadamente 12 dias, quando foi confirmada a confluência das células.

As células então foram tripsinizadas (Tripsina 0.05\%; Gibco, Life Technologies, Grand Island, EUA), ressuspendidas em meio DMEM F12 e contadas em câmara de neubauer. Após a contagem, as células foram incubadas em placas de 6 poços revestidas com Poly-L-Lisina na concentração de $5 \times 10^{5}$, onde foram acompanhadas para observação da confluência ( \pm 1 semana), com o meio sendo trocado a cada 3 dias. Ao atingirem confluência, as células foram tratadas ou não

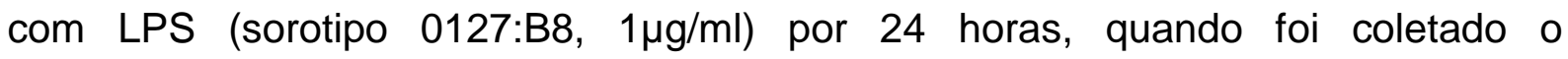
sobrenadante da cultura e as células foram destinadas a diferentes análises, como Imuno-fluorecência. 


\subsection{CARACTERIZAÇÃO DOS TIPOS CELULARES DA CULTURA MISTA POR IMUNOFLUORECÊNCIA}

As células foram contadas e semeadas em placas de 6 wells sobre lamínulas revestidas com Poly-L-Lisina. Após o estímulo com LPS por 24 horas, as lamínulas com as células aderidas foram lavadas 3 vezes com PBS $\left(37^{\circ} \mathrm{C}\right)$ para remoção de fenol vermelho, seguido pela etapa de fixação e permeabilização com metanol por 10 min. Após mais 3 lavagens com PBS (Temperatura ambiente), as células foram saturadas com uma solução de albumina bovina sérica (BSA) $5 \%$ por 30 min (T amb), e em seguida incubadas overnight $\left(4^{\circ} \mathrm{C}\right)$ com os anticorpos primários conjugados GFAP (1:1000) e MAP-2 (1:1000), e GFAP (1:1000) e Iba-1 (1:100). Após mais 3 lavagens com PBS ( $T$ amb), as células foram incubadas com anticorpos secundários Anti-mouse Alexa-488 ou Anti-rabbit Alexa-568 (1/100) por 1 hora. Em seguida, as células foram lavadas mais 3 vezes com PBS ( $T$ amb) e fixadas em lâminas com Vectashield com DAPI.

\subsection{QUANTIFICAÇÃO DE NITRITOS PELA REAÇÃO DE GRIESS}

Os sobrenadantes da cultura mista foram analisados para quantificação de nitritos, que representa uma medida indireta da atividade do óxido nítrico. Para isso, utilizou-se o reagente de griess (Promega BioSciences, Madison, EUA), conforme instruções do fabricante. 


\subsection{INDUÇÃO DA ENCEFALOMIELITE AUTOIMUNE EXPERIMENTAL}

Para indução da $E A E$, a prole adulta foi imunizada por via subcutânea com $150 \mu \mathrm{g}$ de MOG ${ }_{35-55}$ emulsificados em CFA ( $\left.\mathrm{v} / \mathrm{v}\right)$ com um total de $400 \mu \mathrm{g}$ de BCG. Além disso, foram dadas duas doses de $0,2 \mu \mathrm{g}$ toxina de Bordetella pertussis 0 e 48 horas após a imunização.

\subsection{MEDIDA DA ATIVIDADE LOCOMOTORA NO CAMPO ABERTO}

O campo aberto consiste de uma arena redonda feita de madeira, pintada de preto (40 cm de diâmetro e com paredes de $25 \mathrm{~cm}$ de altura, sendo o conjunto todo elevado a $55 \mathrm{~cm}$ do solo). A atividade locomotora dos animais foi avaliada por meio de observação indireta através do sistema ETHOVISION XT (versão 7.0; Noldus Information Technology, Leesburg, EUA). Desta forma, a presença do observador não interferiu com os parâmetros observados, uma vez que este ficou fora da sala onde se encontravam os animais em teste. É importante ressaltar que a sala onde foi realizado o experimento era pouco iluminada e sem nenhum tipo de ruído. Ainda, os animais dos diferentes grupos foram intercalados entre si para evitar possíveis interferências do ritmo circadiano sobre os resultados. Os animais foram colocados no centro da arena e observados por 5 minutos. A avaliação da atividade foi feita sempre no mesmo período do dia (entre as 8:00 hs e 12:00 hs) e, entre as observações, o aparelho foi limpo com solução aquosa de etanol 5\%, com a finalidade de evitar influência de odores deixados pelo animal anterior.

Os parâmetros considerados no presente estudo foram os seguintes: 1) distância percorrida $(\mathrm{cm})$ : corresponde à distância total percorrida pelo animal durante os 10 minutos de teste; 2) velocidade média $(\mathrm{cm} / \mathrm{s})$ : corresponde à média da distância percorrida pelo animal, por unidade de tempo. 


\subsection{OBTENÇÃO DE CÉLULAS MONONUCLEARES DO SNC E CITOMETRIA DE FLUXO}

Após a dissociação mecânica, os cérebros e as medulas dos animais com EAE foram colocados em placas de Petry contendo $2,5 \mathrm{mg} / \mathrm{ml}$ de collagenase $D$ (Roche, Indianapolis, EUA) em $4 \mathrm{ml}$ DMEM durante 45 minutos em estufa à $37^{\circ} \mathrm{C}$. Após esse período de incubação, as amostras foram processadas em cell strainers (peneiras) e transferidas para tubos contendo $15 \mathrm{ml}$ de DMEM. Os tubos então foram centrifugados a $450 \times \mathrm{g}$ por 5 minutos a $4^{\circ} \mathrm{C}$. O pellet foi ressuspendido em 6 $\mathrm{ml}$ de Percoll (Sigma-Aldrich, St. Louis, EUA) a 37\%. Essa suspenção foi então adicionada lentamente sobre Percoll $70 \%$ em tubos de $15 \mathrm{ml}$ e centrifugados a $950 \mathrm{x}$ g por 20 minutos a $4^{\circ} \mathrm{C}$ em centrífuga e, de relevância, com os freios desativados. Ao fim da centrifugação, a fase superior contendo grande concentração de mielina foi coletada e desprezada. $\mathrm{O}$ anel contendo as células mononucleares foi coletado e transferido a tubos de $15 \mathrm{ml}$ contendo DMEM gelado. As células foram então centrifugadas a $450 \times$ g por 5 minutos a $4^{\circ} \mathrm{C}$. O pellet foi ressuspendido em $1 \mathrm{ml} \mathrm{de}$ DMEM ( $5 \%$ SFB) e as células foram então contadas e utilizadas.

Após a contagem, as células foram plaqueadas na concentração mínima de 2 x 10 ${ }^{5}$, e estimuladas com MOG 35-55 (50 $\left.\mu \mathrm{g} / \mathrm{ml}\right)$ e brefeldina (golgi stoper, $1 \mu \mathrm{g} / \mathrm{ml}$ ) overnight. Na manhã seguinte, foram adicionados às células PMA (50 ng/ml) e ionomicina $(1 \mu \mathrm{g} / \mathrm{ml})$ por 3 horas. Após os estímulo, as células foram lavadas, permeabilizadas e incubadas com os seguintes anticorpos:

- Coquetel 1: IFN- $\gamma$ (FITC), IL-17 (PE), CD4 (PercP) e IL-10 (APC).

- Coquetel 2: IA-IE (FITC), CD45 (PercP) e CD11b (Pacific blue).

A imunofenotipagem das células isoladas foi realizada analisando-se a freqüência e a intensidade de fluorescência dos marcadores citados, em citômetro de fluxo FACScanto (Becton Dickison Immunocytometry Sistem, San Jose, EUA). Para a aquisição dos resultados foi utilizado o software CellQuest Pro (Becton Dickison Biosciences, San Jose, EUA). Para a análise dos resultados foi utilizado o software FlowJo (Tree Star, Ashland, EUA). 


\subsection{OBTENÇÃO DE CÉLULAS DO BAÇO E LINFONODOS E CITOMETRIA DE FLUXO}

Após a coleta de baço e linfonodos regionais e dissociação mecânica, os orgãos linfóides foram colocados em cell strainers e transferidas para tubos contendo $15 \mathrm{ml}$ de DMEM. Os tubos então foram centrifugados a $450 \times \mathrm{g}$ por 5 minutos a $4^{\circ} \mathrm{C}$. O pellet foi ressuspendido em $1 \mathrm{ml}$ de DMEM completo e as células foram então contadas e utilizadas como desejado.

Após a contagem, as células foram pipetadas em duas placas de 96 poços na concentração mínima de $1 \times 10^{6}$. A primeira placa foi estimulada com MOG 35-55 $(50 \mu \mathrm{g} / \mathrm{ml})$ e brefeldina (golgi stoper, $1 \mu \mathrm{g} / \mathrm{ml}$; Becton Dickison Biosciences, San Jose, EUA) overnight. Na manhã seguinte, foram adicionados às células PMA (50 $\mathrm{ng} / \mathrm{ml})$ e ionomicina $(1 \mu \mathrm{g} / \mathrm{ml})$ por 3 horas. A segunda placa com as mesmas células foi estimulada somente com MOG $35-55(50 \mu \mathrm{g} / \mathrm{ml})$, e teve seu sobrenadante coletado após 48 horas para avaliação de citocinas de perfil Th1/Th2/Th17.

Após os estímulos, as células da placa 1 foram lavadas, permeabilizadas (Citofix/Citoperm kit, Becton Dickison Biosciences, San Jose, EUA) e incubadas com os anticorpos IA-IE (FITC), IL-17 (PE), CD4 (PercP), IFN- $\gamma$ (APC) e CD11b (Pacific blue). A imunofenotipagem das células isoladas foi realizada analisando-se a freqüência e a intensidade de fluorescência dos marcadores citados, em citômetro de fluxo FACScanto (Becton Dickison Immunocytometry Sistem, San Jose, EUA). Para a aquisição dos resultados foi utilizado o software CellQuest Pro (Becton Dickison Biosciences, San Jose, EUA). Para a análise dos resultados foi utilizado o software FlowJo (Tree Star, Ashland, EUA).

\subsection{QUANTIFICAÇÃO DE CITOCINAS NO SOBRENADANTE}

Os sobrenadantes de cultura foram analisados para as concentrações de IL-2, IL-4, IL-6, IFN- $\gamma$, TNF, IL-17 e IL-10. A quantificação de citocinas foi realizada por citometria de fluxo, utilizando o kit CBA (Cytometric Bead Array) específico para 
Th1/Th2/Th17 (Becton Dickison Biosciences, San Jose, EUA), de acordo com as instruções do fabricante.

As dosagens das citocinas IL-12 e IL-1 $\beta$ foram realizadas por ELISA, utilizando-se os kits ElisaMax (Biolegend, San Diego, EUA), conforme instruções do fabricante.

\subsection{RT-PCR}

A extração de RNA do tecido nervoso foi realizado com o kit para extração de RNA - RNAspin Mini RNA Isolation Kit (GE). Cerca de 10-20 mg de tecido nervoso (cerebelo e córtex) foi adicionado em $350 \mu \mathrm{L}$ da solução de lise RA1 do kit, acrescido de 3,5 $\mu \mathrm{L}$ de B-mercaptoetanol, sendo macerado com a ajuda de um pistilo autoclavado e RNAse-free. A partir deste momento, a mistura foi transferida para colunas de extração, seguindo-se o protocolo determinado pelo fabricante. $O$ processo consistiu basicamente em colocar as células em pequenas colunas de extração (adaptáveis a um eppendorff de 1,5 mL), estas reteram o RNA enquanto o mesmo foi lavado e purificado com uma seqüência de reagentes. Na etapa final, o reagente promoveu a liberação do RNA da coluna, o qual foi mantido em freezer $80^{\circ} \mathrm{C}$ até o momento do uso.

Uma alíquota de $10 \mu \mathrm{L}$ foi retirada para quantificação e verificação da integridade do RNA. O restante foi armazenado imediatamente em freezer $-80^{\circ} \mathrm{C}$ até sua utilização. A análise qualitativa foi realizada submetendo-se as amostras a eletroforese em gel de agarose 1,5\% diluída em TAE 1 X (48,4g de Tris base; $20 \mathrm{~mL}$ de EDTA 0,5M, pH 8,0; 1L,4mL de Ácido Acético; $\mathrm{H} 2 \mathrm{O}$ MilliQ autoclavada q.s.p. $1000 \mathrm{~mL}$ ), $60 \mathrm{~V}$, por 1,5 hora. Após a eletroforese, o gel foi corado em solução de brometo de etídio $\left(0,5 \mathrm{mg} / \mathrm{mL}\right.$ em $\mathrm{H}_{2} \mathrm{O}$ destilada) para a visualização das bandas $28 \mathrm{~S}$ e $18 S$ em luz UV. A correta identificação destas bandas indica a qualidade do RNA. A quantificação foi realizada pelo NanoDrop 2000 (Thermo Scientific, Lafayette, EUA) $(260 / 280 \mathrm{~nm})$. Amostras num alcance de 1,7 até 2,0 $\mathrm{ng} / \mu \mathrm{L}$ indicaram baixa contaminação do RNA, sendo consideradas de boa qualidade para a transcrição reversa. 
Para eliminar quaisquer resquícios de DNA, o RNA total foi tratado com DNAse I. Foi utilizado $1 \mu \mathrm{l}$ de DNAse I para tratar $4 \mu \mathrm{g} / \mu \mathrm{l}$ de RNAtotal. Os eppendorfs foram mantidos à temperatura ambiente por 15 minutos, sendo adicionado $1 \mu$ de EDTA (25mM) para bloquear a ação da enzima e aquecidos por 10 minutos a $65^{\circ} \mathrm{C}$ em banho seco seguido de resfriamento em banho de gelo. As amostras receberam $1 \mu \mathrm{L}$ de Oligo DT; $1 \mu \mathrm{L}$ de dNTPs (mix 10mM-2,5mM de cada dNTP) e posteriormente foram incubadas a $65^{\circ} \mathrm{C}$ por 5 minutos e resfriadas em gelo. Ainda no gelo, foram adicionados a cada tudo $4 \mu \mathrm{L}$ do buffer $5 \mathrm{X}$ (superscript II); $2 \mu \mathrm{l}$ de DTT 1M; $1 \mu \mathrm{L}$ de RNAse OUT incubando-se por 2 minutos a $42^{\circ} \mathrm{C}$ e resfriadas no gelo. Foi acrescido $1 \mu \mathrm{Lda}$ enzima de transcrição reversa superscript II, permanecendo em incubação a $42^{\circ} \mathrm{C}$, por 50 minutos e em seguida por $70^{\circ} \mathrm{C}$ por 15 minutos e resfriados no gelo. Em seguida foi acrescido $1 \mu \mathrm{L}$ da enzima RNAse $\mathrm{H}$ (para eliminação de resíduos de RNA da amostra de cDNA), permanecendo por 20 minutos a $37^{\circ} \mathrm{C}$. O cDNA foi armazenado a $-20^{\circ} \mathrm{C}$ até o momento da amplificação do cDNA. Todos os reagentes foram fornecidos pela Invitrogen (Life Technologies, Grand Island, EUA).

A análise por PCR em tempo real foi realizada em sistema de detecção StepOnePlus Real Time PCR Systems (Applied Biosystems, Life Technologies, Grand Island, EUA). Para avaliação da expressão foram colocados em tubos apropriados (Optical Tubes, Applied Biosystems, Life Technologies, Grand Island, EUA) $2 \mu \mathrm{L}$ de cada produto de PCR (cerca de 10ng de RNA total), tampão A TaqMan 1X, MgCl2 5,5 mM, 200 nM de dATP/dCTP/dGTP, 400vM dUTP, $200 \mathrm{nM}$ dos primers (senso e antisenso), $100 \mathrm{nM}$ das probes TaqMan, 0,01U/mL de AmpErase e $0.025 \mathrm{U} / \mu \mathrm{l}$ da DNA polimerase AmpliTaq Gold em um volume total de $50 \mu \mathrm{L}$. Após a completa mistura dos reagentes, cada tubo foi fechado com tampas MicroAmp Optical (Applied Biosystems, Life Technologies, Grand Island, EUA). Todas as reações foram corridas em duplicata. As condições de amplificação utilizadas para a maior parte dos genes foram: 2 minutos a $50^{\circ} \mathrm{C}, 10$ minutos à $95^{\circ} \mathrm{C}$; seguidos de 50 ciclos a $90^{\circ} \mathrm{C}$ por 15 segundos para desnaturação da fita de cDNA e a $60^{\circ} \mathrm{C}$ por 1 minuto para sua extensão. A interpretação dos resultados foi realizada conforme descrito pelo método comparativo de (LIVAK; SCHMITTGEN, 2001) onde a expressão relativa dos genes corresponde a $2-\Delta \Delta \mathrm{Ct}$. 
Todos os assays (primers) foram adquiridos da empresa Applied Biosystems (Life Technologies, Grand Island, EUA), e seus respectivos IDs estão descritos a seguir: IL-1ß(Mm99999061_mH), IL-6(Mm00446191_m1), TNF(Mm00443258_m1), e 18S(Controle endógeno, 4352930E).

\subsection{DETERMINAÇÃO DA EXPRESSÃO PROTÉICA POR WESTERN BLOTTING}

Os tecidos isolados foram homogeneizados em tampão de extração proteica total $(\mathrm{pH} \mathrm{7,4)}$ contendo $120 \mathrm{mM}$ Tris $(\mathrm{pH} \mathrm{6,8),10 \%} \mathrm{de} \mathrm{dodecil} \mathrm{sulfato} \mathrm{de} \mathrm{sódio}$ (SDS), $0,25 \%$ de deoxicolato de sódio, $1 \mathrm{mM}$ ditodtreiol (DTT), $20 \mu \mathrm{M}$ polimetilsulfonilclorida (PMSF), além do tablete completo de inibidores de proteases (Roche, Indianapolis, EUA). O lisado foi então centrifugado a $12.000 \mathrm{xg}$ a $4^{\circ} \mathrm{C}$ por 13 minutos.

Massas iguais de proteínas totais (50 $\mu \mathrm{g}$ por linha) foram aplicadas em gel de poliacrilamida-SDS $8 \%, 10 \%$ ou $15 \%$, utilizando-se o sistema BioRad (Hercules, EUA). Adicionou-se o tampão de corrida e, em seguida, iniciou-se a corrida em condições constantes de voltagem ( $80 \mathrm{~V}$ ) e variável de amperagem (15 a $45 \mathrm{~mA}$ ). Após a separação protéica, deu-se início à transferência para a membrana de nitrocelulose onde utilizou-se o sistema IBlot gel transfert system (Invitrogen, Life Technologies, Grand Island, EUA). Após a transferência, as membranas foram coradas em solução de ponceau $S$, para verificação da qualidade do processo. Em seguida, as membranas foram lavadas (descoradas) em tampão TBS-T (Tris Buffer solution+Tween) $3 \times 10 \mathrm{~min}$ em agitação constante. Após isso, foram realizados 0 bloqueio e a incubação com o anticorpo primário overnight, diluído em TBST $+3 \%$ BSA (Sigma-Aldrich, St. Louis, EUA ): anti-GFAP, anti-lba-1, anti-pSTAT3, anti-lkk, anti-COX 2, anti-iNOS e anti- $\beta$-actina (1:1000; Millipore, Billerica, EUA). Em seguida, foram feitas várias lavagens em TBS-T $3 \times 10$ min para a retirada do excesso de anticorpo primário, para que assim se pudesse proceder com a incubação do anticorpo secundário adequado anti-mouse (1:10.000; Millipore, Billerica, EUA).

A visualização das bandas foi realizada através do emprego do substrato quimioluminescente ECL (GE Healthcare, Pittsburgh EUA) e posterior exposição ao 
filme fotográfico. A quantificação densitométrica das bandas obtidas se deu por intermédio de uma análise computadorizada utilizando o software ImageJ.

\subsection{ANÁLISE ESTATÍSTICA}

Os resultados foram analisados para verificação de distribuição normal usando-se o teste de Kolmogorov-Smirnov. Quando paramétricos, os dados foram analisados pelo teste-t de Student ou ANOVA de duas vias seguida do teste post hoc de Bonferroni quando apropriado. Quandos não paramétricos, os resultados foram analisados pelo teste "U" de Mann Whitney. Os resultados foram apresentados como média \pm erro padrão e o nível de significância estabelecido foi de $p \leq 0,05$. 


\section{DELINEAMENTO EXPERIMENTAL E RESULTADOS}

\subsection{EXPERIMENTO 1: AVALIAÇÃO DAS ALTERAÇÕES IMUNES PERIFÉRICAS}

Esse experimento inicial foi pautado pela necessidade de se descobrir se a ativação imune pré-natal é capaz de influenciar aspectos específicos da imunidade periférica da prole analisada na vida adulta. Para esse experimento, um grupo de machos adultos proveniente de cada tratamento pré-natal (salina e LPS, $n=10$ ) foram levados a uma sala adjacente, sendo sacrificados por decapitação após insensibilização em câmara de $\mathrm{CO}_{2}$. O sangue dos animais foi coletado em tubos contendo solução anticoagulante (heparina) para análise da atividade de neutrófilos; o baço dos animais foi coletado da forma mais asséptica possível para cultura de esplenócitos.

Esse experimento foi realizado em duplicata com metade do " $\mathrm{n}$ " amostral de cada vez ( 5 animais de proles diferentes por vez), no intuito de se evitar diferenças genotípicas eventualmente presentes. Além disso, um novo grupo de animais de cada tratamento pré-natal ( $n=10 /$ grupo) foi submetido ao protocolo de DTH, conforme descrito anteriormente. No desmame, a prole de fêmeas foram separadas e usadas em outros experimentos. A figura 6 ilustra o desenho experimental adotado. 
Figura 6 - Representação esquemática do desenho experimental adotado no experimento 1

$$
\begin{aligned}
& D G \text { - dia gestacional } \\
& \text { DPN - dia pós-natal }
\end{aligned}
$$

$\begin{array}{ccc}\text { DG } 0 & \text { DG } 17 \text { DPN } 0 & \text { DPN 70 } \\ \begin{array}{c}\text { Presença do } \\ \text { tampão vaginal }\end{array} & \begin{array}{c}\text { Injeção de } \\ \text { salina ou LPS }\end{array} & \begin{array}{c}\text { Coleta de } \\ \text { amostras e } \\ \text { DTH }\end{array} \\ & \text { Nascimento }\end{array}$

\subsubsection{Avaliação do burst oxidativo e da fagocitose por neutrófilos}

O teste-t não demonstrou existência de diferenças estatísticas entre animais dos diferentes grupos quanto aos parâmetros de fagocitose e burst oxidativo de neutrófilos, conforme representado na tabela 1.

Tabela 1 - Índices da atividade de neutrófilos sanguíneos da prole de animais tratados com salina ou LPS durante a gestação e avaliados na vida adulta

\begin{tabular}{ccc}
\hline & \multicolumn{2}{c}{ Grupos } \\
\cline { 2 - 3 } & Salina & LPS \\
\hline \% Fagocitose & $90.3 \pm 1.3$ & $89.5 \pm 2.1$ \\
Intensidade de fagocitose & $589.6 \pm 237.0$ & $809.7 \pm 321.4$ \\
Burst oxidativo basal & $35.7 \pm 4.4$ & $27.3 \pm 4.8$ \\
Burst oxidativo induzido por PMA & $98.9 \pm 11.2$ & $104.1 \pm 9.8$ \\
Burst oxidativo induzido por SAPI & $166.5 \pm 21.8$ & $214.7 \pm 21.0$
\end{tabular}

Os valores estão expressos em média \pm erro padrão $(n=10)$. 


\subsubsection{Quantificação de citocinas no sobrenadante das culturas}

5.1.2.1 Células não aderentes estimuladas com con-A

O teste-t não mostrou existência de efeito significante do tratamento pré-natal com LPS nas concentrações de IL-2, IL-4, IL-6, IFN- $\gamma$, TNF, IL-17 e IL-10 produzidas em culturas de células não-aderentes estimuladas com con-A, a partir dos baços dos descendentes. A figura 7 ilustra esses achados.

Figura 7 - Concentrações de citocinas de perfil Th1, Th2 e Th17 produzidas após estímulo com con-A em cultura de células não aderentes de baço (linfócitos) da prole de fêmeas tratadas com salina ou LPS durante o final da gestação

A

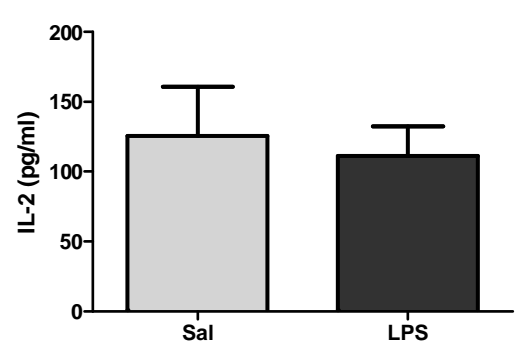

D

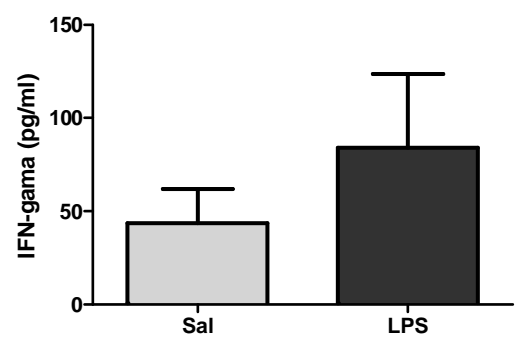

G

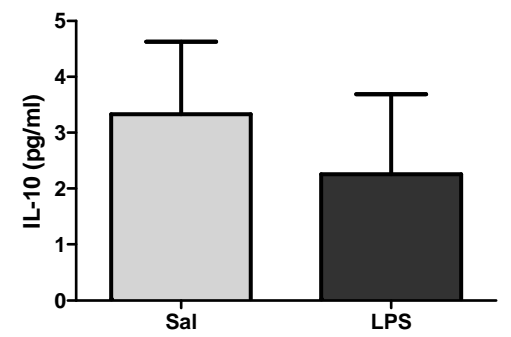

B

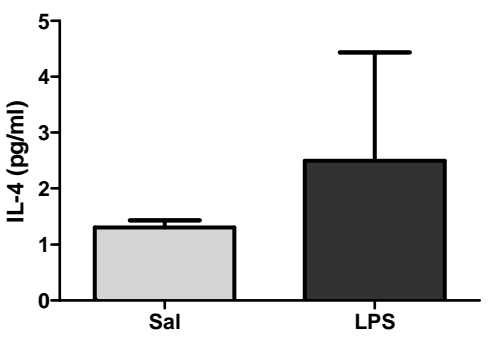

E

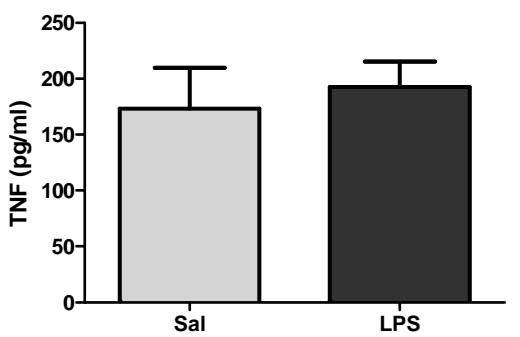

C

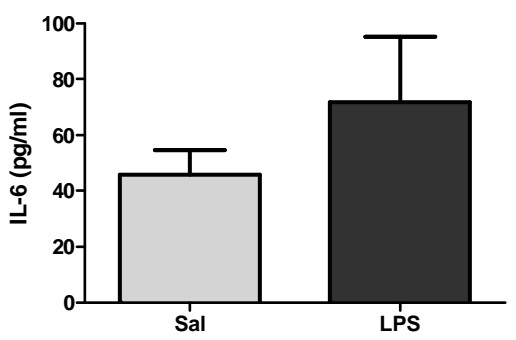

$\mathbf{F}$

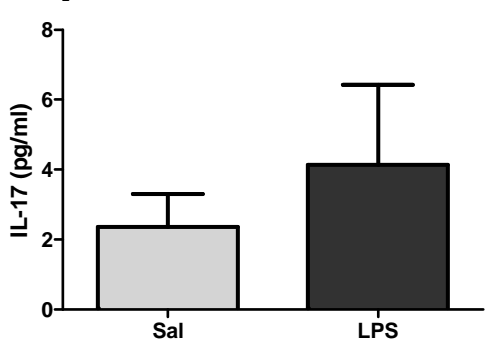

Legenda: Os valores estão expressos em média \pm erro padrão $(n=10)$. 
5.1.2.2 Células aderentes estimuladas com LPS

Como mostrado na figura $8 \mathrm{C}$, o teste-t revelou uma diminuição significante na produção de IL-10 em culturas de células aderentes da prole de mães pré-tratadas com LPS, quando comparado ao grupo controle $(p \leq 0,02)$. Nenhuma diferença entre os grupos foi encontrada nos níveis de IL-6, TNF e IL-12 produzidos após estímulo com LPS, como mostram as figuras $8 \mathrm{~A}$, B e D.

5.1.2.3 Células aderentes estimuladas com LPS e IFN- $\gamma$

O teste-t revelou um aumento significante nos níveis de IL-12 produzidos por esplenócitos aderentes da prole de mães pré-tratadas com LPS, em comparação com o seu respectivo grupo salina $(p \leq 0,01)$. Figura $8 D$ ilustra esses dados. Nenhuma diferença entre os grupos foi encontrada nos níveis de IL-6, TNF e IL-10 produzidos após estímulo com LPS e IFN- $\gamma$, como mostram as figuras 8A, B e C. 
Figura 8 - Concentrações das citocinas IL-6, TNF, IL-10 e IL-12 produzidas após estímulo com LPS ou LPS+IFN- $\gamma$ em cultura de células aderentes de baço (APCs) da prole de fêmeas tratadas com salina ou LPS durante o final da gestação
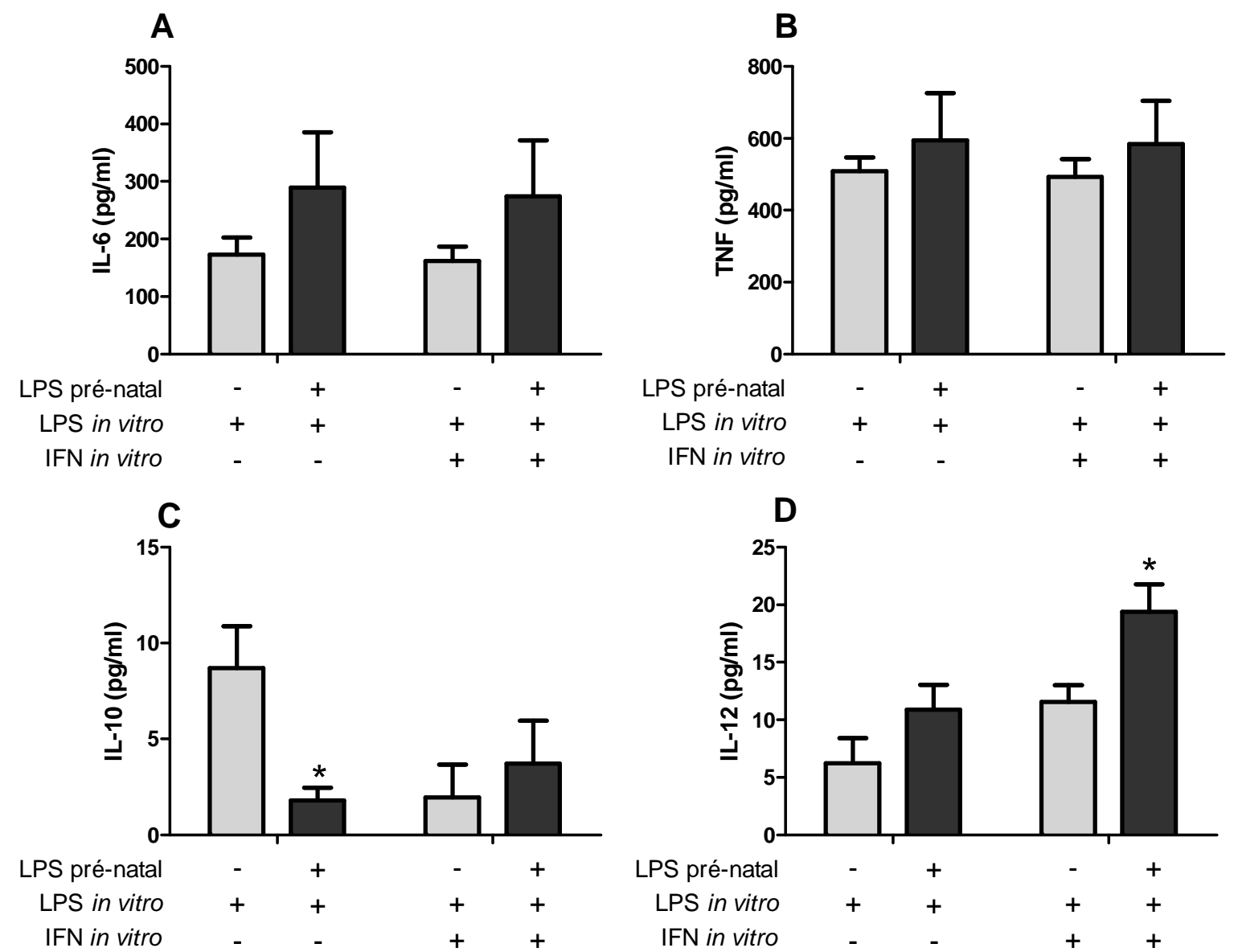

Legenda: Os valores estão expressos em média \pm erro padrão $(n=10) .{ }^{*}$ difere do grupo controle após o mesmo estímulo.

\subsubsection{Fenotipagem de células dendríticas}

Como evidenciado pelo teste-t, as células aderentes em culturas estimuladas com LPS e LPS + IFN- $\gamma$ não apresentaram quaisquer diferenças entre os grupos com relação à intensidade média de fluorescência (MFI) dos marcadores CD80, CD86 e IA ${ }^{b}$ (MHC II), bem como da dupla marcação de células CD80 ${ }^{+} \mathrm{CD} 86^{+}$. Além disso, o teste $U$ de Mann Whitney não mostrou diferenças significativas relativas à dupla coloração de células $C D 11 C^{+} I A^{b+}$. A figura 9 ilustra estes resultados. 
Figura 9 - Fenotipagem de células dendríticas da prole de fêmeas tratadas com salina ou LPS durante o final da gestação
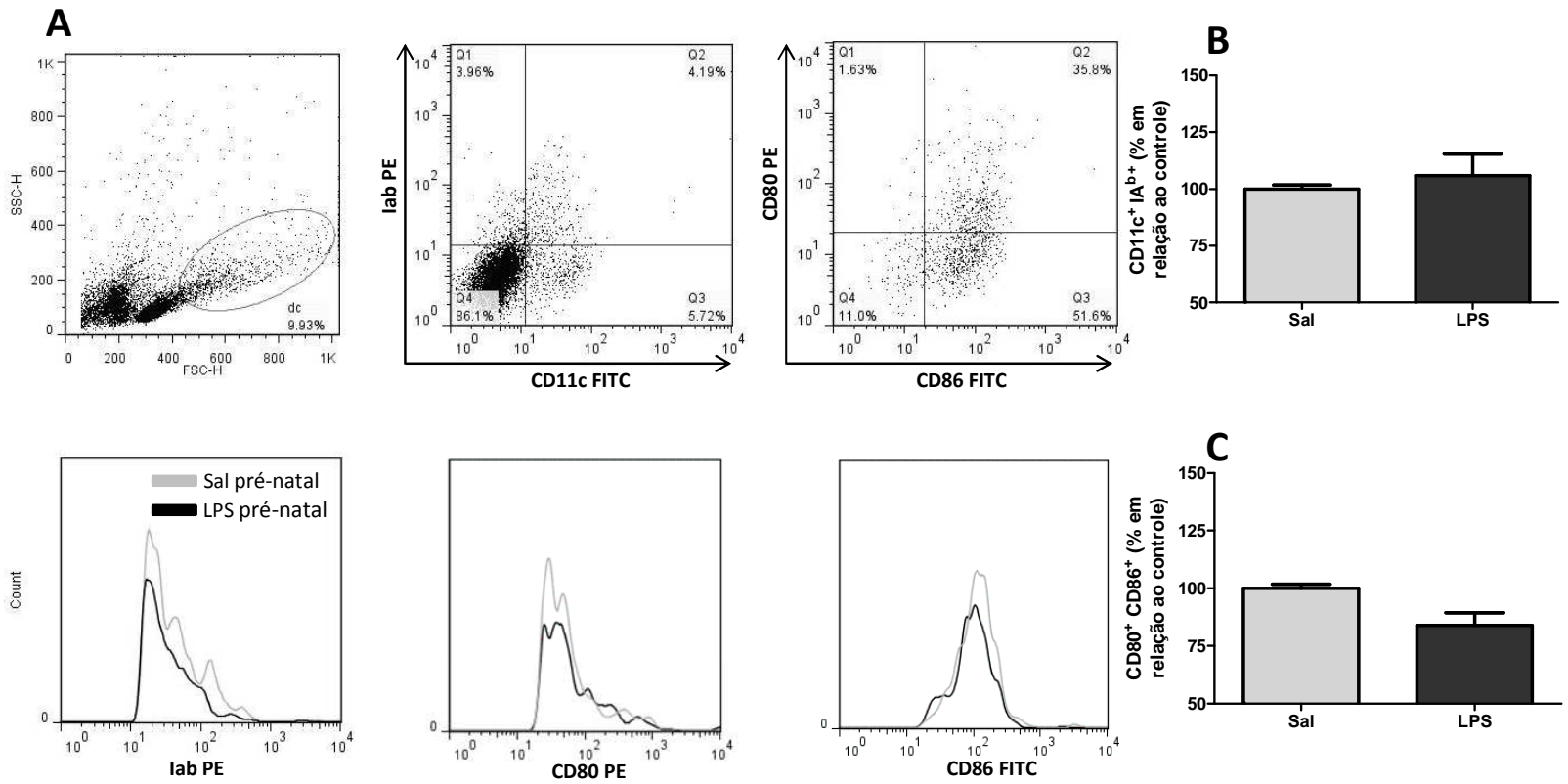

D
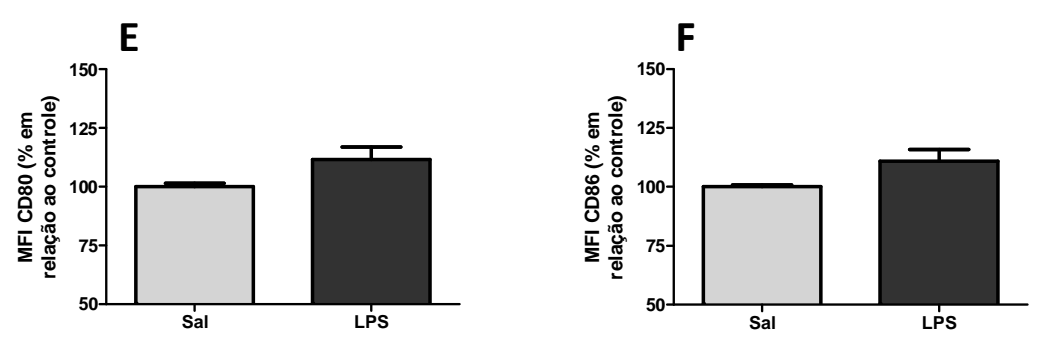

Legenda: Porcentagem de células $\mathrm{CD} 80^{+} \mathrm{CD} 6^{+}(\mathrm{A})$ e $\mathrm{CD}_{11 \mathrm{C}^{+}} \mathrm{I}^{\mathrm{b}+}(\mathrm{B})$ em cultura de células aderentes de baço estimuladas com LPS da prole de animais tratados com salina ou LPS durante a gestação e estressados na vida adulta. Os valores estão expressos em média \pm erro padrão $(n=10)$.

\subsubsection{Hipersensibilidade do tipo tardia (DTH)}

Como representado na figura 10, a ANOVA de duas vias demonstrou um efeito do tratamento pré-natal $[F(1,56)=4,05, p=0,05]$, do tempo $[F(4,56)=60,21$, $p=0,001]$ e da interação tratamento pré-natal $x$ tempo $[F(4,56)=2,53, p=0,05]$ sobre o aumento da espessura da pata, durante o desenvolvimento da DTH. O teste pos-hoc de Bonferroni revelou um aumento significante da espessura da pata, na 
prole de mães tratadas com LPS às $6 \mathrm{~h}, 24 \mathrm{~h}$ e $48 \mathrm{~h}(\mathrm{p} \leq 0,05)$ quando comparado com o grupo salina, nos mesmos intervalos de tempo.

Figura 10 - Desenvolvimento da resposta de hipersensibilidade do tipo tardia (DTH) na prole de mães tratadas com salina ou LPS no final da gestação (DG17)

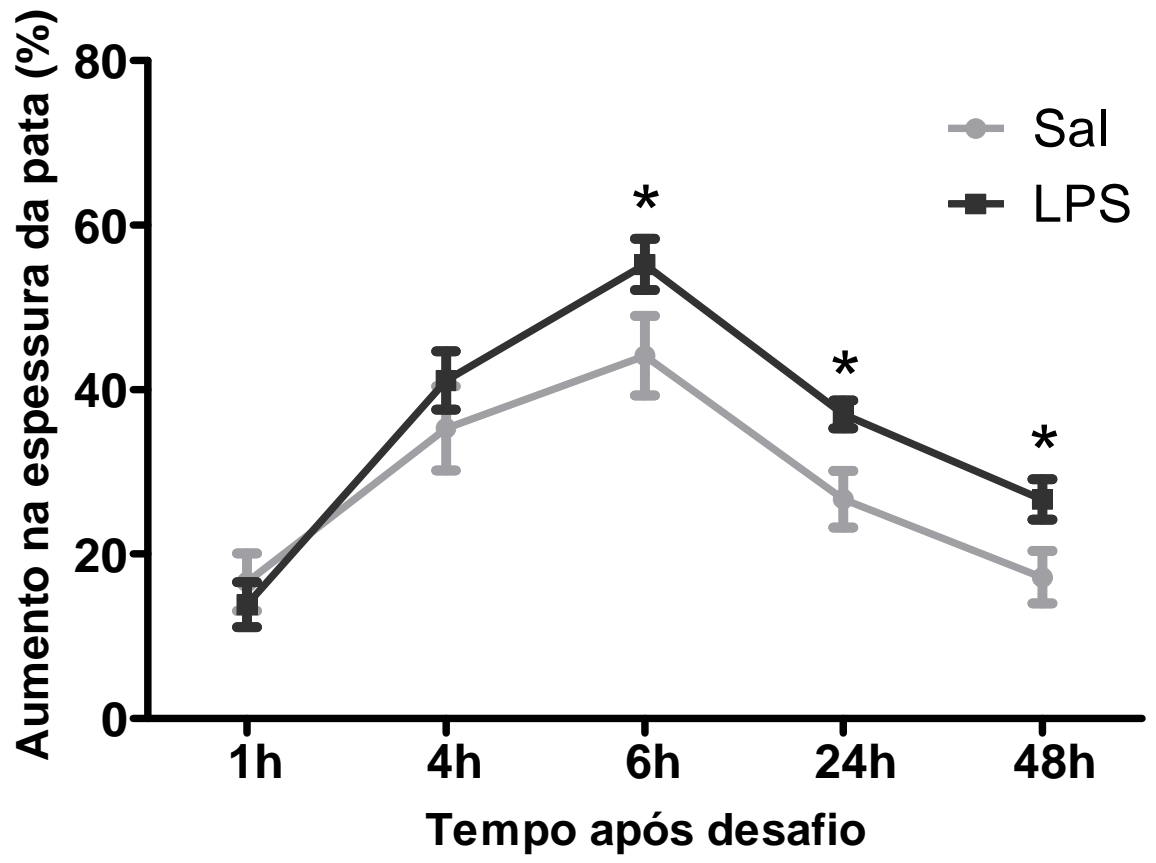

Legenda: Valores médios de aumento da espessura da pata (\%) medida 1, 4, 6, 24 e 48h após o desafio com OVA ( $n=10 /$ grupo). Os valores estão expressos em média \pm erro padrão. * Diferente do grupo do Sal no mesmo ponto temporal.

5.2 EXPERIMENTO 2: PRODUÇÃO DE MEDIADORES INFLAMATÓRIOS NA CULTURA MISTA NEURÔNIO X GLIA

Esse experimento foi desenvolvido com o intuito de investigar se a ativação imune materna provocada pelo LPS é capaz de influenciar a resposta imuneinflamatória de células residentes do SNC, através de cultura primária. Para tanto, fêmeas C57BL6 prenhes foram tratadas com LPS no DG17 e, entre o primeiro e terceiro dia após o nascimento, os encéfalos dos neonatos foram coletados, processados e estimulados in vitro conforme descrito anteriormente e ilustrado na figura 11. 
Figura 11 - Representação esquemática do desenho experimental adotado no experimento 2

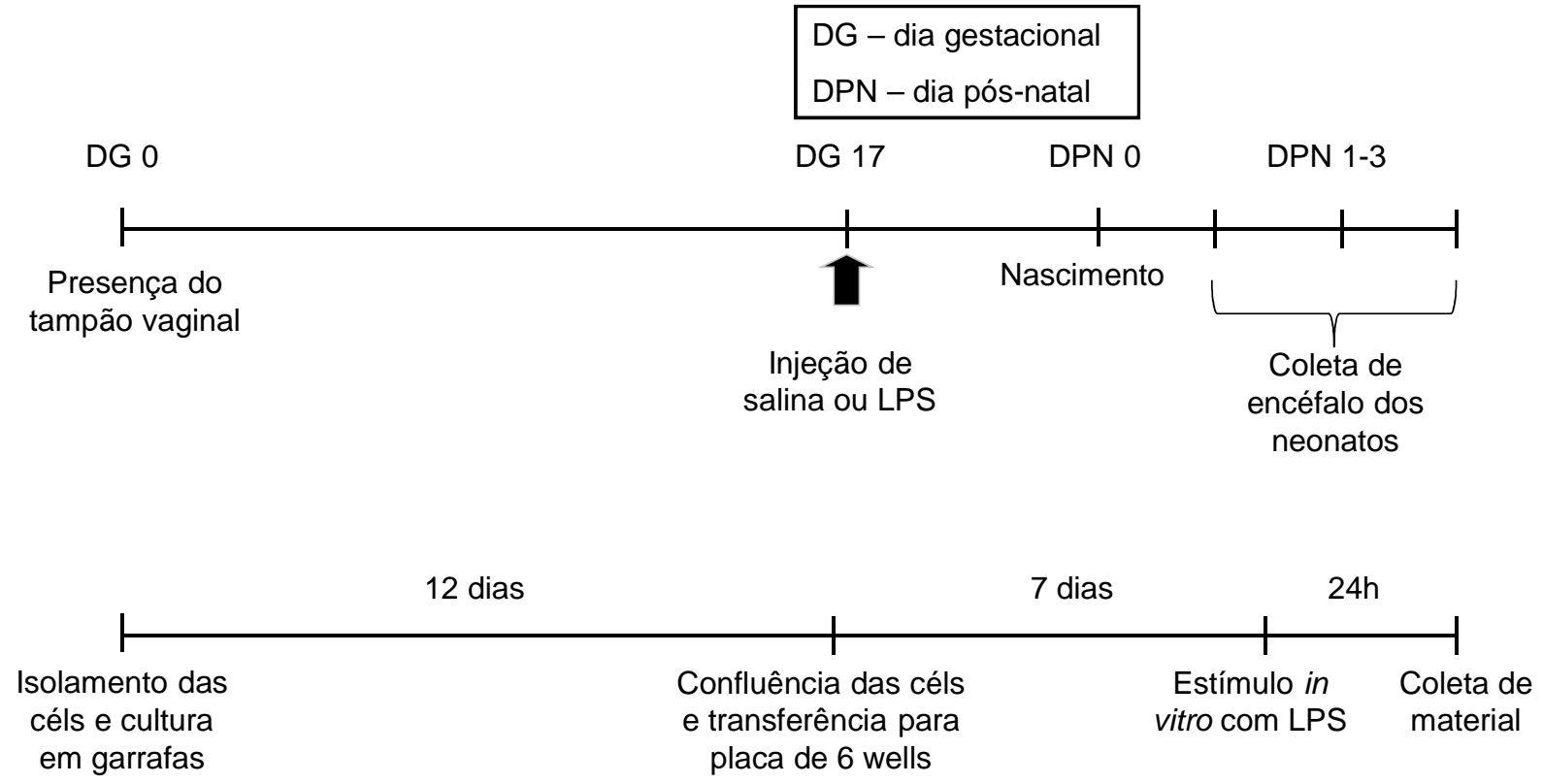

Legenda: Acima estão ilustrados os procedimentos in vivo e, abaixo, os procedimentos in vitro.

\subsubsection{Caracterização celular por imuno-fluorecência}

A microscopia de fluorescência revelou que os principais tipos celulares isolados na cultura mista são, astrócitos (céls GFAP positivas), microglia (céls Iba-1 positivas) e neurônios (céls MAP-2 positivas), como indicado na figura 12A e B em células estimuladas in vitro ou não com LPS. 
Figura 12 - Microscopia de fluorescência ilustrando os tipos celulares da cultura mista como Astrócitos $\left(\mathrm{GFAP}^{+}\right)$, microglia (Iba- $\left.1^{+}\right)$e neurônios (MAP-2 ${ }^{+}$)
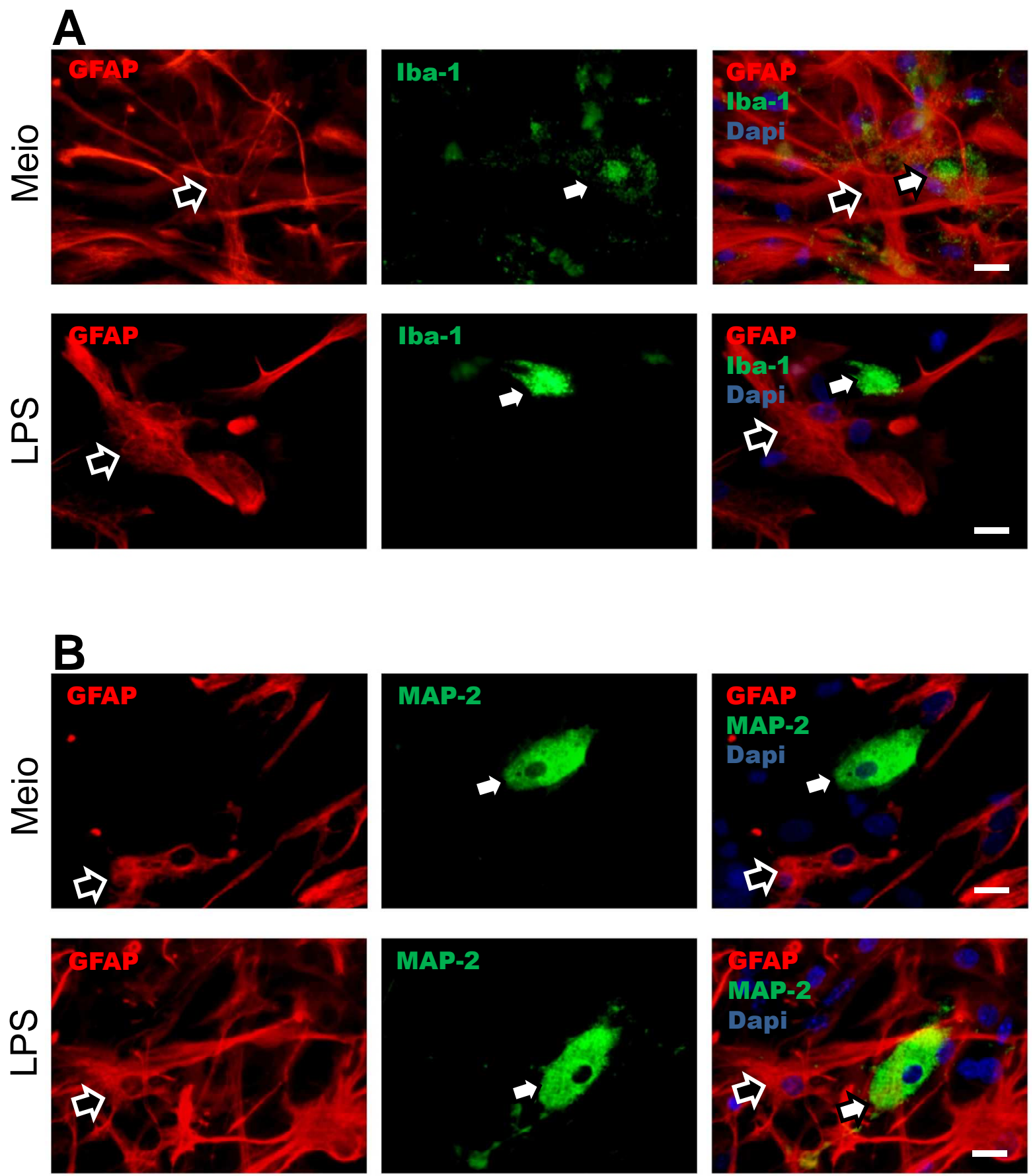

Legenda: No painel A, fica evidente a dupla marcação GFAP (setas pretas) e lba-1 (setas brancas) em células não estimuladas (meio) e estimuladas (LPS) in vitro. No painel B, ilustra-se a dupla marcação GFAP (setas pretas) e MAP-2 (setas brancas), estimuladas ou não in vitro. Aumento 40X, barra representativa de $10 \mu \mathrm{m}$.

Fonte: Zager et al. (2013). 


\subsubsection{Produção de citocinas}

A ANOVA de duas vias demonstrou um efeito do tratamento pré-natal [ $F$ $(1,24)=6,08, p=0,01]$, do estímulo em cultura $[F(1,56)=793,69, p=0,01]$ e da interação tratamento $X$ estímulo $[F(1,24)=7,71, p=0,01]$ nos níveis de IL-6 na cultura mista. O teste de pos-hoc de Bonferroni revelou um aumento significante da produção de IL-6 por células do grupo experimental após o estímulo in vitro, em relação ao grupo controle na mesma condição $(p \leq 0,01)$, como ilustrado na figura $13 \mathrm{~A}$.

Com relação aos níveis de IL-1 $\beta$, a ANOVA de duas vias demonstrou um efeito do tratamento pré-natal $[F(1,17)=10,10, p=0,01]$ e do estímulo em cultura [F $(1,17)=9,25, p=0,01]$. O teste de pos-hoc revelou um aumento significante da produção de IL-1 $\beta$ por células do grupo experimental após o estímulo in vitro, em relação ao grupo controle na mesma condição $(p \leq 0,05)$. A figura 13B ilustra esses achados.

A ANOVA de duas vias demonstrou um efeito do estímulo em cultura $[F(1,26)$ $=125,71, p=0,001]$ nos níveis de TNF na cultura mista. No entanto, o teste de poshoc não revelou diferenças significantes entre os tratamentos pré-natais, como mostrado na figura $13 \mathrm{C}$.

A ANOVA de duas vias demonstrou um efeito do tratamento pré-natal [ $F$ $(1,24)=7,87, p=0,01]$, do estímulo em cultura $[F(1,24)=32,03, p=0,001]$ e da interação tratamento $X$ estímulo $[F(1,24)=5,42, p=0,02]$ nos níveis de IL-10 na cultura mista. O teste de pos-hoc de Bonferroni revelou uma diminuição significante da produção de IL-10 por células do grupo experimental após o estímulo in vitro, em relação ao grupo controle na mesma condição $(p \leq 0,01)$, como ilustrado na figura 13D. 
Figura 13 - Concentrações das citocinas IL-6, IL-1 $1 \beta$, TNF e IL-10 produzidas após estímulo com LPS em cultura mista de células residentes do SNC da prole de fêmeas tratadas com salina ou LPS durante o final da gestação
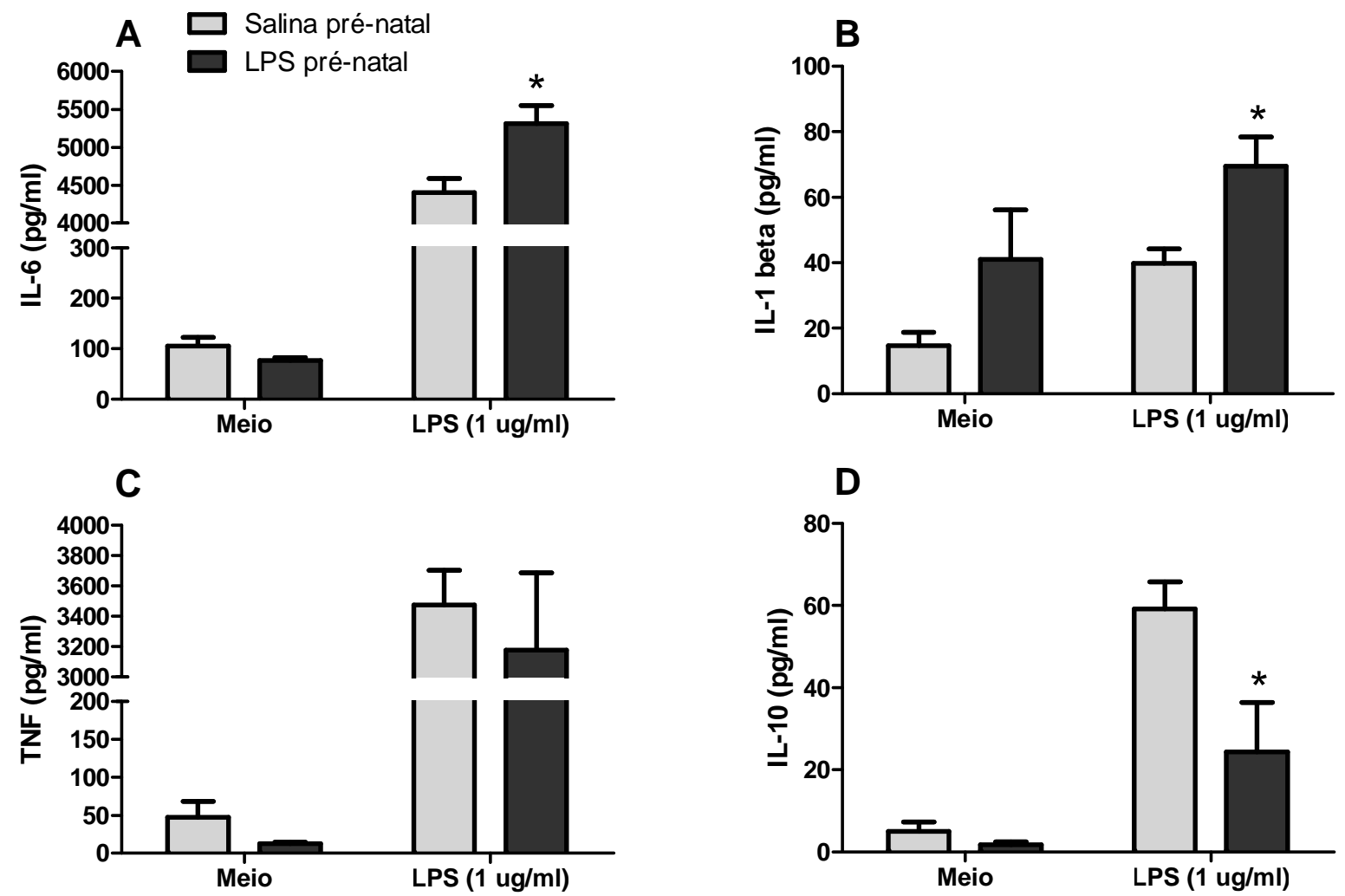

Legenda: Os valores estão expressos em média \pm erro padrão $(n=4) .{ }^{*}$ difere do grupo salina na mesma condição.

\subsubsection{Produção de nitritos}

A anova de duas vias demonstrou um efeito do tratamento pré-natal $[F(1,19)$ $=6,40 ; p=0,02]$, do estímulo em cultura $[F(1,19)=180,49 ; p=0,001]$ e da interação tratamento $X$ estímulo $[F(1,19)=9,04 ; p=0,001]$ nos níveis de nitritos nos sobrenadantes da cultura mista. O teste de pos-hoc de Bonferroni revelou um aumento significante da produção de nitritos por células do grupo experimental após o estímulo in vitro, em relação ao grupo controle na mesma condição $(p \leq 0,01)$, como ilustrado na figura 14. 
Figura 14 - Concentração de nitritos produzidos em cultura mista de células residentes do SNC da prole de fêmeas tratadas com salina ou LPS durante o final da gestação

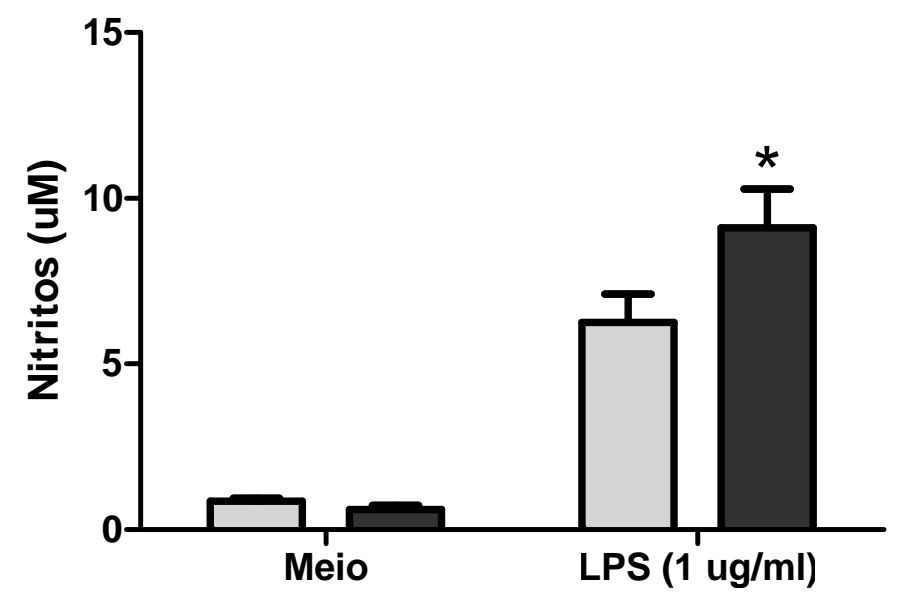

Legenda: Os valores estão expressos em média \pm erro padrão $(n=4) .{ }^{*}$ difere do grupo salina na mesma condição.

\subsection{EXPERIMENTO 3: DESENVOLVIMENTO DA ENCEFALOMIELITE AUTOIMUNE EXPERIMENTAL}

Com o intuito de se verificar se os resultados anteriores poderiam ocasionar um aumento na susceptibilidade da prole à condições neuroinflamatórias e de perfil Th1, desenvolvemos o experimento 3 cujo objetivo foi determinar se a ativação imune materna provocada pelo LPS é capaz de influenciar o desenvolvimento do modelo murino da EM, a EAE.

Para tanto, fêmeas prenhes foram tratadas com LPS no DG17; após o nascimento, desmame e formação dos grupos, os filhotes não foram manipulados até a idade adulta. Ao atingirem a vida adulta (60 dias), a prole foi imunizada com o peptídeo MOG $35-55$ conforme ilustrado na figura 15 , e foram observadas diariamente para determinação do escore da doença por 30 dias conforme o seguinte critério: 0 sem doença, 1 - cauda flácida, 2 - fraqueza/imobilidade parcial das patas traseiras, 3 - imobilidade total das patas traseiras, 4 - paralisia parcial das patas dianteiras, 5 paralisia completa/morte. A figura 16 ilustra esse desenho experimental. 
Figura 15 - Representação esquemática do desenho experimental adotado no experimento 3

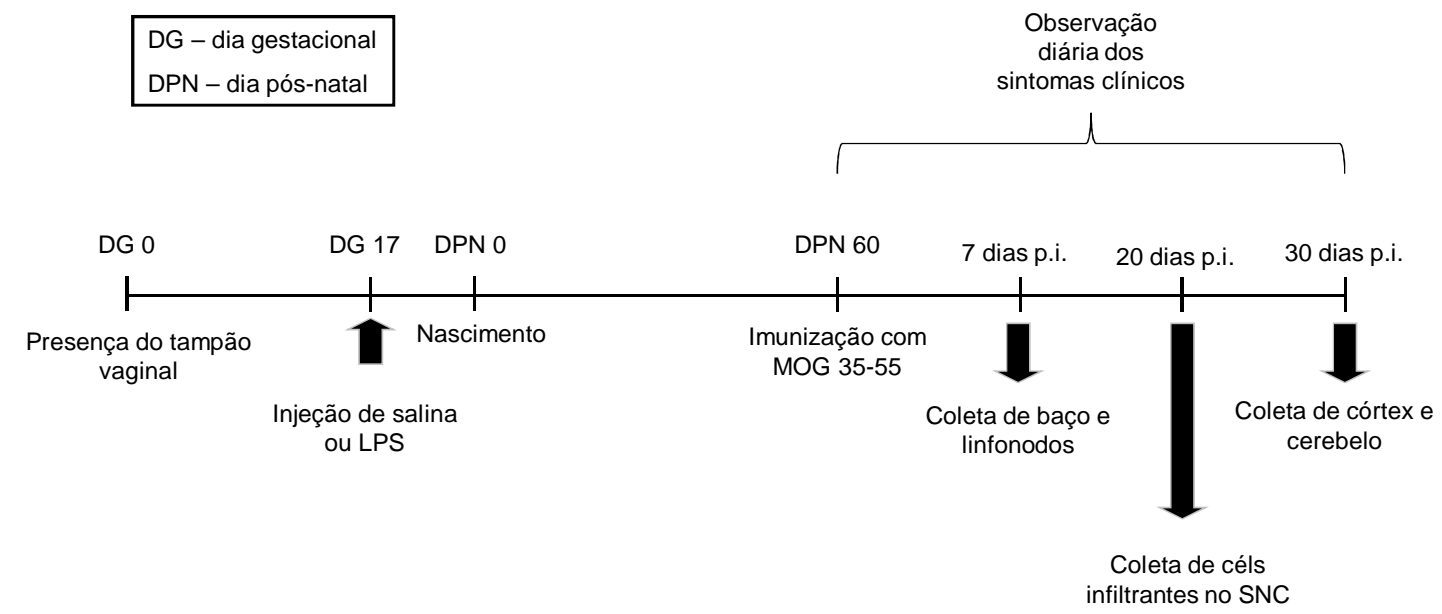

Legenda: Ilustração indicando a imunização para EAE e as coletas de material biológico 7, 20 e 30 dias pós-imunização (p.i.).

\subsubsection{Manifestação clínica da EAE}

Quanto ao desenvolvimento dos sintomas clínicos da EAE na prole de fêmeas, a ANOVA de duas vias demonstrou um efeito do tratamento pré-natal $[F(1,493)=6,98 ; p=0,01]$, do tempo $[F(29,493)=43,01 ; p=0,001]$ e da interação tratamento $x$ tempo $[F(29,493)=4,04 ; p=0,001]$ no escore clínico da $E A E$ observado durante 30 dias. O teste de pos hoc de Bonferroni revelou uma piora no escore da doença na prole de fêmeas tratadas com LPS, nos dias 21 ( $p \leq 0,05$ ), 22, 23, 24 e 25 $(p \leq 0,01)$ pós-imunização, em relação ao grupo salina nos mesmos tempos. Esses achados estão ilustrados na figura 16. 
Figura 16 - Desenvolvimento dos sintomas clínicos da encefalomielite autoimune experimental na prole de camundongos C57BL/6J fêmeas tratadas com Salina ou LPS durante a gestação (DG17)

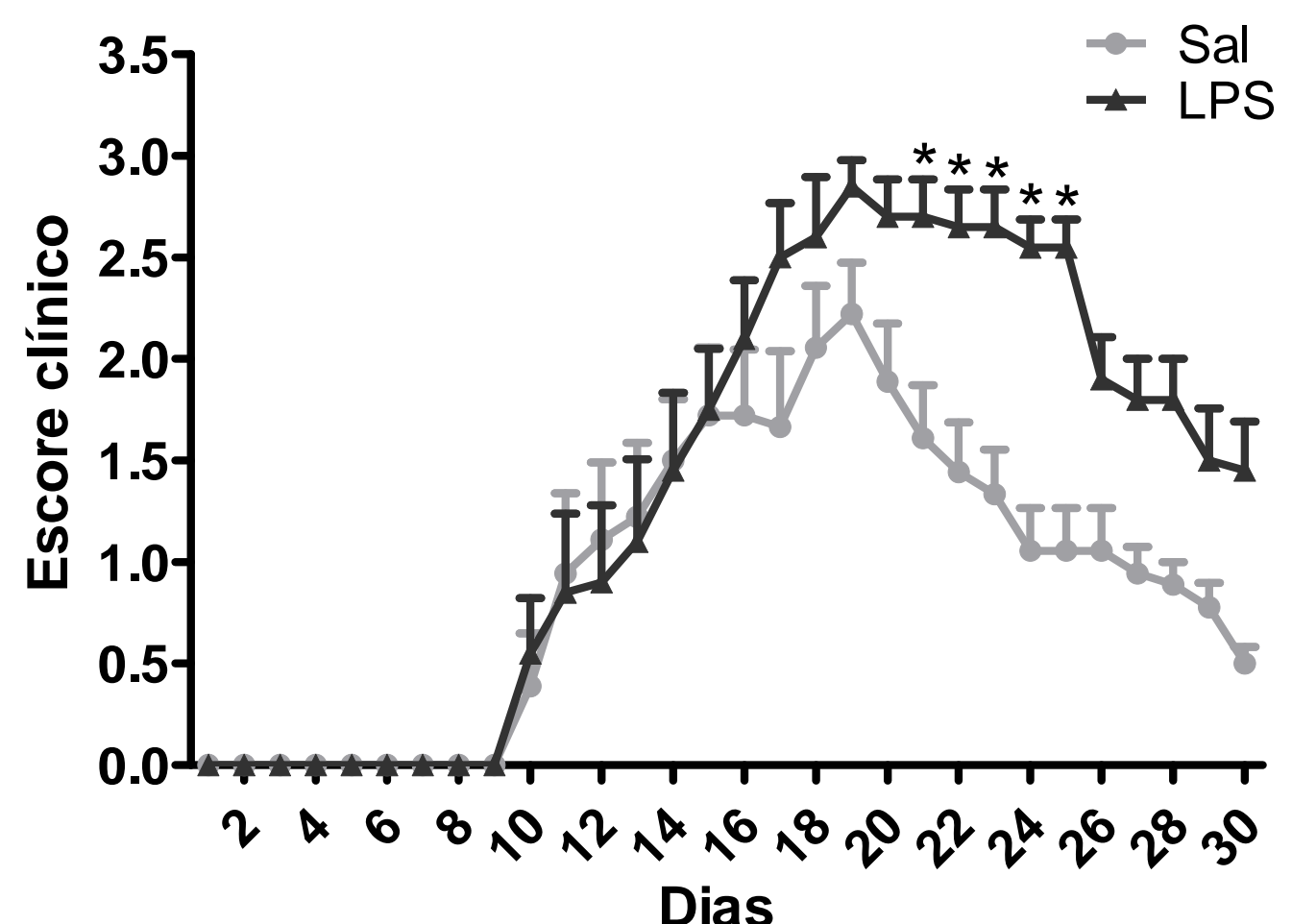

Legenda: Os valores estão expressos em em média \pm erro padrão $(n=9) .{ }^{*}$ Diferente do grupo Sal no mesmo ponto temporal.

\subsubsection{Atividade locomotora no campo aberto}

A fim de se determinar se existe alguma diferença entre os tratamentos prénatais em parâmetros locomotores, as fêmeas imunizadas para EAE foram submetidas ao teste de campo aberto durante a progressão dos sintomas motores, 15 dias pós-imunização.

Como comprovado pelo teste $t$, o tratamento pré-natal não provocou alterações quanto à distância percorrida no campo aberto, ilustrado pela locomoção total no campo aberto. No entanto, o teste t de student evidenciou uma diminuição da velocidade média de locomoção em animais EAE que foram expostos à ativação 
imune materna com LPS, quando comparados aos do grupo salina $(p \leq 0,05)$. A figura 17 ilustra esses achados.

Figura 17 - Parâmetros locomotores no campo aberto de animais EAE
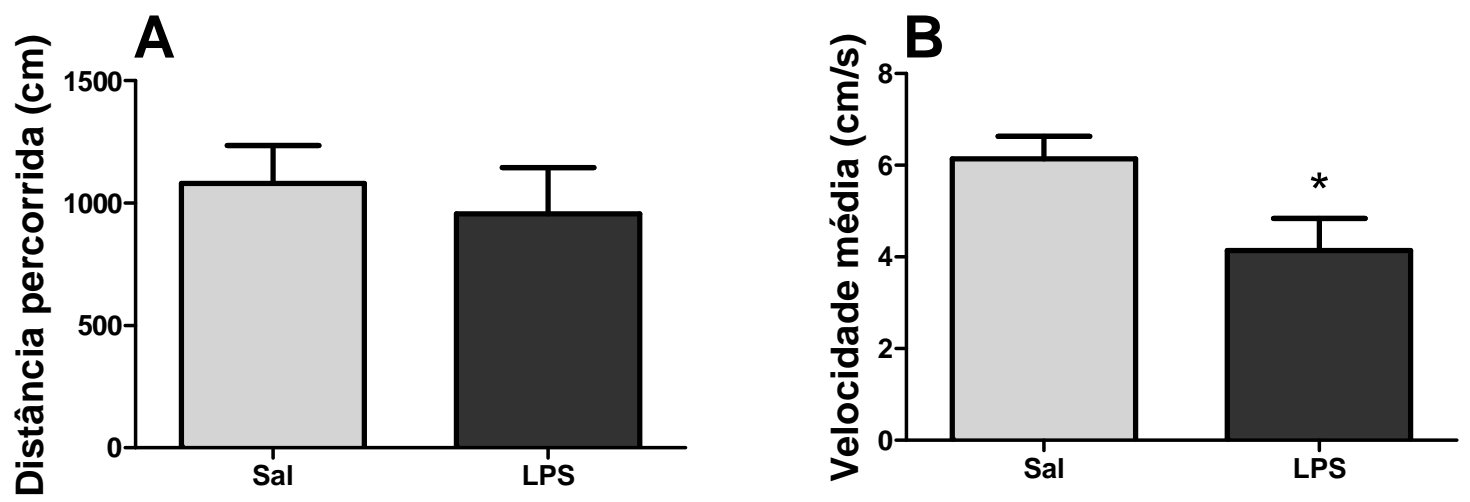

Legenda: Distância percorrida (A) e velocidade média (B), analisados 15 dias após a imunização para EAE da prole de mães tratadas com salina ou LPS ao final da gestação. Os valores estão expressos em em média \pm erro padrão $(n=9)$. ${ }^{*}$ difere do grupo Sal.

\subsubsection{Caracterização do infiltrado celular do SNC durante o pico da EAE}

Esse experimento foi realizado com a intenção de descrever os mecanismos desse fenômeno assim como caracterizar o infiltrado celular no SNC durante o pico da doença. Através da observação diária, determinamos o pico da EAE por volta do vigésimo dia após a imunização. Ao atingirem o pico da doença, as fêmeas foram levados a uma sala adjacente e anestesiados com uma solução de Xilazina/Ketamina. Após a perfusão do animal com PBS, o encéfalo foi imediatamente dissecado para a coleta do córtex e cerebelo, que em seguida foram armazenados a $-80^{\circ} \mathrm{C}$ até os ensaios de western blotting e RT-PCR. O restante do encéfalo, juntamente com a medula espinhal, foi maçerado e dissociado mecanicamente para obtenção das células do SNC conforme descrito anteriormente. 


\subsubsection{Fenotipagem de células mononucleares}

O teste-t de student demonstrou um aumento significante na porcentagem de linfócitos T CD4 não estimulados em cultura na prole de fêmeas tratadas com LPS, quando comparados aos dos animais do grupo salina $(p \leq 0,01)$, conforme mostra a figura 18B.

A ANOVA de duas vias revelou um efeito do pré-tratamento $[F(1,18)=7,75$; $p=0,01]$, do estímulo em cultura $[F(1,18)=32,04 ; p=0,001]$ e da interação prétratamento $x$ estímulo $F(1,18)=4,70 ; p=0,04]$ na porcentagem de células $T$ CD4 produtoras de IFN- $\gamma$ (cels Th1) infiltrantes no SNC, conforme ilustrado na figura 18C. O teste pos-hoc de Bonferroni mostrou um aumento na porcentagem de células Th1 estimuladas na prole de fêmeas tratadas com LPS, quando comparadas ao grupo salina $(p \leq 0,01)$ na mesma condição.

A ANOVA de duas vias revelou um efeito do pré-tratamento $[F(1,17)=8,49$; $p=0,01]$, do estímulo $[F(1,17)=82,53 ; p=0,001]$ e da interação pré-tratamento $x$ estímulo $F(1,17)=7,11 ; p=0,01$ ] na porcentagem de células $T$ CD4 produtoras de IL17 (cels Th17) infiltrantes no SNC, conforme ilustrado na figura 18D. O teste pos-hoc de Bonferroni mostrou um aumento de células Th17 estimuladas in vitro na prole de fêmeas tratadas com LPS, quando comparadas ao grupo salina na mesma condição $(p \leq 0,01)$.

A ANOVA de duas vias revelou um efeito do pré-tratamento $[F(1,17)=4,80$; $p=0,04]$, do estímulo $[F(1,17)=17,93 ; p=0,001]$ e da interação pré-tratamento $x$ estímulo $F(1,17)=5,06 ; p=0,03$ ] na porcentagem de células T CD4 produtoras de IL10 (cels Treg) infiltrantes no SNC, conforme ilustrado na figura 18E. O teste pos-hoc de Bonferroni mostrou uma diminuição de células Treg estimuladas in vitro na prole de fêmeas tratadas com LPS, quando comparadas ao grupo salina na mesma condição $(p \leq 0,05)$. 
Figura 18 - Caracterização de linfócitos infiltrantes no SNC durante o pico dos sintomas da EAE

A

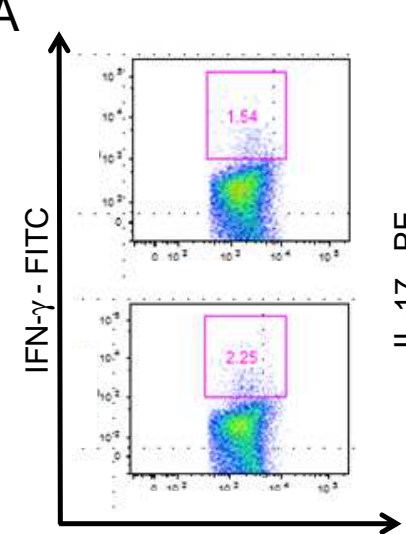

CD4 - PercP

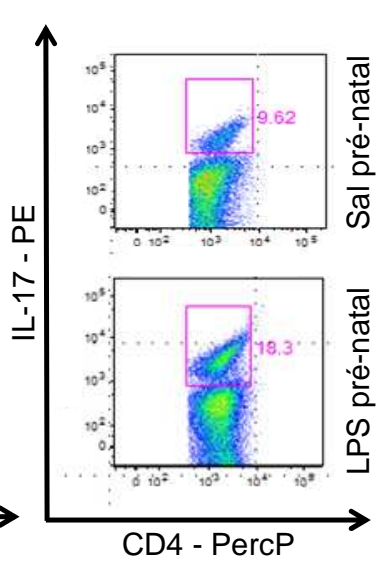

$\mathrm{D}$

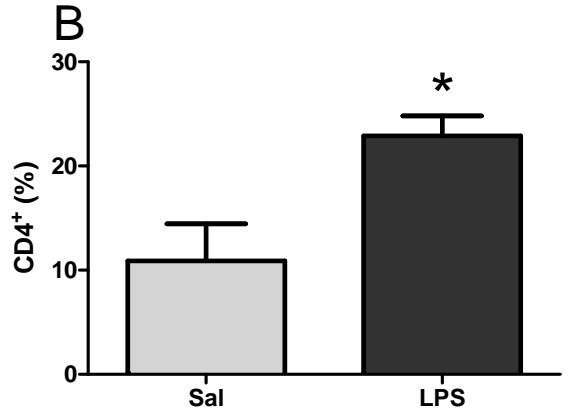

$E$
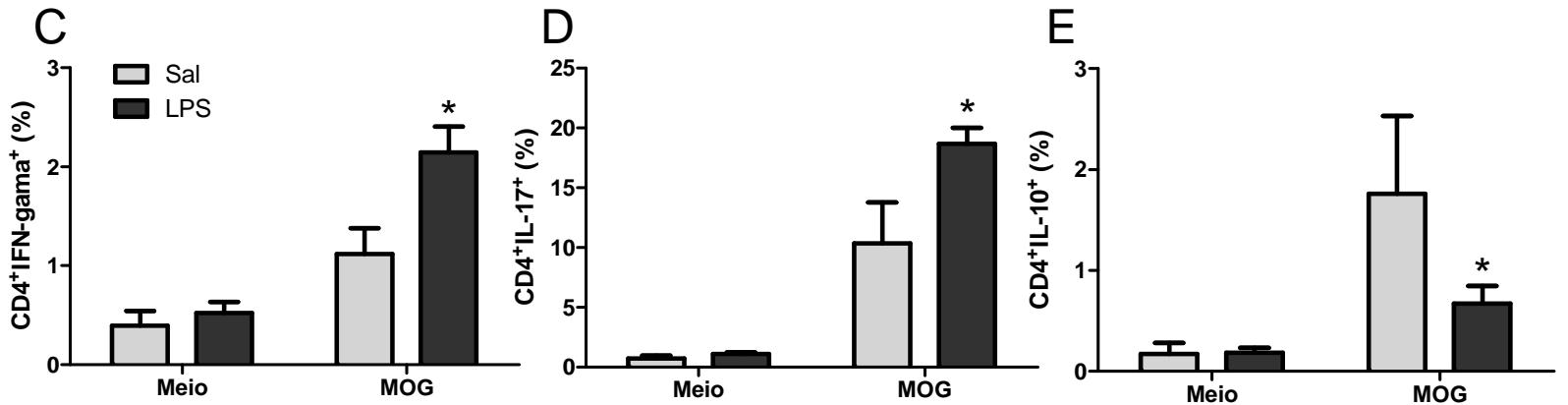

Legenda: Exemplo de citometria de fluxo para células $\mathrm{CD}^{+}(\mathrm{A})$. Porcentagem de células CD4 totais (B), assim como das células Th1 (C), Th17 (D) ou Treg (E) infiltrantes no SNC da prole de animais tratados ou não com LPS ao final da gestação. $\mathrm{Na}$ vida adulta os animais foram imunizados com MOG 35-55 e sacrificados durante o pico da EAE, e as células do SNC coletadas foram reestimuladas in vitro. Os valores estão expressos em média \pm erro padrão $(n=9)$. * difere do grupo Sal na mesma condição.

A ANOVA de duas vias revelou um efeito do estímulo em cultura $[F(1,18)=28,41 ; p=0,001]$ e da interação pré-tratamento $x$ estímulo $F(1,18)=6,29$; $\mathrm{p}=0,02]$ na porcentagem de células $C D 45^{+} \mathrm{CD} 11 \mathrm{~b}^{-}$(linfócitos) infiltrantes no $\mathrm{SNC}$, conforme ilustrado na figura 19B. O teste pos-hoc de Bonferroni demonstrou existência de um aumento de linfócitos infiltrantes na prole de fêmeas tratadas com LPS, quando comparadas às do grupo salina na mesma condição $(p \leq 0,05)$.

A ANOVA de duas vias revelou um efeito do pré-tratamento $[F(1,19)=7,25$; $\mathrm{p}=0,01$ ], na porcentagem de células $\mathrm{CD} 45^{\text {high }} \mathrm{CD} 11 \mathrm{~b}^{+}$(macrófagos) infiltrantes no SNC, conforme ilustrado na figura 19C. O teste pos-hoc de Bonferroni mostrou um aumento na porcentagem de macrófagos na prole de fêmeas tratadas com LPS, quando comparadas ao grupo salina $(p \leq 0,05)$ na mesma condição. A ANOVA de duas vias revelou somente um efeito do estímulo em cultura $[F(1,20)=6,23 ; p=0,02]$ na porcentagem de $C D 45^{\text {low }} \mathrm{CD} 11 \mathrm{~b}^{+}$(microglia) no SNC. No entanto, o teste de pos- 
hoc não foi capaz de evidenciar quaisquer diferenças entre os tratamentos prénatais $(p \geq 0,05)$, conforme ilustrado na figura 19D.

Com relação à expressão de $\mathrm{MHC}$ de classe II por macrófagos infiltrantes, a ANOVA de duas vias revelou um efeito do pré-tratamento $[F(1,16)=4,57 ; p=0,04]$, do estímulo em cultura $[F(1,16)=13,82 ; p=0,001]$ e da interação pré-tratamento $x$ estímulo $F(1,16)=5,48 ; \quad p=0,03]$, representado pela intensidade média de fluorecência do marcador IA-IE. O teste pos-hoc de Bonferroni evidenciou um aumento na expressão de MHC II nos macrófagos da prole de fêmeas tratadas com LPS, quando comparados aos do grupo salina $(p \leq 0,01)$ na mesma condição, conforme ilustrado na figura 19E.

Com relação à expressão de MHC de classe II por células microgliais, a ANOVA de duas vias revelou um efeito da interação pré-tratamento $x$ estímulo $F(1,15)=6,53 ; p=0,02]$, representado pela intensidade média de fluorecência do marcador IA-IE. O teste pos-hoc de Bonferroni mostrou um aumento na expressão de MHC II nas células microgliais da prole de fêmeas tratadas com LPS, quando comparadas ao grupo salina $(p \leq 0,05)$ na mesma condição, conforme ilustrado na figura $19 \mathrm{~F}$. 
Figura 19 - Caracterização de macrófagos e microglia no SNC durante o pico dos sintomas da EAE
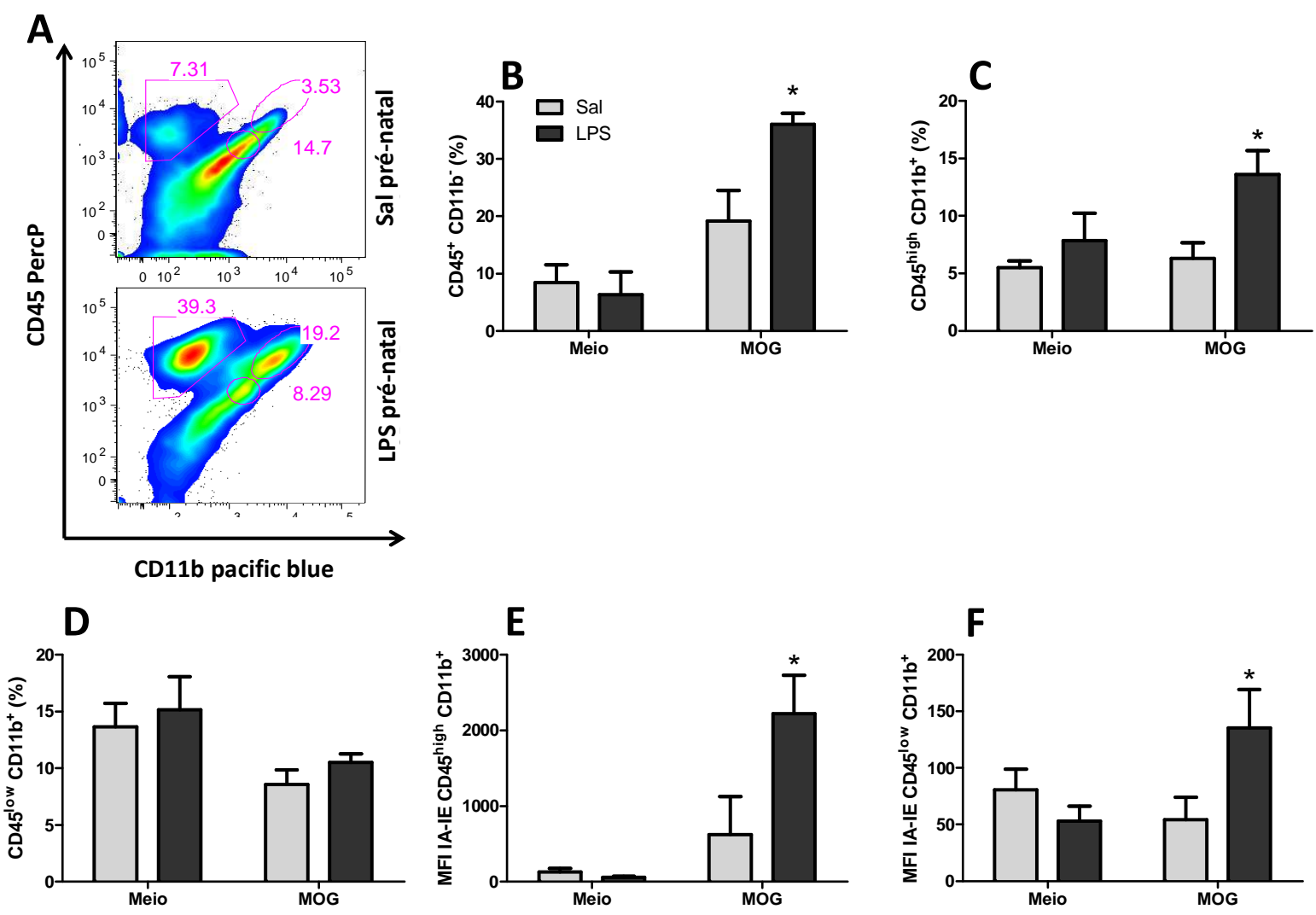

Legenda: Exemplos de citometria da dupla marcação CD45 e CD11b (A). Porcentagem de linfócitos (B) e macrófagos (C) infiltrantes, assim como de céls microgliais (D) no SNC da prole de animais tratados ou não com LPS ao final da gestação. Ainda, ilustra-se Intensidade média de fluorecência do marcador IA-IE (MHC II) por macrófagos (E) e microglia (F). Na vida adulta os animais foram imunizados com MOG 35-55 e sacrificados durante o pico da EAE, e as células do SNC coletadas foram reestimuladas in vitro. Os valores estão expressos em média \pm erro padrão $(n=9)$. * difere do grupo Sal na mesma condição.

\subsubsection{Quantificação de citocinas no SNC por RT-PCR}

Como mostra a figura 20, o teste-t de Student revelou um aumento significante na expressão de mRNA para IL-6 ( $p \leq 0,05)$, IL-1 $\beta(p \leq 0,05)$ e TNF $(p \leq 0,05)$ no cerebelo da prole de mães tratadas com LPS na gestação (DG17), em comparação ao grupo controle. Não obstante, essas alterações estavam presentes apenas no cerebelo, uma vez que não encontramos diferenças entre os grupos no córtex cerebral (dados não mostrados). 
Figura 20 - Expressão de mRNA de citocinas inflamatórias no SNC da prole de animais tratados ou não com LPS ao final da gestação
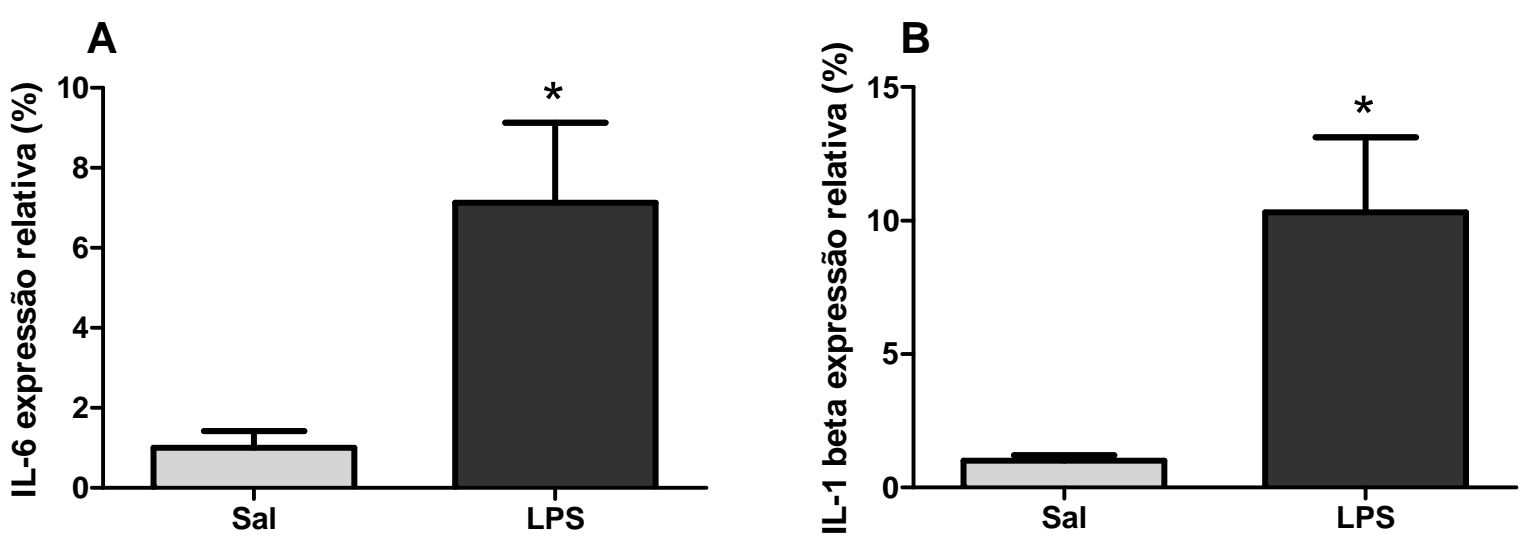

\section{C}

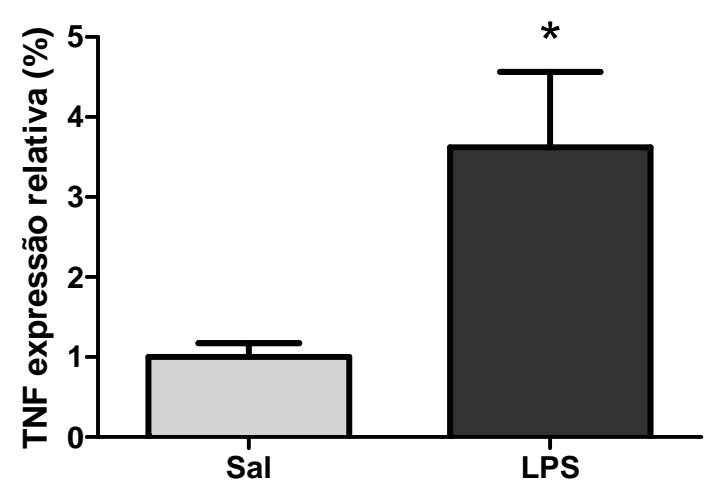

Legenda: Expressão relativa de mRNA para IL-6 (A), IL-1 1 (B) e TNF (C) normalizados em relação ao gene constitutivo $18 \mathrm{~S}$, no cerebelo da prole de animais tratados ou não com LPS ao final da gestação. Na vida adulta os animais foram imunizados com MOG 35-55 e sacrificados durante o pico da EAE, e amostras de cerebelo e córtex foram coletadas para RT-PCR. Os valores estão expressos em média \pm erro padrão $(n=5)$. * difere do grupo Sal.

\subsubsection{Quantificação proteica por Western Blotting}

A análise da expressão proteica no córtex e cerebelo de animais EAE realizada aos 7, 20 e 30 dias após a imunização revelou efeito do pré-tratamento $[F(1,8)=11,28 ; p=0,02]$, do tempo pós-imunização $[F(2,8)=17,34 ; p=0,001]$ e da interação tratamento $x$ tempo $[F(2,8)=4,46 ; p=0,005]$ na expressão proteica de GFAP no cerebelo da prole, como evidenciado pela ANOVA de duas vias. O teste de Bonferroni revelou um aumento significante dos níveis de GFAP na prole de mães 
desafiadas com LPS durante o final da fase aguda da EAE, aos 30 dias pósimunização ( $p \leq 0,01)$. A figura 21 ilustra esses achados.

No entanto, não encontramos diferenças entre os tratamentos pré-natais quanto aos níveis proteicos de Iba-1, pSTAT3, Ikk, COX-2, e iNOS no córtex e no cerebelo de animais imunizados durante o curso da EAE.

Figura 21 - Expressão de proteínas no córtex e cerebelo durante o decorrer da EAE pela prole de animais desafiados ou não com LPS ao final da gestação

A
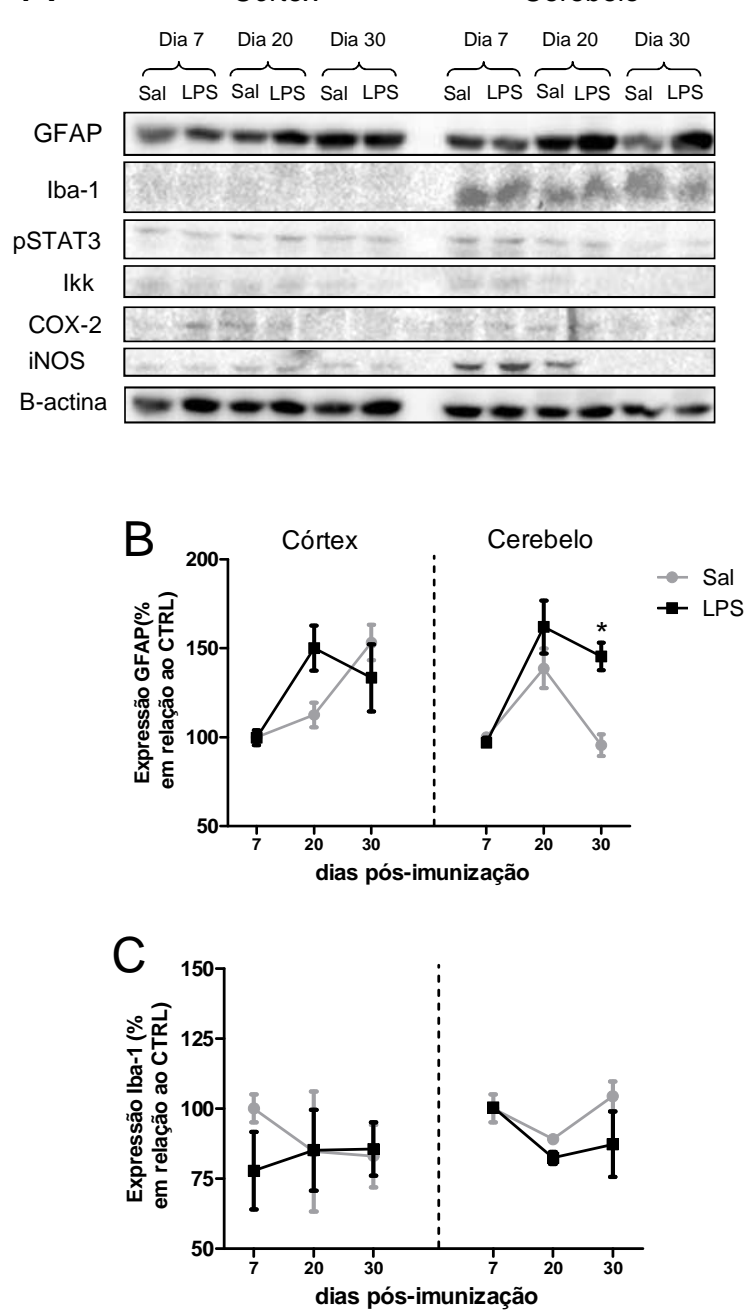

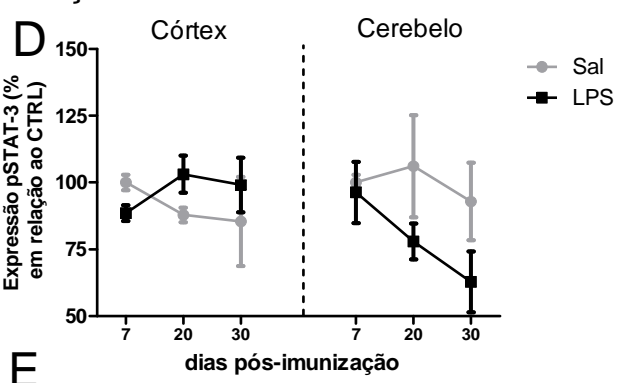

E
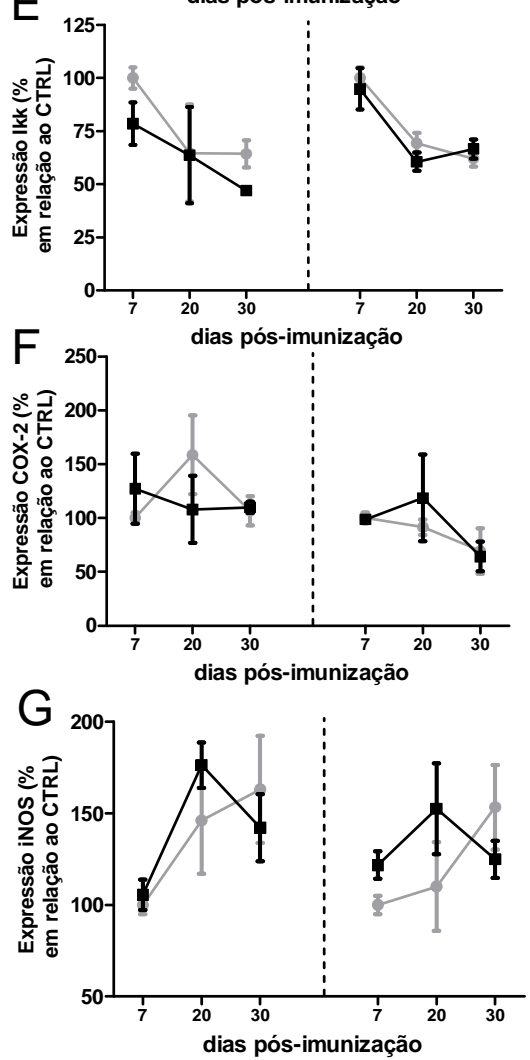

Legenda: llustração da expressão proteica por western blotting $(A)$ e expressão relativa das proteínas GFAP (B), Iba-1 (C), pSTAT3 (D), Ikk (E), COX-2 (F) e iNOS (G) no córtex e cerebelo durante o decorrer da EAE pela prole de animais desafiados ou não com LPS ao final da gestação. Na vida adulta os animais foram imunizados com MOG 35-55 e sacrificados 7, 20 e 30 dias pós-imunização e amostras de cerebelo e córtex foram coletadas Western Blott. Os valores estão expressos em média \pm erro padrão $(n=4)$. ${ }^{*}$ difere do grupo Sal. 


\subsubsection{Alterações imunes periféricas durante o início da EAE}

Com base nos resultados apresentados, nosso próximo passo foi analisar as alterações imunes periféricas eventualmente presentes, na tentativa de melhor compreender o fenômeno. Para tanto, a prole de fêmeas adultas foi imunizada conforme descrito anteriormente; no entanto, os animais foram sacrificados antes do aparecimento dos sintomas clínicos da doença, aos 7 dias pós-imunização. Procedeu-se então com a coleta do baço e dos linfonodos regionais (inguinais e mesentéricos) para plaqueamento e reestimulação in vitro.

\subsubsection{Fenotipagem de células do Baço}

A ANOVA de duas vias revelou um efeito do pré-tratamento $[F(1,27)=8,17$; $p=0,008]$, do estímulo em cultura $[F(1,27)=316,32 ; p=0,001]$ e da interação prétratamento $x$ estímulo $F(1,27)=4,32 ; p=0,04]$, na expressão de $M H C$ de classe II por macrófagos. O teste pos-hoc de Bonferroni mostrou um aumento de macrófagos expressando MHC II da prole de fêmeas tratadas com LPS, quando comparadas às do grupo salina $(p \leq 0,01)$ na mesma condição, conforme ilustrado na figura $22 \mathrm{E}$.

A ANOVA de duas vias revelou um efeito do estímulo em cultura $[F(1,27)=316,32 ; p=0,001]$, na porcentagem de células $C^{2} 11 b^{+}$(macrófagos) produtoras de IL-17, conforme ilustrado na figura 22F. O teste pos-hoc de Bonferroni mostrou um aumento na porcentagem de macrófagos produtores de IL-17 na prole de fêmeas tratadas com LPS, quando comparadas ao grupo salina $(p \leq 0,01)$ na mesma condição. 
Figura 22 - Caracterização de linfócitos e macrófagos no baço da prole de animais tratados ou não com LPS ao final da gestação
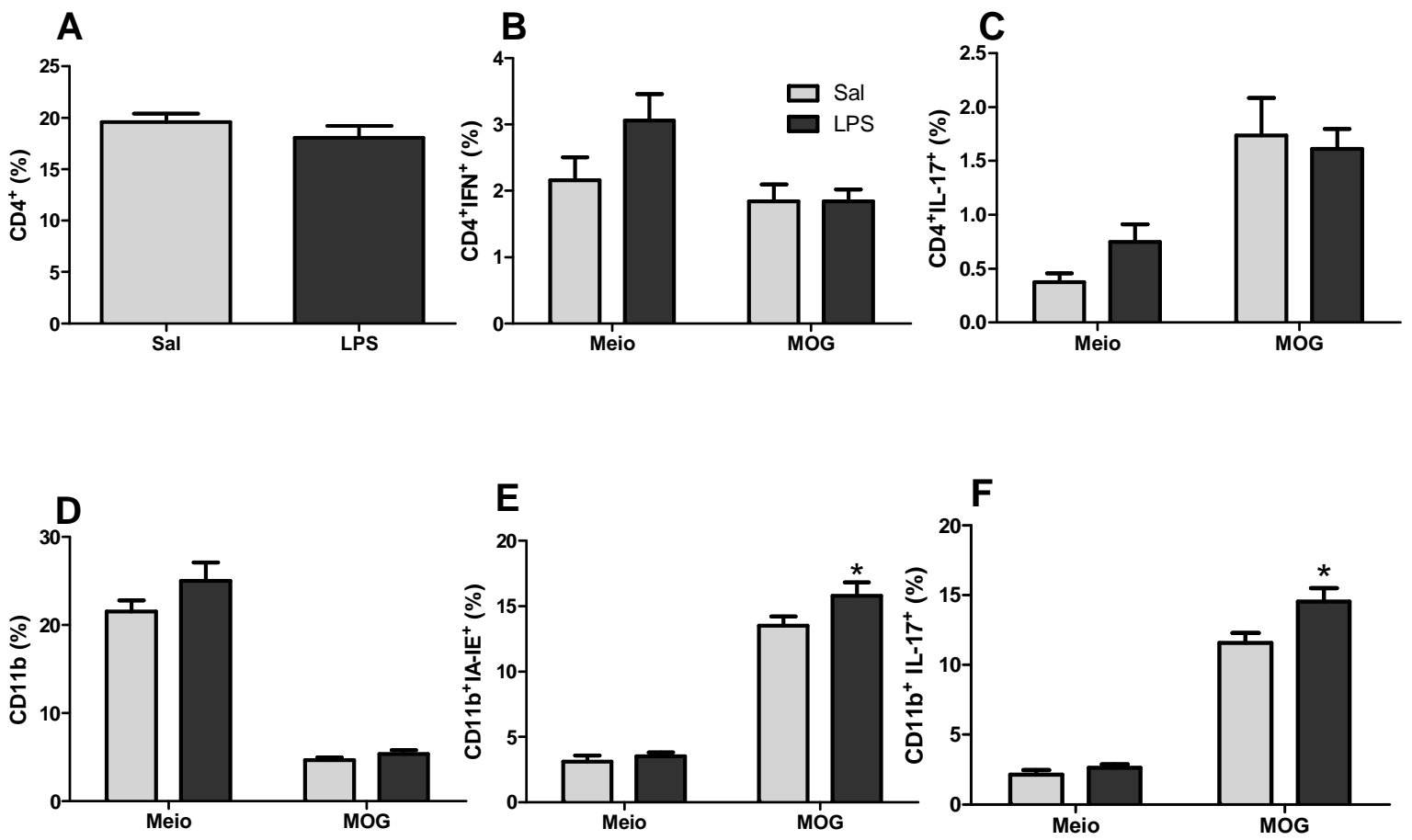

Legenda: Porcentagem de células CD4 totais (A), Th1 (B) e Th17 (C), assim como de macrófagos totais (D) ou expressando MHC II (E) e IL-17 (F) no baço da prole de animais tratados ou não com LPS ao final da gestação. Na vida adulta os animais foram imunizados com MOG 35-55 e sacrificados durante o início da EAE, e as células do baço coletadas foram reestimuladas in vitro. Os valores estão expressos em média \pm erro padrão $(n=9)$. * difere do grupo Sal na mesma condição.

\subsubsection{Fenotipagem de células dos Linfonodos}

A ANOVA de duas vias não mostrou diferenças significantes entre os tratamentos pré-natais nas porcentagens de células $\mathrm{CD} 4, \mathrm{CD} 4^{+} \mathrm{IFN}-\gamma^{+}, \mathrm{CD} 4^{+} \mathrm{IL}-17^{+}$, CD11 $b^{+}, C D 11 b^{+} \mid A-I E^{+}$e CD11 $b^{+} I L 17^{+}$nos linfonodos de animais com EAE (dados não mostrados). 


\subsubsection{Produção de citocinas no Baço}

A ANOVA de duas vias revelou um efeito do pré-tratamento $[F(1,19)=8,80$; $\mathrm{p}=0,007]$, e do estímulo in vitro $[\mathrm{F}(1,19)=4,77 ; \mathrm{p}=0,04]$ nos níveis de IL-6 produzidos no baço, conforme ilustrado na figura 23C. O teste pos-hoc de Bonferroni mostrou um aumento de IL-6 por células estimuladas in vitro da prole de fêmeas tratadas com LPS, quando comparadas ao grupo salina na mesma condição $(p \leq 0,05)$.

Com relação à produção de IL-17, a ANOVA de duas vias revelou um efeito do estímulo em cultura $[F(1,19)=28,39 ; p=0,001]$. $O$ teste de Bonferroni mostrou um aumento na produção de IL-17 pela prole de fêmeas tratadas com LPS, quando comparadas ao grupo salina $(p \leq 0,05)$ na mesma condição, conforme ilustrado na figura $23 \mathrm{~F}$.

Figura 23 - Citocinas produzidas por células de baço no início da EAE
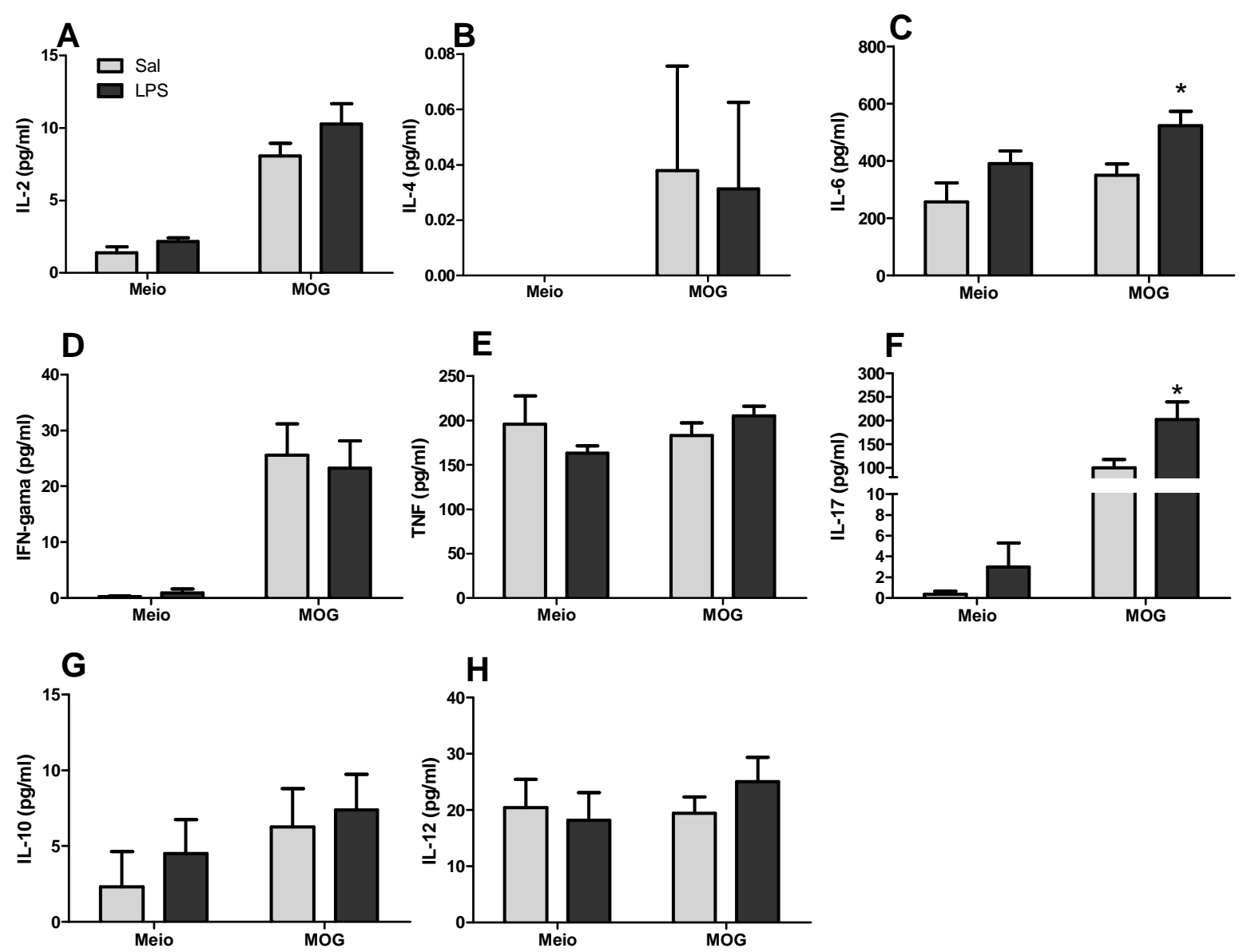

Legenda: Concentrações das citocinas IL-2 (A), IL-4 (B), IL-6 (C), IFN- $\gamma$ (D), TNF (E), IL-17 (F), IL-10 (G) e IL-12 $(\mathrm{H})$ produzidas após estímulo com MOG 35-55 em cultura de células de baço da prole de fêmeas tratadas com salina ou LPS durante o final da gestação. Os valores estão expressos em média \pm erro padrão $(n=9)$. ${ }^{*}$ difere do grupo Sal na mesma condição. 


\subsubsection{Produção de citocinas nos Linfonodos}

A ANOVA de duas vias revelou um efeito do estímulo em cultura $[F(1,20)=28,60 ; p=0,001]$ nos níveis de IL-2 produzidos por celulas dos linfonodos. $O$ teste de Bonferroni mostrou um aumento na produção de IL-2 pela prole de fêmeas tratadas com LPS, quando comparadas às do grupo salina $(p \leq 0,05)$ na mesma condição, conforme ilustrado na figura 24A.

Com relação à produção de IL-17, a ANOVA de duas vias revelou um efeito do estímulo em cultura $[F(1,19)=13,00 ; p=0,001]$. O teste de Bonferroni demonstrou um aumento na produção de IL-17 pela prole de fêmeas tratadas com LPS, quando comparadas ao grupo salina $(p \leq 0,05)$ na mesma condição, conforme ilustrado na figura $24 \mathrm{~F}$.

Figura 24 - Citocinas produzidas por células de linfonodo no início da EAE
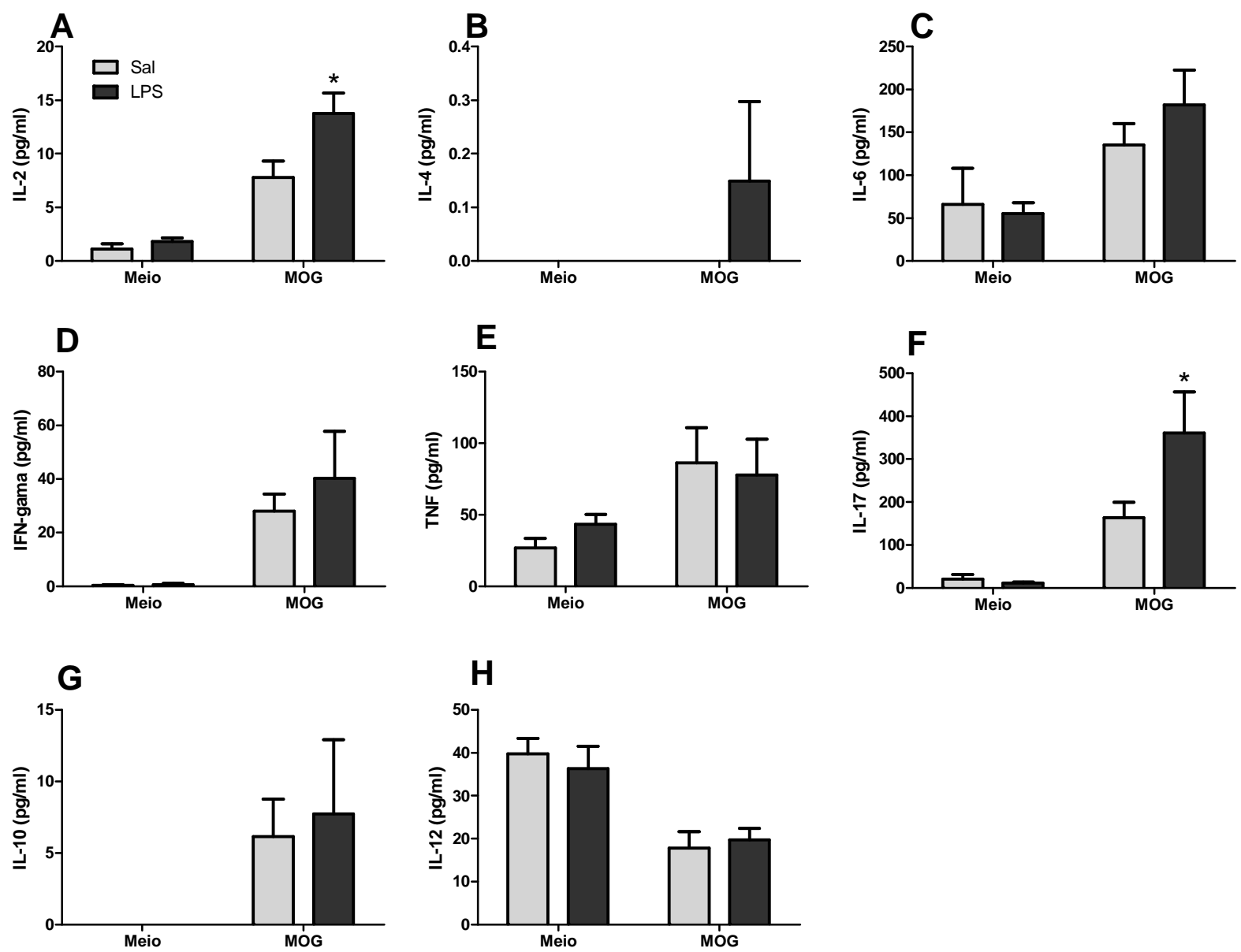

Legenda: Concentrações das citocinas IL-2 (A), IL-4 (B), IL-6 (C), IFN- $\gamma$ (D), TNF (E), IL-17 (F), IL-10 (G) e IL-12 (H) produzidas após estímulo com MOG 35-55 em cultura de células de linfonodos da 
prole de fêmeas tratadas com salina ou LPS durante o final da gestação. Os valores estão expressos em média \pm erro padrão $(n=9)$. * difere do grupo Sal na mesma condição. 


\section{DISCUSSÃO}

Nossos resultados mostram que a ativação imune materna durante a gestação induziram alterações específicas no desenvolvimento fetal, que se refletiram na imunidade da prole, analisada na idade adulta. Especificamente, mostramos que a exposição da mãe a um estímulo imune como o LPS foi suficiente para provocar alterações imunes na periferia e no SNC, além de potencializar a manifestação clínica da EAE na prole de fêmeas.

Dentro do contexto dessa discussão, podemos destacar os trabalhos prévios de nosso grupo nos quais foram encontradas alterações neuroquímicas, comportamentais e endócrinas em decorrência da ativação imune materna causada pelo LPS. A prole de animais expostos ao LPS na metade da gestação apresentou redução do comportamento de brincar (quando jovens) e da interação social (quando adultos), assim como potencialização do comportamento doentio induzido por LPS (KIRSTEN et al., 2010a; KIRSTEN et al., 2010b).

Ainda, trabalhos anteriores deste projeto de doutorado demonstraram que a administração de LPS ao final da gestação potencializou na prole a locomoção induzida pelo tratamento agudo com anfetamina, sem alterar o desenvolvimento da sensibilização comportamental ao tratamento crônico com a mesma droga (ZAGER et al., 2012). Além disso, a prole de fêmeas desafiadas exibiu comportamento estereotipado exacerbado (auto-limpeza no campo aberto), fato que se correlacionou com a expressão aumentada dos receptores dopaminérgicos D1 por esses animais (Apêndice A).

Não obstante, também mostramos que a prole de fêmeas desafiadas apresentava aumento nos níveis plasmáticos basais de noradrenalina e potencialização da liberação de corticosterona em resposta a um estressor agudo. No entanto, esse aumento da concentração plasmática de corticosterona foi transitório, uma vez que uma hora após a retirada do estímulo, a diferença entre os grupos deixou de existir. Esse fenômeno aconteceu independente de perturbações nos níveis hipotalâmicos de noradrenalina e no padrão de sono dos animais (artigo em revisão, Apêndice B). Tomados em seu conjunto, esses achados indicam que 
aspectos específicos do eixo neuroimune são susceptíveis a perturbações durante a gestação.

\subsection{ALTERAÇÕES IMUNES PERIFÉRICAS}

É importante ressaltar que o DG 17 em camundongos é equivalente a 20 semanas de gestação em seres humanos, um período no qual a medula óssea fetal torna-se o principal orgão hematopoiético, que persiste durante toda a vida pósnatal. O estabelecimento do microambiente da medula óssea hematopoiética é um processo que requer a migração de células tronco, a calcificação do esqueleto cartilaginoso, e remodelação de tecidos ossificados; e este microambiente é essencial para a produção normal de leucócitos na vida pós-natal (HOLLADAY; SMIALOWICZ, 2000; LANDRETH, 2002).

As alterações imunes são um importante indicativo da forma pela qual a exposição pré-natal ao LPS pode afetar o desenvolvimento da prole. Nesse sentido, o primeiro experimento foi desenvolvido para se traçar um perfil imune periférico da prole de mães desafiadas, em termos de citocinas Th1/Th2/Th17, atividade de células imunes e desenvolvimento da hipersensibilidade do tipo tardia.

Nossas análises indicam um aumento da produção de IL-12 por células aderentes da prole de mães tratadas com LPS. IL-12 é o principal mediador da imunidade inata e é um indutor essencial da imunidade mediada por células, além de estimular a produção de IFN- $\gamma$ e diferenciação para resposta do tipo Th1 (ABBAS et al., 2007). $O$ aumento da produção de IL-12 nos leva à hipótese de que a ativação imune materna tenha sido capaz de modificar o desenvolvimento da resposta imune da prole, favorecendo respostas do tipo Th1. No entanto, é interessante observar que a produção de citocinas de perfil Th1, Th2 ou Th17 por linfócitos não foi afetada pelo tratamento pré-natal, sugerindo este fato que as alterações aqui encontradas são restritas às células apresentadoreas de antígeno (APCs), como macrófagos e células dendríticas.

Para determinar se o aumento na produção de IL-12 teria uma consequência funcional da imunidade adaptativa e, se este aumento se refletiria em aumento da 
imunidade mediada por células, a prole das fêmeas tratadas com salina ou LPS foi submetida ao paradigma da hipersensibilidade do tipo tardia (DTH, do inglês delayed type hipersensitivity); neste estudo, o aumento da espessura da pata corresponde à resposta imune de perfil Th1 in vivo em animais que foram previamente sensibilizados (ABBAS et al., 2007). Nossos resultados mostraram que o inchaço pata foi aumentado na prole da mães tratadas com LPS, indicando um aumento da infiltração celular e/ou edema local e fornecendo evidências de um aumento global na imunidade mediada por células nessa prole.

Um estudo que corrobora nossa hipótese de desequilíbrio Th1/Th2 mostrou que a prole de mães desafiadas apresenta inflamação das vias aéreas atenuada em resposta à asma induzida experimentalmente, um modelo clássico de resposta Th2 (KIRSTEN et al., 2011), que é conhecido por ser inibido por citocinas de tipo Th1. Dentro deste contexto, os nossos resultados indicam que a produção da citocina regulatória IL-10 por APCs encontrava-se diminuída na prole de mães tratadas com LPS, comprovando que o tônus regulatório encontra-se prejudicado nesses animais.

Achados prévios mostraram que a prole de mães infectadas apresentavam prejuízo na imunidade inata, caracterizado por atraso na maturação da resposta imune (HODYL et al., 2007; BELOOSESKY et al., 2010), além de polarização preferencial para respostas do tipo Th17 (MANDAL et al., 2010a, b). Sabe-se que a progressão de modelos animais de doenças inflamatórias, como a esclerose múltipla e a artrite reumatóide, é mediada principalmente por células do tipo Th1 (ABBAS et al., 2007). Recentemente, tem-se comprovado, também, a participação de células de perfil Th17 na modulação desses distúrbios (BETTELLI et al., 2006; HIROTA et al., 2010).

Curiosamente, os nossos dados indicam que a ativação imunológica pré-natal não teve quaisquer efeito sobre a atividade de neutrófilos no sangue, em todos os parâmetros analisados, tais como produção de espécies reactivas de oxigênio (burst oxidativo) e fagocitose de $S$. aureus, o que indica que esta manipulação não teve impacto sobre a imunidade inata mediada por neutrófilos. No entanto, há que ressaltar que outros aspectos da resposta imune inata, tais como a atividade de monócitos / macrófagos, não foram analisados.

As células dendríticas são as células apresentadores de antígeno mais eficazes para ativar as células $\mathrm{CD}^{+}$e $\mathrm{CD} 8^{+}$naive e para iniciar as respostas das 
células T (ABBAS et al., 2007). Em resposta à antígenos, as células dendríticas amadurecem durante a migração para os linfonodos tornando-se extremamente eficientes na apresentação de antígenos; mas para isso, devem externalizar algumas moléculas co-estimulatórias, como MHC de classe II, CD80 e CD86, para uma correta apresentação e consequente resposta imune (ABBAS et al., 2007).

No nosso estudo, a prole de mães expostas ao LPS não apresentou diferenças significantes na quantidade de células dendríticas no baço, assim como na expressão de moléculas co-estimulatórias. Embora as células dendríticas sejam o principal foco deste estudo, é importante salientar que os macrófagos são importantes mediadores da imunidade inata e adaptativa e, portanto, podem ter sido eles os responsáveis pelas diferenças observadas na produção de citocinas anteriormente citadas (artigo em revisão, Apêndice C).

\subsection{PRODUÇÃO DE MEDIADORES INFLAMATÓRIOS POR CÉLULAS RESIDENTES DO SNC}

Nosso experimento anterior mostrou que a prole de mães desafiadas ao final da gestação apresentou aumento na produção de IL-12 por células apresentadores de antígeno da periferia, o que se refletiu em aumento da resposta de DTH, corroborando nossa hipótese de aumento da resposta de perfil Th1.

Dessa forma, os resultados obtidos no primeiro experimento levantam o seguinte questionamento: dado que a ativação imune pré-natal altera a imunidade adaptativa para o tipo Th1, predominantemente pró-inflamatória, poderia o tratamento pré-natal afetar a resposta imune no sistema nervoso central? Sabe-se que o aumento da produção de citocinas de perfil Th1 na periferia é um potente estímulo para a ativação da microglia (STREIT et al., 2004), e que essa célula é particularmente susceptível a desafios imunes no período perinatal (BILBO; SCHWARZ, 2009).

Dessa forma, decidimos testar essa hipótese através de uma cultura primária mista de neurônios e células da glia de neonatos cujas mães foram desafiadas ou não. Esse tipo de cultura primária oferece uma série de vantagens em relação a 
modelos in vivo, um vez que, elimina a influência de células e de mediadores da periferia que poderiam interferir nos resultados; após estímulo in vitro, esta técnica fornece uma boa perspectiva da resposta imune-inflamatória do SNC. Nesse experimento, a técnica de imunofluorecência revelou os principais tipos celulares envolvidos na cultura mista: neurônios, astrócitos e microglia, evidenciados pela marcação positiva para MAP-2, GFAP e lba-1, respectivamente.

Com relação às citocinas produzidas em cultura, nossos resultados mostraram que a produção de IL-6 e IL-1 $\beta$ após o estímulo com LPS in vitro foi potencializada nas culturas do grupo experimental, em relação ao grupo salina sem, no entanto, revelar diferenças nos níveis de TNF. A IL-6 e IL-1 $\beta$ são citocinas produzidas durante a fase aguda e que medeiam tanto a imunidade inata quanto a resposta inflamatória (ABBAS et al., 2007). Nossos achados, no entanto, não nos permitem concluir quais os tipos celulares envolvidos na exacerbação dessas citocinas, uma vez que tanto os astrócitos quanto a microglia podem secretar as duas citocinas.

Ainda, é interessante observar que os níveis basais de IL-1 $\beta$ nos tecidos provenientes de animais do grupo experimental foram equivalentes aos obtidos no grupo controle após o estímulo, indicando que essas células possuem um perfil próinflamatório basal aumentado quando expostas a um estímulo imune in utero.

Além disso, a produção de IL-10 após o estímulo in vitro encontra-se reduzida nas culturas de células provenientes dos animais do grupo experimental, indicando um prejuízo no controle da inflamação; este resultado corrobora com os achados periféricos do experimento anterior, no qual a produção periférica de IL-10 encontrava-se prejudicada. Curiosamente, a análise de citocinas revelou que a cultura mista não produziu quantidades detectáveis de IL-2, IL-4, IFN- $\gamma$, e IL-17, sugerindo este fato que a produção de citocinas no SNC seja restrita às citocinas ligadas à imunidade inata, como IL-1 $\beta$, IL-6, TNF e IL-10.

Ainda, a quantificação de nitritos produzidos em cultura mista revelou que a atividade do óxido nítrico encontrava-se potencializada nas culturas do grupo experimental após o estímulo in vitro, em relação ao grupo controle. Esse achado sugere que a produção de óxido nítrico também é afetada por estímulos pré-natais, como a ativação imune materna, exacerbando a resposta inflamatória no SNC. 
Dessa forma então, podemos concluir que a ativação imune materna torna as células residentes do SNC (notadamente a glia) hiper-reativas e susceptíveis a desafios subsequentes, potencializando a secreção de citocinas pró-inflamatórias por essas células.

\subsection{DESENVOLVIMENTO DA EAE}

Nossos resultados indicam que a administração de LPS no final da gestação repercutiu não apenas na imunidade periférica mas, também, na resposta inflamatória por células do SNC da prole. No entanto, esses achados in vitro não nos permitem concluir se esse fenômeno possui relevância biológica e se a prole de mães desafiadas com LPS é mais susceptível a doenças autoimunes e neuroinflamatórias, como a artrite e a EM.

Sabe-se que o início e a evolução dos sintomas da EM está diretamente relacionado com a imunidade do tipo Th1 e com a resposta imune-inflamatória do SNC (GLASS et al., 2010), ambas exacerbadas na prole pelo modelo da ativação imune materna. Baseado nesses achados, nossa hipótese seria de que a prole de mães desafiadas apresentaria uma piora nos sintomas clínicos da doença.

De fato, nossos resultados evidenciaram uma piora nos sintomas da EAE em fêmeas provenientes de mães que receberam o LPS no DG17. Curiosamente, 0 aparecimento dos sintomas da EAE ocorreu de forma similar entre os grupos e essa piora ocorreu somente a partir dos 20 dias após a imunização. Nesse sentido, 0 teste do campo aberto corroborou com nossos achados ao revelar que o prejuízo locomotor já era evidente nos animais do grupo experimental 15 dias após a imunização.

Ainda, nesse mesmo experimento optamos por incluir um grupo no qual as fêmeas prenhes foram desafiadas na metade da gestação, no DG9, na tentativa de se determinar se o estágio gestacional durante 0 qual o desafio é realizado influencia esse fenômeno. Curiosamente, o mesmo não ocorreu quando o insulto é aplicado na metade da gestação (dados não mostrados), indicando este fato e de relevância, que existe uma especificidade quanto ao período gestacional em que o 
desafio é aplicado. A especificidade dessas alterações quanto à idade gestacional sugere que os estágios tardios de gestação sejam os períodos mais críticos para o desenvolvimento da auto-imunidade e/ou neuroinflamação e, assim, a consequente desmielinização.

É importante destacar que a prole de machos também foi submetida ao mesmo procedimento $e$, no entanto, os resultados obtidos nos machos não evidenciaram diferenças entre os grupos quanto aos sintomas clínicos da doença. Desta forma, parece-nos possível propor que as fêmeas, além de serem mais afetadas pela $E A E$, sejam mais susceptíveis às influências ambientais como, por exemplo, ativação imune materna. Alternativamente, é lícito pensar que os machos possam ter desenvolvido algum mecanismo protetor que impeça piora dos sintomas.

A partir desses resultados, decidimos investigar os mecanismos pelos quais essas alterações na EAE acontecem somente na prole fêmea de mães que receberam LPS no DG17. O próximo passo foi, então, estudar e caracterizar o infiltrado celular no orgão alvo (SNC) durante o pico de manifestação dos sintomas clínicos da doença.

\subsection{INFILTRADO DE CÉLULAS IMUNES PERIFÉRICAS DURANTE O PICO DA EAE}

Diversos tipos celulares estão envolvidos na progressão da EM, e de seu modelo murino, a EAE. As APCs são necessárias para a patogênese da doença (GRETER et al., 2005), pois, ao entrar em contato com antígenos de mielina, elas amadurecem e migram para os orgão linfóides onde apresentam o antígeno às células T naive (BAILEY et al., 2007). A ativação e sobrevivência de células $T$ requerem dois sinais das APCs: apresentação do antígeno pelo complexo principal de histocompatibilidade (MHC) para o receptor da célula $T$ (TCR), e um sinal secundário fornecido pela interação de moléculas co-estimulatórias, tais como CD80 e CD86 com CD28 em células $T$.

Durante a ativação, a diferenciação de células $T$ em subpopulações de células $\mathrm{CD}^{+}$efetoras (Th1, Th2, Th17, Treg) depende das citocinas produzidas 
pelas APCs (ZHU; PAUL, 2010). Dados recentes sugerem que a EM seja impulsionada por ambos subtipos Th1 e Th17, embora cada subtipo seja diferente quanto ao seu mecanismo (BAILEY et al., 2007; KANG et al., 2010). Uma vez ativadas, as células T migram para o cérebro e atravessam a BHE onde, elas são reestimuladas pelas APCs (TOMPKINS et al., 2002), levando à indução e à progressão da doença. Conforme a doença progride, novos antígenos da mielina são apresentados pelas APCs (espalhamento de epítopos), levando à ativação subseqüente de células T recém chegadas ao SNC (MCRAE et al., 1995).

Nossos resultados mostraram que a migração para o SNC dos principais subtipos celulares envolvidos na patogenia da doença durante o pico da EAE, pode ser modulada pela ativação imune durante o período gestacional. Especificamente, os tipos celulares responsáveis pelo início e pela propagação da inflamação, tais como os macrófagos, encontravam-se aumentados no SNC da prole de mães tratadas com LPS. Não obstante, os subtipos de linfócitos que têm um papel próinflamatório na EAE, como as células Th1 e Th17, também foram afetados e encontravam-se aumentados na prole do grupo experimental. Além disso, encontramos uma diminuição das células T reguladoras no SNC da prole de mães tratadas com LPS, cuja função, supõe-se seja controlar a inflamação nesse modelo, o que poderia ter contribuído para a propagação do processo inflamatório e consequente destruição da mielina.

Dessa forma, podemos inferir que tanto o estímulo pró-inflamatório esteja aumentado quanto o estímulo regulatório esteja suprimido no orgão alvo durante a progressão da EAE em decorrência da exposição materna ao LPS. Esse fenômeno correlaciona-se intimamente com o aumento dos sintomas clínicos da doença em fêmeas, uma vez que quanto maior o infiltrado celular, maior é a neuroinflamação e, consequentemente, a severidade dos sintomas.

Não obstante, já foi mostrado anteriormente que a ocorrência de fatores ambientais e infecções prévias podem predispor à autoimunidade contra antígenos de mielina. No entanto, nosso estudo é pioneiro em mostrar que processos inflamatórios durante o período fetal também afetam a progressão de doenças desmielinizantes, assim como a migração de linfócitos e macrófagos autoreativos para o orgão alvo, no caso o SNC. Além disso, mostramos aqui que o nível de ativação dos macrófagos infiltrantes na prole experimental também encontrava-se 
exacerbado em relação ao grupo controle, uma vez que a expressão de MHC II por essas células estava sensivelmente aumentada na prole de mães tratadas com LPS.

\subsection{PARTICIPAÇÃO DAS CÉLULAS RESIDENTES DO SNC NA EAE}

Com a hipótese no tocante ao papel das células residentes do SNC na piora da EAE induzida pela ativação imune materna, é de que a microglia seja responsável pelo agravamento da doença por se tornar hiper-reativa após a exposição intra-útero às citocinas inflamatórias.

Trabalhos recentes mostraram que a presença da microglia é fundamental para a progressão da EAE em camundongos. Heppner et al. (2005) mostraram em camundongos trangênicos que a produção de TNF, óxido nítrico e CCL4 é inibida no SNC quando esses animais passam por ablação das células microgliais após tratamento farmacológico, fato que compromete a migração de células $T$ para 0 orgão alvo (SNC) e o desenvolvimento da doença.

Nossos resultados de citometria de fluxo indicam que não existem diferenças entre as proles dos grupos experimental e controle quanto ao número de células microgliais. No entanto, a expressão de MHC de classe II por essas células está aumentada na prole de mães tratadas com LPS, indicando um fenótipo próinflamatório exacerbado. Esses dados permitem inferir que o número de células microgliais não seja suscetível a alterações; porém o grau de ativação dessas células e, possivelmente, o fenótipo de citocinas secretadas deve ter sido exacerbado pela ativação imune materna. A microglia expressa constitutivamente os marcadores CD45, CD86 e CD40 em baixos níveis (CARSON et al., 1998); no entanto, a expressão de CD45, MHC II, CD80, CD86 e CD40 torna-se aumentada em resposta a um estímulo inflamatório, dessa forma aumentando sua função de APC (SHRIKANT; BENVENISTE, 1996). Além disso, sabe-se que a microglia atua de duas formas distintas durante o desenvolvimento da EAE: (1) liberando citocinas como IL-6, IL-23, e TGF- $\beta$, propagando a inflamação iniciada pelas células T infiltrantes e, (2) secretando espécies reativas de oxigênio (ROS) e, desta forma, contribuindo para a destruição da mielina (GLASS et al., 2010). 
A despeito do conhecido papel da microglia como APC dentro do SNC, nossos resultados de quantificação proteica em regiões cerebrais mostram um evidente aumento progressivo da expressão de GFAP (Glial fibrillary acidic protein) no cerebelo da prole do grupo experimental, culminando 30 dias após a imunização. Foi proposto que a expressão de GFAP por astrócitos desempenha um papel na interação astrócito-neurônio e que seu aumento seja um indicativo de ativação imune-inflamatória ou astrogliose (LITTLE; O'CALLAGHA, 2001). Curiosamente, a mesma tendência não ocorreu no córtex cerebral, o que poderia ser explicado pelas diferenças entre as duas regiões encefálicas quanto à densidade relativa glia $x$ neurônio, uma vez que o cerebelo é uma região rica em células da glia enquanto que no córtex predominam os neurônios. Esses achados podem nos ajudar a entender o motivo pelo qual a piora dos sintomas da EAE seja evidente apenas durante o pico dos sintomas.

Durante o pico da $E A E$, foi analisada a expressão de mRNA para diversas citocinas em regiões do SNC, como córtex cerebral e cerebelo. Nossos resultados mostraram um aumento significante do mRNA para IL-6, IL-1 $\beta$ e TNF no cerebelo da prole de mães tratadas com LPS, em comparação àquela do grupo salina. Esses achados indicam que essas citocinas estão sendo produzidas no orgão alvo (SNC) durante o pico da EAE e podem nos ajudar a entender a diferença entre os tratamentos pré-natais quanto aos sintomas clínicos da doença.

Dessa forma, nossos resultados in vivo e in vitro corroboram com trabalhos publicados anteriormente que sugerem sejam desafios imunes peri-natais capazes de predispor as células gliais a um fenótipo pró-inflamatório, tornando-as hiperreativas a desafios subsequentes (BILBO; SCHWARZ, 2009).

\subsection{ATERAÇÕES IMUNES PERIFÉRICAS DURANTE O INÍCIO DA EAE}

No experimento seguinte, investigamos o papel da resposta imune periférica nesse fenômeno. Assim sendo, analisamos os tipos celulares presentes e a citocinas produzidas em sítios de apresentação de antígeno como baço e linfonodos 
regionais no início da EAE (7 dias após a imunização) e antes do aparecimento dos sintomas,.

Nossos resultados mostraram que os animais cujas mães foram desafiadas com LPS no DG17 apresentaram uma maior porcentagem de macrófagos expressando $\mathrm{MHC}$ de classe II e IL-17 no baço, mas não revelaram diferenças nos linfonodos. Curiosamente, os macrófagos não mudaram em número, mas sim em ativação e capacidade apresentadora de antígeno.

A respeito da liberação de citocinas em orgãos linfóides, a produção de IL-17 encontrava-se aumentada na prole de mães tratadas com LPS, em ambos orgãos linfóides, corroborando este fato com nossos resultados de fenotipagem das celulas CD11 $\mathrm{b}^{+}$, indicando que a fonte de IL-17 aumentada pode ser os macrófagos, e não os linfócitos, como inicialmente previsto. Adicionalmente, encontramos um aumento de IL-6 no baço, e de IL-2 nos linfonodos do grupo experimental.

A IL-6 é um importante mediador da imunidade inata e adaptativa, uma vez que relaciona-se tanto com a resposta inflamatória de fase aguda quanto a diferenciação das células Th17 (ABBAS et al., 2007). Nossos achados da produção dessa citocina no baço de animais EAE e na cultura mista indicam que a IL-6 encontra-se aumentada em ambos sitios (periferia e SNC) na prole de fêmeas desafiadas com LPS. Dessa forma, nos parece que a IL-6 possa ser mesmo considerada responsável pelo aumento da produção de IL-17 na periferia e pelo aumento de infiltrado inflamatório na EAE.

\subsection{CONSIDERAÇÕES FINAIS}

Tomando em seu conjunto, os resultados dos 3 experimentos realizados nessa tese, permitem um melhor entendimento do fenômeno estudado. Nesse sentido, um prejuízo da produção da citocina regulatória IL-10 parece central, estando envolvido nos 3 paradigmas aqui estudados. De fato, a produção de IL-10 na periferia e no SNC foi drasticamente reduzida nos animais expostos à ativação imune materna, assim como o infiltrado de linfócitos produtores de IL-10 (Células Treg) no SNC de animais EAE. Dessa forma, podemos sugerir que o prejuízo na 
síntese e liberação de IL-10 tenha desempenhado um papel fundamental no aumento da inflamação provocado pelo desafio imune pré-natal, tanto em animais naive quanto em animais imunizados para EAE.

Quer nos parecer, também, que a IL-6 também está envolvida nesse fenômeno, uma vez que a produção dessa citocina por células do baço de animais EAE e por células residentes do SNC, encontrava-se elevada. Ainda, encontramos um aumento no mRNA para IL-6 no cerebelo de animais EAE que foram expostos à ativação imune materna, sugerindo este achado que essa citocina esteja sendo expressa de forma exacerbada no SNC desses animais. Além disso, nossos resultados com cultura primária sugerem que as células do SNC da prole produzem mais IL-6 em decorrência da ativação imune materna. Tomados em seu conjunto, esses dados permitem a proposição de que a IL-6 desempenhe papel fundamental nesse fênomeno, uma vez que seu aumento no orgão alvo (SNC) pode ter potencializado a diferenciação para células Th17, aumentando a permeabilidade da BHE e contribuindo para o aumento de células infiltrantes durante o pico da EAE. Nesse contexto, sabe-se ser a IL-6 um importante mediador do fenômeno da ativação imune materna (HSIAO; PATTERSON, 2011); de fato, a ativação dessa via na placenta é necessária para a ocorrência dos efeitos causados pela ativação imune materna (HSIAO; PATTERSON, 2011). No entanto, os dados do presente trabalho, não permitem precisar a fonte, que no SNC seria responsável pela diminuição da IL-10 e pelo aumento da IL-6 encontrados na cultura mista.

Quer nos parecer seja ainda possível levantar a hipótese de participação de outras vias inflamatórias não analisadas neste trabalho. Um exemplo seria a via CD200-CD200R, na qual o ligante presente em linfócitos e neurônios envia, através de contato celular, um sinal anti-inflamatório através de seu receptor em macrófagos e microglia (MEUTH et al., 2008). Essa sinalização aconteceria em resposta a uma inflamação local, e seu prejuízo poderia tornar o organismo mais susceptível às condições inflamatórias. De fato, foi demonstrado que camundongos knock out para a proteína CD200 são mais susceptíveis ao aumento da inflamação por DTH, artrite induzida por colágeno, transsecção do nervo facial e EAE (HOEK et al., 2000).

Ainda e levando-se em consideração trabalhos da literatura que relatam ser a ativação imune pré-natal capaz de potencializar na prole a inflamação e a perda neuronal em modelos animais de Parkinson (LING et al., 2004a; LING et al., 2006) e 
Alzheimer (KRSTIC et al., 2012) e, tomando-se esses trabalhos em seu conjunto com nossos achados com a EAE, pode-se concluir que a ativação imune materna atue como fator de risco, tornando a prole mais suscetível a doenças neurodegenerativas na vida adulta. Esse fenômeno pode se dar através de uma reprogramação do sistema imune da prole e, principalmente da resposta imuneinflamatória do SNC de modo tal a tornar o organismo mais propício a apresentar inflamações exacerbadas. 


\section{CONCLUSÕES}

\subsection{CONCLUSÕES ESPECÍFICAS}

A ativação imune materna com LPS ao final da gestação provocou na prole:

- Alterações imunes periféricas, como aumento da produção de IL-12 e diminuição de IL-10 por APCs;

- Exacerbação da resposta de hipersensibilidade do tipo tardia, sugestivo de imunidade de perfil Th1 aumentada;

- Potencialização da produção de citocinas pró-inflamatórias e nitritos em cultura primária de células residentes do SNC estimuladas in vitro;

- Piora na severidade dos sintomas clínicos e no prejuízo motor causados pela encefalomielite autoimune experimental (EAE);

- Aumento do infiltrado inflamatório no SNC característico da EAE, como céls Th1, Th17 e macrófagos;

- Ativação imune-inflamatória das células da glia durante a EAE, como aumento da expressão de MHC II pela microglia e GFAP por astrócitos;

- Aumento da frequência de APCs ativadas e da produção de IL-17 e IL-6 no baço de animais imunizados para EAE.

\subsection{CONCLUSÃO GERAL}

Tomados em seu conjunto, os resultados da presente tese indicam que a ativação imune materna provocada pela administração de LPS ao final da gestação causou, na prole adulta, alterações imunes periféricas condizentes com o aumento 
da imunidade mediada por células. No SNC, a ativação imune materna potencializou a resposta neuroinflamatória das células residentes (glia) em cultura primária.

Sugere-se que essas alterações imunes observadas na periferia e no SNC da prole tenham causado uma piora na severidade dos sintomas da encefalomielite autoimune experimental, fato este que correlacionou-se positivamente com aumento global de células infiltrantes no SNC e concomitante gliose. Dessa forma, podemos concluir que condições inflamatórias durante a gestação, particularmente no final da gestação, predispõem o feto a distúrbios autoimunes e neurodegenerativos na vida adulta. 


\section{REFERÊNCIAS}

ABBAS, A. K.; LICHTMAN, A. H.; PILLAI, S. Imunologia celular e molecular. St. Louis: Saunders Elsevier, 2007.

AISEMBERG, J.; VERCELLI, C.; WOLFSON, M.; SALAZAR, A. I.; OSYCKA-SALUT, C.; BILLI, S.; RIBEIRO, M. L.; FARINA, M.; FRANCHI, A. M. Inflammatory agents involved in septic miscarriage. Neuroimmunomodulation, v. 17, n. 3, p. 150-152, 2010.

ASHDOWN, H.; DUMONT, Y.; NG, M.; POOLE, S.; BOKSA, P.; LUHESHI, G. N. The role of cytokines in mediating effects of prenatal infection on the fetus: implications for schizophrenia. Mol Psychiatry, v. 11, n. 1, p. 47-55, 2006.

BAILEY, S. L.; SCHREINER, B.; MCMAHON, E. J.; MILLER, S. D. CNS myeloid DCs presenting endogenous myelin peptides 'preferentially' polarize CD4+ $\mathrm{T}(\mathrm{H})-17$ cells in relapsing EAE. Nat Immunol, v. 8, n. 2, p. 172-180, 2007.

BELOOSESKY, R.; MARAVI, N.; WEINER, Z.; KHATIB, N.; AWAD, N.; BOLES, J.; ROSS, M. G.; ITSKOVITZ-ELDOR, J. Maternal lipopolysaccharide-induced inflammation during pregnancy programs impaired offspring innate immune responses. Am J Obstet Gynecol, v. 203, n. 2, p. 185 e181-184, 2010.

BERNARDI, M. M.; KIRSTEN, T. B.; MATSUOKA, S. M.; TEODOROV, E.; HABR, S. F.; PENTEADO, S. H.; PALERMO-NETO, J. Prenatal lipopolysaccharide exposure affects maternal behavior and male offspring sexual behavior in adulthood.

Neuroimmunomodulation, v. 17, n. 1, p. 47-55, 2010.

BETTELLI, E.; CARRIER, Y.; GAO, W.; KORN, T.; STROM, T. B.; OUKKA, M.; WEINER, H. L.; KUCHROO, V. K. Reciprocal developmental pathways for the generation of pathogenic effector TH17 and regulatory T cells. Nature, v. 441, n. 7090, p. 235-238, 2006.

BILBO, S. D.; SCHWARZ, J. M. Early-life programming of later-life brain and behavior: a critical role for the immune system. Front Behav Neurosci, v. 3, n. 14, 2009.

BILBO, S. D.; SMITH, S. H.; SCHWARZ, J. M. A Lifespan Approach to Neuroinflammatory and Cognitive Disorders: A Critical Role for Glia. J Neuroimmune Pharmacol, v. 7, n. 1, p.24-41, 2011.

CARSON, M. J.; DOOSE, J. M.; MELCHIOR, B.; SCHMID, C. D.; PLOIX, C. C. CNS immune privilege: hiding in plain sight. Immunol Rev, v. 213, p. 48-65, 2006.

CARSON, M. J.; REILLY, C. R.; SUTCLIFFE, J. G.; LO, D. Mature microglia resemble immature antigen-presenting cells. Glia, v. 22, n. 1, p. 72-85, 1998. 
CARVEY, P. M.; CHANG, Q.; LIPTON, J. W.; LING, Z. Prenatal exposure to the bacteriotoxin lipopolysaccharide leads to long-term losses of dopamine neurons in offspring: a potential, new model of Parkinson's disease. Front Biosci, v. 8, p. s826837, 2003.

CUNNINGHAM, C. Microglia and neurodegeneration: The role of systemic inflammation. Glia, v. 61, n. 1, p. 71-90, 2013.

DENNEY, J. M.; CULHANE, J. F. Bacterial vaginosis: A problematic infection from both a perinatal and neonatal perspective. Seminars in Fetal \& Neonatal Medicine, v. 14 , n. 4 , p. 200-203, 2009.

FARO, S.; FENNER, D. E. Urinary tract infections. Clin Obstet Gynecol, v. 41, n. 3, p. 744-754, 1998.

FERNANDES DE ABREU, D. A.; LANDEL, V.; FERON, F. Seasonal, gestational and postnatal influences on multiple sclerosis: the beneficial role of a vitamin $D$ supplementation during early life. J Neurol Sci, v. 311, n. 1-2, p. 64-68, 2011.

FORTIER, M. E.; JOOBER, R.; LUHESHI, G. N.; BOKSA, P. Maternal exposure to bacterial endotoxin during pregnancy enhances amphetamine-induced locomotion and startle responses in adult rat offspring. J Psychiatr Res, v. 38, n. 3, p. 335-345, 2004.

GIOVANNONI, G.; EBERS, G. Multiple sclerosis: the environment and causation. Curr Opin Neurol, v. 20, n. 3, p. 261-268, 2007.

GIOVANOLI, S.; ENGLER, H.; ENGLER, A.; RICHETTO, J.; VOGET, M.; WILLI, R.; WINTER, C.; RIVA, M. A.; MORTENSEN, P. B.; SCHEDLOWSKI, M.; MEYER, U. Stress in puberty unmasks latent neuropathological consequences of prenatal immune activation in mice. Science, v. 339, n. 6123, p. 1095-1099, 2013.

GIRALT, M.; RAMOS, R.; QUINTANA, A.; FERRER, B.; ERTA, M.; CASTROFREIRE, M.; COMES, G.; SANZ, E.; UNZETA, M.; PIFARRE, P.; GARCIA, A.; CAMPBELL, I. L.; HIDALGO, J. Induction of atypical EAE mediated by transgenic production of IL-6 in astrocytes in the absence of systemic IL-6. Glia, v. 61, n. 4, p. 587-600, 2013.

GLASS, C. K.; SAIJO, K.; WINNER, B.; MARCHETTO, M. C.; GAGE, F. H. Mechanisms underlying inflammation in neurodegeneration. Cell, v. 140, n. 6, p. 918934, 2010.

GOLAN, H. M.; LEV, V.; HALLAK, M.; SOROKIN, Y.; HULEIHEL, M. Specific neurodevelopmental damage in mice offspring following maternal inflammation during pregnancy. Neuropharmacology, v. 48, n. 6, p. 903-917, 2005.

GRETER, M.; HEPPNER, F. L.; LEMOS, M. P.; ODERMATT, B. M.; GOEBELS, N.; LAUFER, T.; NOELLE, R. J.; BECHER, B. Dendritic cells permit immune invasion of the CNS in an animal model of multiple sclerosis. Nat Med, v. 11, n. 3, p. 328-334, 2005. 
HANDEL, A. E.; HANDUNNETTHI, L.; GIOVANNONI, G.; EBERS, G. C.; RAMAGOPALAN, S. V. Genetic and environmental factors and the distribution of multiple sclerosis in Europe. Eur J Neurol, v. 17, n. 9, p. 1210-1214, 2010.

HEPPNER, F. L.; GRETER, M.; MARINO, D.; FALSIG, J.; RAIVICH, G.; HOVELMEYER, N.; WAISMAN, A.; RULICKE, T.; PRINZ, M.; PRILLER, J.; BECHER, B.; AGUZZI, A. Experimental autoimmune encephalomyelitis repressed by microglial paralysis. Nat Med, v. 11, n. 2, p. 146-152, 2005.

HIROTA, K.; MARTIN, B.; VELDHOEN, M. Development, regulation and functional capacities of Th17 cells. Semin Immunopathol, v. 32, n. 1, p. 3-16, 2010.

HODYL, N. A.; KRIVANEK, K. M.; LAWRENCE, E.; CLIFTON, V. L.; HODGSON, D. $M$. Prenatal exposure to a pro-inflammatory stimulus causes delays in the development of the innate immune response to LPS in the offspring. $\mathbf{J}$ Neuroimmunol, v. 190, n. 1-2, p. 61-71, 2007.

HOEK, R. M.; RUULS, S. R.; MURPHY, C. A.; WRIGHT, G. J.; GODDARD, R.; ZURAWSKI, S. M.; BLOM, B.; HOMOLA, M. E.; STREIT, W. J.; BROWN, M. H.; BARCLAY, A. N.; SEDGWICK, J. D. Down-regulation of the macrophage lineage through interaction with OX2 (CD200). Science, v. 290, n. 5497, p. 1768-1771, 2000.

HOLLADAY, S. D.; SMIALOWICZ, R. J. Development of the murine and human immune system: differential effects of immunotoxicants depend on time of exposure. Environ Health Perspect, v. 108, p. 463-473, 2000. Supplement, 3.

HSIAO, E. Y.; PATTERSON, P. H. Activation of the maternal immune system induces endocrine changes in the placenta via IL-6. Brain Behav Immun, v. 25, n. 4, p. 604-615, 2011.

KANG, Z.; ALTUNTAS, C. Z.; GULEN, M. F.; LIU, C.; GILTIAY, N.; QIN, H.; LIU, L.; QIAN, W.; RANSOHOFF, R. M.; BERGMANN, C.; STOHLMAN, S.; TUOHY, V. K.; $\mathrm{LI}, \mathrm{X}$. Astrocyte-restricted ablation of interleukin-17-induced Act1-mediated signaling ameliorates autoimmune encephalomyelitis. Immunity, v. 32, n. 3, p. 414-425, 2010.

KIRSTEN, T. B.; DE OLIVEIRA, B. P.; DE OLIVEIRA, A. P.; KIELING, K.; DE LIMA, W. T.; PALERMO-NETO, J.; BERNARDI, M. M. Single early prenatal lipopolysaccharide exposure prevents subsequent airway inflammation response in an experimental model of asthma. Life Sci, v. 89, n. 1-2, p. 15-19, 2011.

KIRSTEN, T. B.; TARICANO, M.; FLORIO, J. C.; PALERMO-NETO, J.; BERNARDI, M. M. Prenatal lipopolysaccharide reduces motor activity after an immune challenge in adult male offspring. Behav Brain Res, v. 211, n. 1, p. 77-82, 2010a.

KIRSTEN, T. B.; TARICANO, M.; MAIORKA, P. C.; PALERMO-NETO, J.; BERNARDI, M. M. Prenatal lipopolysaccharide reduces social behavior in male offspring. Neuroimmunomodulation, v. 17, n. 4, p. 240-251, 2010 b.

KORNEK, B.; LASSMANN, H. Neuropathology of multiple sclerosis-new concepts.

Brain Res Bull, v. 61, n. 3, p. 321-326, 2003. 
KRSTIC, D.; MADHUSUDAN, A.; DOEHNER, J.; VOGEL, P.; NOTTER, T.; IMHOF, C.; MANALASTAS, A.; HILFIKER, M.; PFISTER, S.; SCHWERDEL, C.; RIETHER, C.; MEYER, U.; KNUESEL, I. Systemic immune challenges trigger and drive Alzheimer-like neuropathology in mice. J Neuroinflammation, v. 9, n. 151, 2012.

KYLE, U. G.; PICHARD, C. The Dutch Famine of 1944-1945: a pathophysiological model of long-term consequences of wasting disease. Curr Opin Clin Nutr Metab Care, v. 9, n. 4, p. 388-394, 2006.

LANDRETH, K. S. Critical windows in development of the rodent immune system. Hum Exp Toxicol, v. 21, n. 9-10, p. 493-498, 2002.

LIBBEY, J. E.; TSUNODA, I.; FUJINAMI, R. S. Studies in the modulation of experimental autoimmune encephalomyelitis. J Neuroimmune Pharmacol, v. 5, n. 2, p. 168-175, 2010.

LING, Z.; CHANG, Q. A.; TONG, C. W.; LEURGANS, S. E.; LIPTON, J. W.; CARVEY, P. M. Rotenone potentiates dopamine neuron loss in animals exposed to lipopolysaccharide prenatally. Exp Neurol, v. 190, n. 2, p. 373-383, 2004a.

LING, Z.; GAYLE, D. A.; MA, S. Y.; LIPTON, J. W.; TONG, C. W.; HONG, J. S.; CARVEY, P. M. In utero bacterial endotoxin exposure causes loss of tyrosine hydroxylase neurons in the postnatal rat midbrain. Mov Disord, v. 17, n. 1, p. 116124, 2002.

LING, Z.; ZHU, Y.; TONG, C.; SNYDER, J. A.; LIPTON, J. W.; CARVEY, P. M. Progressive dopamine neuron loss following supra-nigral lipopolysaccharide (LPS) infusion into rats exposed to LPS prenatally. Exp Neurol, v. 199, n. 2, p. 499-512, 2006.

LING, Z. D.; CHANG, Q.; LIPTON, J. W.; TONG, C. W.; LANDERS, T. M.; CARVEY, P. M. Combined toxicity of prenatal bacterial endotoxin exposure and postnatal 6hydroxydopamine in the adult rat midbrain. Neuroscience, v. 124, n. 3, p. 619-628, 2004b.

LITTLE, A. R.; O'CALLAGHA, J. P. Astrogliosis in the adult and developing CNS: is there a role for proinflammatory cytokines? Neurotoxicology, v. 22, n. 5, p. 607-618, 2001.

LIVAK, K. J.; SCHMITTGEN, T. D. Analysis of relative gene expression data using real-time quantitative PCR and the 2(-Delta Delta C(T)) Method. Methods, v. 25, n. 4, p. 402-408, 2001.

MANDAL, M.; MARZOUK, A. C.; DONNELLY, R.; PONZIO, N. M. Maternal immune stimulation during pregnancy affects adaptive immunity in offspring to promote development of TH17 cells. Brain Behav Immunity, v. 25, n. 5, p. 863-871, 2010a.

MANDAL, M.; MARZOUK, A. C.; DONNELLY, R.; PONZIO, N. M. Preferential development of Th17 cells in offspring of immunostimulated pregnant mice. $\mathbf{J}$ Reprod Immunol, v. 87, n. 1-2, p. 97-100, 2010b. 
MCRAE, B. L.; VANDERLUGT, C. L.; DAL CANTO, M. C.; MILLER, S. D. Functional evidence for epitope spreading in the relapsing pathology of experimental autoimmune encephalomyelitis. J Exp Med, v. 182, n. 1, p. 75-85, 1995.

MEUTH, S. G.; SIMON, O. J.; GRIMM, A.; MELZER, N.; HERRMANN, A. M.; SPITZER, P.; LANDGRAF, P.; WIENDL, H. CNS inflammation and neuronal degeneration is aggravated by impaired CD200-CD200R-mediated macrophage silencing. J Neuroimmunol, v. 194, n. 1-2, p. 62-69, 2008.

MEYER, U.; ENGLER, A.; WEBER, L.; SCHEDLOWSKI, M.; FELDON, J. Preliminary evidence for a modulation of fetal dopaminergic development by maternal immune activation during pregnancy. Neuroscience, v. 154, n. 2, p. 701-709, 2008a.

MEYER, U.; FELDON, J.; FATEMI, S. H. In-vivo rodent models for the experimental investigation of prenatal immune activation effects in neurodevelopmental brain disorders. Neurosci Biobehav Rev, v. 33, n. 7, p. 1061-1079, 2009.

MEYER, U.; KNUESEL, I.; NYFFELER, M.; FELDON, J. Chronic clozapine treatment improves prenatal infection-induced working memory deficits without influencing adult hippocampal neurogenesis. Psychopharmacology (Berl), v. 208, n. 4, p. 531-543, 2010.

MEYER, U.; NYFFELER, M.; SCHWENDENER, S.; KNUESEL, I.; YEE, B. K.; FELDON, J. Relative prenatal and postnatal maternal contributions to schizophreniarelated neurochemical dysfunction after in utero immune challenge.

Neuropsychopharmacology, v. 33, n. 2, p. 441-456, 2008b.

MEYER, U.; NYFFELER, M.; YEE, B. K.; KNUESEL, I.; FELDON, J. Adult brain and behavioral pathological markers of prenatal immune challenge during early/middle and late fetal development in mice. Brain Behav Immun, v. 22, n. 4, p. 469-486, 2008c.

MEYER, U.; SPOERRI, E.; YEE, B. K.; SCHWARZ, M. J.; FELDON, J. Evaluating early preventive antipsychotic and antidepressant drug treatment in an infectionbased neurodevelopmental mouse model of schizophrenia. Schizophr Bull, v. 36, n. 3, p. 607-623, 2008d.

MEYER, U.; YEE, B. K.; FELDON, J. The neurodevelopmental impact of prenatal infections at different times of pregnancy: the earlier the worse? Neuroscientist, $v$. 13, n. 3, p. 241-256, 2007.

NOSEWORTHY, J. H.; LUCCHINETTI, C.; RODRIGUEZ, M.; WEINSHENKER, B. G. Multiple sclerosis. N Engl J Med, v. 343, n. 13, p. 938-952, 2000.

OZAWA, K.; HASHIMOTO, K.; KISHIMOTO, T.; SHIMIZU, E.; ISHIKURA, H.; IYO, $M$. Immune activation during pregnancy in mice leads to dopaminergic hyperfunction and cognitive impairment in the offspring: a neurodevelopmental animal model of schizophrenia. Biol Psychiatry, v. 59, n. 6, p. 546-554, 2006. 
PAINTER, R. C.; ROSEBOOM, T. J.; BLEKER, O. P. Prenatal exposure to the Dutch famine and disease in later life: an overview. Reprod Toxicol, v. 20, n. 3, p. 345352, 2005.

RIBEIRO, A.; FERRAZ-DE-PAULA, V.; PINHEIRO, M. L.; SAKAI, M.; COSTAPINTO, F. A.; PALERMO-NETO, J. Anandamide prior to sensitization increases cellmediated immunity in mice. Int Immunopharmacol, v. 10, n. 4, p. 431-439, 2010.

RITZ, B.; WILHELM, M. Ambient air pollution and adverse birth outcomes: methodologic issues in an emerging field. Basic Clin Pharmacol Toxicol, v. 102, n. 2, p. 182-190, 2008.

ROMERO, E.; ALI, C.; MOLINA-HOLGADO, E.; CASTELLANO, B.; GUAZA, C.; BORRELL, J. Neurobehavioral and immunological consequences of prenatal immune activation in rats. Influence of antipsychotics. Neuropsychopharmacology, v. 32, n. 8, p. 1791-1804, 2007.

SHRIKANT, P.; BENVENISTE, E. N. The central nervous system as an immunocompetent organ: role of glial cells in antigen presentation. J Immunol, v. 157, n. 5, p. 1819-1822, 1996.

SMITH, S. E.; LI, J.; GARBETT, K.; MIRNICS, K.; PATTERSON, P. H. Maternal immune activation alters fetal brain development through interleukin-6. J Neurosci, v. 27 , n. 40, p. 10695-10702, 2007.

SOSPEDRA, M.; MARTIN, R. Immunology of multiple sclerosis. Annu Rev Immunol, v. 23, p. 683-747, 2005.

STREIT, W. J.; MRAK, R. E.; GRIFFIN, W. S. Microglia and neuroinflammation: a pathological perspective. J Neuroinflammation, v. 1, n. 1, p. 14, 2004.

TOMPKINS, S. M.; PADILLA, J.; DAL CANTO, M. C.; TING, J. P.; VAN KAER, L.; MILLER, S. D. De novo central nervous system processing of myelin antigen is required for the initiation of experimental autoimmune encephalomyelitis. $\mathbf{J} \mathbf{~ I m m u n o l}$, v. 168, n. 8, p. 4173-4183, 2002.

VILTART, O.; VANBESIEN-MAILLIOT, C. C. Impact of prenatal stress on neuroendocrine programming. ScientificWorldJournal, v. 7, p. 1493-1537, 2007.

WINTER, C.; DJODARI-IRANI, A.; SOHR, R.; MORGENSTERN, R.; FELDON, J.; JUCKEL, G.; MEYER, U. Prenatal immune activation leads to multiple changes in basal neurotransmitter levels in the adult brain: implications for brain disorders of neurodevelopmental origin such as schizophrenia. Int J Neuropsychopharmacol, v. 12, n. 4, p. 513-524, 2009.

YANG, J. F.; TAO, H. Q.; LIU, Y. M.; ZHAN, X. X.; LIU, Y.; WANG, X. Y.; WANG, J. H.; MU, L. L.; YANG, L. L.; GAO, Z. M.; KONG, Q. F.; WANG, G. Y.; HAN, J. H.; SUN, B.; LI, H. L. Characterization of the interaction between astrocytes and encephalitogenic lymphocytes during the development of experimental autoimmune encephalitomyelitis (EAE) in mice. Clin Exp Immunol, v. 170, n. 3, p. 254-265, 2012. 
ZAGER, A.; MENNECIER, G.; PALERMO-NETO, J. Maternal immune activation in late gestation enhances locomotor response to acute but not chronic amphetamine treatment in male mice offspring: Role of the D1 receptor. Behav Brain Res, v. 232, n. 1, p. 30-36, 2012.

ZHANG, X.; SLIWOWSKA, J. H.; WEINBERG, J. Prenatal alcohol exposure and fetal programming: effects on neuroendocrine and immune function. Exp Biol Med (Maywood), v. 230, n. 6, p. 376-388, 2005.

ZHU, J.; PAUL, W. E. Heterogeneity and plasticity of T helper cells. Cell Res, v. 20, n. 1, p. 4-12, 2010.

ZUCKERMAN, L.; REHAVI, M.; NACHMAN, R.; WEINER, I. Immune activation during pregnancy in rats leads to a postpubertal emergence of disrupted latent inhibition, dopaminergic hyperfunction, and altered limbic morphology in the offspring: a novel neurodevelopmental model of schizophrenia.

Neuropsychopharmacology, v. 28, n. 10, p. 1778-1789, 2003. 
APÊNDICES 
APÊNDICE A 
Research report

\title{
Maternal immune activation in late gestation enhances locomotor response to acute but not chronic amphetamine treatment in male mice offspring: Role of the D1 receptor
}

\author{
Adriano Zager, Gregory Mennecier, João Palermo-Neto* \\ Neuroimmunomodulation Research Group, Department of Pathology, School of Veterinary Medicine, University of São Paulo, São Paulo, Brazil
}

\section{A R T I C L E I N F O}

\section{Article history:}

Received 21 September 2011

Received in revised form 19 March 2012

Accepted 23 March 2012

Available online $\mathrm{xxx}$

\section{Keywords:}

Maternal immune activation

Amphetamine

Behavioral sensitization

Prenatal LPS

Mesolimbic pathway

D1 dopamine receptor

Late gestation

\begin{abstract}
A B S T R A C T
Exposure to elevated levels of maternal cytokines can lead to functional abnormalities of the dopaminergic system in the adult offspring, including enhanced amphetamine (AMPH)-induced locomotion. Therefore, it seems reasonable to consider that offspring of challenged mothers would behave differently in models of addictive behavior, such as behavioral sensitization. Thus, we sought to evaluate the effects of prenatal exposure to lipopolysaccharide (LPS) on the locomotor response to acute and chronic AMPH treatment in male mice offspring. For this purpose, LPS (Escherichia coli 0127:B8; $120 \mu \mathrm{g} / \mathrm{kg}$ ) was administered intraperitoneally to pregnant Swiss mice on gestational day 17. At adulthood, male offspring were studied under one of the following conditions: (1) locomotor response to acute AMPH treatment $(2.5$ or $5.0 \mathrm{mg} / \mathrm{kg}$ ) in an open field test; (2) behavioral sensitization paradigm, which consists of a daily injection of AMPH $(1.0 \mathrm{mg} / \mathrm{kg})$ for 10 days and observation of locomotion in the open field on days 1, 5, 10 (development phase), 15 and 17 (expression phase). The LPS stimulated offspring showed enhancement of the locomotor-stimulant effect after an acute AMPH challenge in comparison to baseline and saline pre-treated mice. They also showed development of behavioral sensitization earlier than the saline pre-treated group, although no changes between saline and LPS pre-treated groups were observed on development or expression of locomotor behavioral sensitization to AMPH. Furthermore, there was up-regulation of D1 receptor protein level within striatum in the LPS-stimulated offspring which was strongly correlated with increased grooming behavior. Taken together, our results indicate that motor and dopaminergic alterations caused by maternal immune activation are restricted to the acute AMPH challenge, mostly due to up-regulation of the $\mathrm{D} 1$ receptor within the mesolimbic and nigrostriatal pathways, but no locomotor differences were observed for behavioral sensitization to AMPH.
\end{abstract}

(C) 2012 Elsevier B.V. All rights reserved.

\section{Introduction}

The occurrence of maternal infection during pregnancy is considered an environmental risk factor that can lead to emergence of many neuropsychiatric disorders in later life, including autism [1] and schizophrenia [2]. It is worth noting that many studies have attempted to mimic the long-term consequences of maternal immune activation (MIA) during pregnancy on the subsequent brain development of the offspring. These models include exposure to lipopolysaccharide (LPS) and polyriboinosinic-polyribocytidylic acid (PolyI:C), which mimic gram-negative bacterial infection and viral infection, respectively [for recent reviews, see 3,4]. LPS is

\footnotetext{
* Corresponding author at: Department of Pathology, School of Veterinary Medicine, University of São Paulo, Av. Prof. Dr. Orlando Marques de Paiva, 87, 05508 270 Cidade Universitária, São Paulo, SP, Brazil. Tel.: +55 113091 7957; fax: +55 1130917829 .

E-mail address: jpalermo@usp.br (J. Palermo-Neto).
}

recognized by toll-like receptor (TLR) 2 and TLR4, whereas PolyI:C is recognized primarily by TLR3 $[5,6]$. Upon binding to TLRs, LPS and PolyI:C both stimulate the production and release of many pro-inflammatory cytokines by immune cells, including interleukin (IL)-1 $\beta$, IL-6, and tumor necrosis factor (TNF)- $\alpha[7,8]$. Additionally, PolyI: $C$ is a potent inducer of type I interferon (IFN)- $\alpha$ and IFN- $\beta$ $[5,9]$. It is now widely accepted that elevated levels of maternal pro-inflammatory cytokines during specific stages of fetal brain development could lead to abnormalities in the adult offspring's central neurotransmission and behavior.

In this sense, maternal immune activation during pregnancy can lead to functional abnormalities in the adult offspring's dopaminergic system, including altered expression of tyrosine hydroxylase (TH) in the dorsal and ventral striatum $[10,11]$ and the dopamine (DA) receptors in the prefrontal cortex [11,12]. Disruption of normal dopaminergic development may thus represent a mechanism by which maternal immune challenge during pregnancy can lead to brain and behavioral pathological changes in the offspring. Additionally, behavioral alterations in the offspring exposed 
to inflammatory stimuli include impaired social behavior [13], reduced motor activity after an immune challenge [14], impaired sensorimotor gating [12], and enhanced amphetamine (AMPH)induced locomotor response [7,11,12,15].

The locomotor response to acute AMPH treatment is routinely used as a behavioral indicator of mesolimbic DA pathway activity $[16,17]$. Moreover, enhanced susceptibility to dopaminergic stimulation by acute AMPH treatment has been associated with the positive symptoms of schizophrenia [18-20]. Therefore, in light of the fact that sensitization of the DA pathways has been related to schizophrenia symptoms [21], it seems reasonable to consider that offspring exposed to pro-inflammatory stimuli during pregnancy would behave differently in models of addictive behavior, such as behavioral sensitization.

Behavioral sensitization consists of the ability of addictive drugs to increase drug-elicited behavioral responses (locomotion) progressively after repeated exposure in laboratory animals [22]. This has been demonstrated for different drugs of abuse, such as cocaine [23], AMPH [24], ethanol [25], morphine [26] and nicotine [27]. Sensitization to drug-induced hyperlocomotion is a powerful tool for the study of drug reinforcement properties and drug-seeking behavior, which promote understanding of the mechanisms of plasticity in the dopaminergic mesolimbic pathway, which is crucial to the establishment of drug addiction and cravings [28-30].

Based on this background, we sought to determine the differential outcomes of maternal immune activation induced by LPS injection on locomotor response to acute and chronic AMPH treatment (i.e., behavioral sensitization) in male mice offspring. Furthermore, the participation of the D1 dopaminergic receptor was also evaluated.

\section{Methods}

\subsection{Animals}

Pregnant Swiss mice from our own colony, weighing 45-60 g each, were used (gestational day (GD) 0: presence of vaginal plug). Dams were individually housed in standard polypropylene cages at a room with controlled temperature $\left(22 \pm 2^{\circ} \mathrm{C}\right)$, humidity (65-70\%), and artificial lighting (12 h light/12 h dark cycle, lights on at $6: 00 \mathrm{am}$ ), and the mice were given free access to Nuvilab ${ }^{\circledR}$ rodent chow (Nuvital company, São Paulo, Brazil) and filtered water. Sterilized and residue-free wood shavings were used as animal bedding. The animals used in this study were maintained in accordance with the guidelines of the Committee on Care and Use of Laboratory Animal Resources of the School of Veterinary Medicine, University of São Paulo, Brazil (protocol \# 1683/2009, FMVZ-USP).

\subsection{Drugs}

LPS derived from Escherichia coli serotype 0127:B8 (Sigma, USA) was freshly dissolved in $0.9 \%$ sterile saline and was administered intraperitoneally (i.p.) to pregnant mice at a dose of $120 \mu \mathrm{g} / \mathrm{kg}$ (approximately $4 \mu \mathrm{g} / \mathrm{animal}$ ) on GD 17 . This dose and gestational period was chosen based on previous studies in which maternal inflammation was achieved without inducing preterm delivery or influencing the offspring's growth and sensory-motor reflex development [31-33].

Amphetamine sulfate (Sigma, USA) was freshly dissolved in $0.9 \%$ sterile saline and was administered i.p. at doses of $1.0,2.5$ or $5.0 \mathrm{mg} / \mathrm{kg}$. The doses used and timelag were chosen according to previous studies in which differences between prenatal treatments were reported following higher AMPH doses [12,15], whereas behavioral sensitization is achieved after repeated exposure to lower AMPH doses [34].

\subsection{Open field test}

The open field device consisted of a round wooden arena $(40 \mathrm{~cm}$ in diameter, $25.5 \mathrm{~cm}$ high walls) painted black with an acrylic washable covering. For the observations, each mouse was individually placed in the center of the apparatus, and the total locomotor activity (distance traveled in centimeters) and mean velocity were automatically measured over a period of $10 \mathrm{~min}$. A video camera mounted $100 \mathrm{~cm}$ above the arena was used to collect the data, which were analyzed with the Ethovision 2.3 software (Noldus Information Technology, Leesburg, VA) installed on an IBM-compatible computer placed in an adjacent room. The time spent in grooming behavior was manually scored by an experimenter unaware of the pharmacological treatments. The device was washed with a $5 \%$ alcohol/water solution before placement of the animals to eliminate possible biasing effects from odor clues left by the previous subject. Control and experimental mice were intermixed for observations that were performed from 08:00 am to $12: 00 \mathrm{pm}$.

\subsection{Determination of $D 1 R$ protein expression}

The frontal cortex and striatum from mice were lysed in 1.5-ml Eppendorf tubes by sonication in the presence of an ice-cold buffer containing $120 \mathrm{mM}$ Tris- $\mathrm{HCl}$ (pH 6.8), 10\% sodium dodecyl sulfate (SDS), 20\% glycerol, $1 \mathrm{mM}$ dithio-DL-threitol (DTT), $1 \mathrm{mM}$ phenylmethylsulfonyl fluoride (PMSF), and a protease inhibitor cocktail (Sigma). Extracts were centrifuged at $13,000 \times \mathrm{g}$ for $13 \mathrm{~min}$ at $4{ }^{\circ} \mathrm{C}$, and the supernatants were collected and stored at $-80^{\circ} \mathrm{C}$. Proteins were quantified by the Bradford method (Bio-Rad protein essay), and $50 \mu \mathrm{g}$ of total protein was electrophoresed on a $13 \%$ SDS-polyacrylamide gel (Bio-Rad system). The proteins were transferred to a nitrocellulose membrane (Invitrogen) using an iBlot gel transfer system (Invitrogen). The membrane was blocked for $1 \mathrm{~h}$ in $5 \%$ nonfat dry milk and $1 \%$ Tween-20 in Tris-buffered saline ( $\mathrm{pH} \mathrm{8.0)}$ ). Subsequently, each membrane was probed overnight at $4{ }^{\circ} \mathrm{C}$ with monoclonal antibodies against D1R $(1: 500$; Chemicon, USA) or $\beta$-actin (1:1000; Sigma), followed by several washes in TBS-T. The membranes were then incubated with an anti-mouse secondary antibody conjugated to horseradish peroxidase ( $1: 1000)$ for $120 \mathrm{~min}$ and visualized by chemiluminescence (ECL; Amersham, USA). The bands were quantified using the software ImageJ.

\subsection{Experimental procedure}

\subsubsection{Experiment 1: locomotor response to acute AMPH challenge}

During adulthood (postnatal day 70-90), saline or LPS-treated mice offspring ( $n=9$ /group) were subjected to an injection of saline prior to an open field test to define the baseline locomotion. Immediately after that test, all mice received a single administration of AMPH (2.5 or $5.0 \mathrm{mg} / \mathrm{kg}$ ) and were subjected to open field test 25 min later (AMPH induced locomotion). To prevent possible cumulative effects of the drug and habituation of the open field arena, the same subject received only one dose of AMPH.

\subsubsection{Experiment 2: behavioral sensitization to repeated AMPH treatment}

2.5.2.1. Development phase. During adulthood, saline or LPS-treated mice offspring were initially placed in the open field for $5 \mathrm{~min}$ without drug administration to evaluate their baseline locomotor response in a novel environment (novelty test). To prevent the influence of reactivity to novelty in treatment outcomes, we equated the different treatment groups according to their baseline locomotor activity. A $t$-test confirmed that there were no differences in baseline activity between treatment groups. Five days after the novelty test, mice of each prenatal treatment group received vehicle ( $n=7 /$ group) or $1.0 \mathrm{mg} / \mathrm{kg}$ of AMPH ( $n=13 /$ group) for 10 days. On days 1,5 and $10,10 \mathrm{~min}$ after vehicle or AMPH administration, the mice were tested for $10 \mathrm{~min}$ in the open field arena.

2.5.2.2. Expression phase. After a 5 day withdrawal period, all mice received a saline and an AMPH $(1.0 \mathrm{mg} / \mathrm{kg})$ challenge on days 15 and 17, respectively. Ten min after administration, locomotor activity was recorded for $10 \mathrm{~min}$. Immediately after the AMPH challenge test (day 17), the animals were decapitated in an adjacent room, and their brains were collected. The cortex and striatum were dissected and stored at $-80^{\circ} \mathrm{C}$ until analysis of $\mathrm{D} 1$ receptor expression.

\subsection{Statistical analysis}

Values are expressed as the mean \pm SEM. For analysis of the acute locomotor response and the locomotion during the expression phase, a two-way analysis of variance (ANOVA) was performed, followed by a Bonferroni post hoc test. For the locomotion during the development phase, a repeated measures ANOVA followed by a Bonferroni test was performed. For protein levels, a one-way ANOVA followed by Dunnett's test was performed. Pearson's correlation coefficient was calculated to compare D1R protein levels in the striatum with time spent in grooming behavior during the AMPH challenge. The results were analyzed with the GraphPad Prism 5.0 software, and the level of statistical significance was set at $p \leq 0.05$.

\section{Results}

\subsection{Experiment 1: locomotor response to acute AMPH challenge}

\subsubsection{Total locomotion}

A two-way ANOVA revealed an effect of prenatal treatment $\left[F_{(1,11)}=8.3 ; p=0.01\right]$ and AMPH challenge $\left[F_{(2,22)}=96.455\right.$; $p=0.001]$ on the distance traveled in centimeters. Bonferroni post hoc analyses indicated that the $2.5 \mathrm{mg} / \mathrm{kg}$ dose of AMPH increased locomotion in the offspring of LPS-treated dams compared to the baseline locomotion $(p \leq 0.01)$ and the saline group $(p \leq 0.01)$. After a $5.0 \mathrm{mg} / \mathrm{kg}$ dose, AMPH increased locomotion in the saline group in comparison with baseline $(p \leq 0.01)$ and AMPH-treated mice 

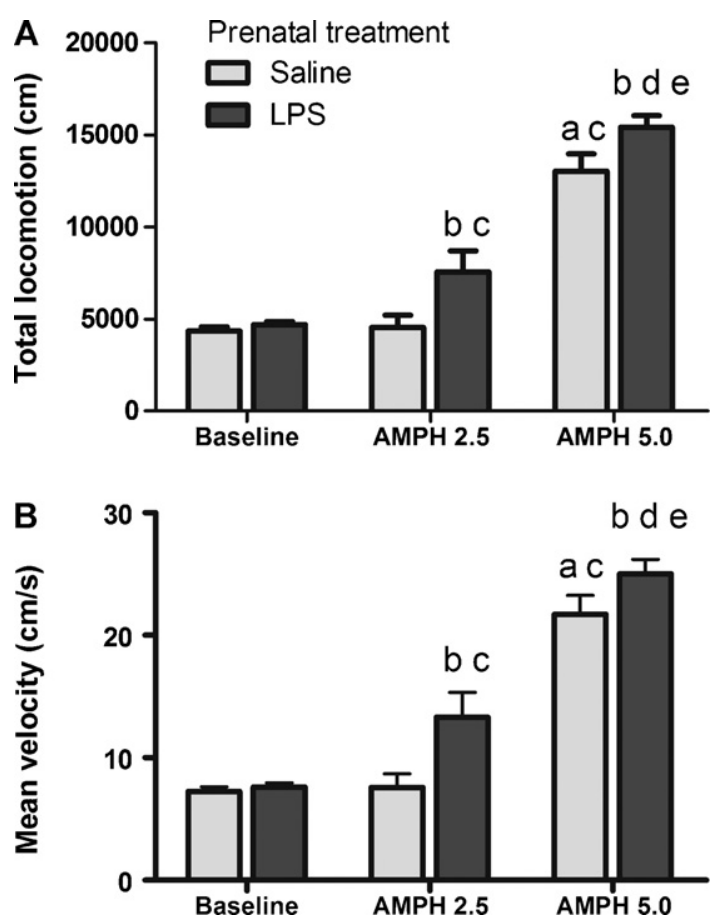

Fig. 1. Locomotor response after acute administration of amphetamine (AMPH 2.5 or $5.0 \mathrm{mg} / \mathrm{kg}$ ) in the offspring of mice treated with saline or LPS on GD 17. Mean values $( \pm$ SEM) of the total distance traveled (Panel A) and mean velocity (Panel B). ${ }^{a}$ Different from baseline of the Sal group, ${ }^{b}$ different from baseline of the LPS group, ${ }^{c}$ different from the Sal group treated with AMPH 2.5, ddifferent from the LPS group

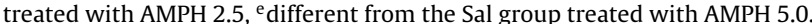

$(2.5 \mathrm{mg} / \mathrm{kg}, p \leq 0.01)$. In addition, the LPS pre-treated group presented an increase of the stimulant effect induced by the $5.0 \mathrm{mg} / \mathrm{kg}$ dose compared to the baseline $(p \leq 0.01)$ and the $2.5 \mathrm{mg} / \mathrm{kg}$ AMPH $(p \leq 0.05)$ and the saline pre-treated groups $(p \leq 0.05)$, as shown in Fig. 1A.

\subsubsection{Mean velocity}

An ANOVA test showed that changes in the mean velocity were observed for both prenatal treatment $\left[F_{(1,11)}=6.8 ; p=0.05\right]$ and AMPH challenge $\left[F_{(2,22)}=89.2 ; p=0.001\right]$. The post hoc test indicated that the $2.5 \mathrm{mg} / \mathrm{kg}$ dose of AMPH increased the mean velocity of the offspring of LPS-treated dams compared to the baseline locomotion $(p \leq 0.01)$ and the saline group $(p \leq 0.01)$. After a $5.0 \mathrm{mg} / \mathrm{kg}$ dose, AMPH increased velocity in the saline group in comparison with the baseline $(p \leq 0.01)$ and AMPH-treated mice $(2.5 \mathrm{mg} / \mathrm{kg}, p \leq 0.01)$. In addition, the LPS pre-treated group presented an increase in the stimulant effect induced by the $5.0 \mathrm{mg} / \mathrm{kg}$ dose compared to the baseline $(p \leq 0.01)$ and the $2.5 \mathrm{mg} / \mathrm{kg}$ AMPH $(p \leq 0.05)$ and the saline pre-treated groups $(p \leq 0.05)$, as shown in Fig. $1 \mathrm{~B}$.

\subsection{Experiment 2: behavioral sensitization to chronic AMPH treatment}

\subsubsection{Development phase}

A repeated measures ANOVA revealed an effect of the groups $\left[F_{(3,27)}=6.1 ; p=0.01\right]$ and a group $\times$ time interaction $\left[F_{(6,54)}=2.7\right.$; $p=0.02]$ on the total locomotion during the development phase of behavioral sensitization, as illustrated in Fig. 2. The post hoc test indicated that the Sal-AMPH group presented an increase in locomotion on day 10 compared to day $1(p \leq 0.05)$ and to the Sal-Sal group $(p \leq 0.05)$. On the other hand, the groups pre-treated with LPS showed increased locomotion in response to daily AMPH administration earlier, on day 5 , in relation to the LPS-Sal group (day 5,

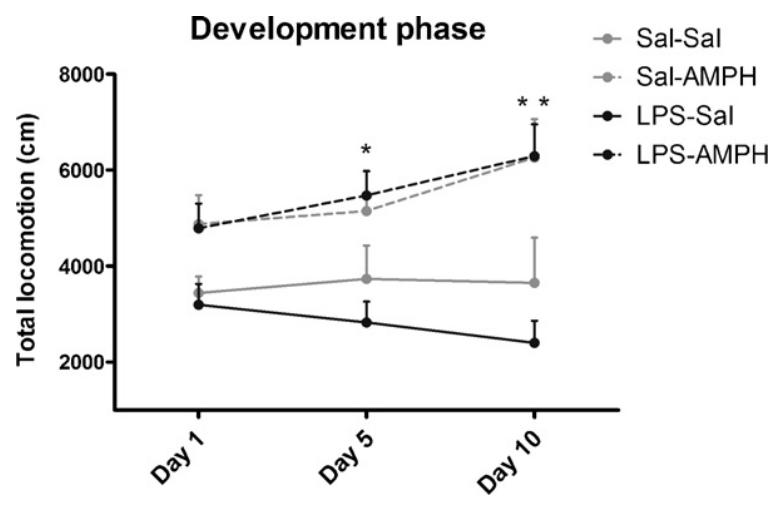

Fig. 2. Development phase of behavioral sensitization shows a progressive increase in locomotor response after repeated administration of amphetamine (AMPH $1.0 \mathrm{mg} / \mathrm{kg}$ ) in the offspring of mice treated with saline or LPS on GD 17. Mean values $\left( \pm\right.$ SEM) of the total distance traveled during tests on day 1,5 and $10 .{ }^{*}$ LPS-AMPH vs. LPS-Sal on day $5,{ }^{* *}$ different from days 1 and 5 and from the vehicle group on day 10.

$p \leq 0.05$ ). On day 10 , the LPS-AMPH group presented a locomotion pattern significantly different from that observed on day 1 $(p \leq 0.01)$ and in the LPS-Sal group $(p \leq 0.05)$.

\subsubsection{Expression phase}

The total locomotion analysis in the open-field after the saline challenge presented a significant treatment effect $\left[F_{(1,29)}=12.8\right.$; $p=0.001]$, as indicated by a two-way ANOVA (Fig. 3A). For both prenatal treatments, mice that received daily $\mathrm{AMPH}$ injections showed increased locomotion after the withdrawal period compared to the respective saline group $(p \leq 0.05)$. The total time in grooming behavior after the saline challenge presented a significant pre-treatment $\left[F_{(1,27)}=4.99 ; p=0.03\right]$ and treatment $\left[F_{(1,27)}=6.30\right.$; $p=0.01$ ] effects, as indicated by a two-way ANOVA (Fig. 3C). The grooming was marked increased in the LPS-saline group $(p<0.01)$ based on Bonferroni post hoc test.

Regarding the locomotor response to AMPH challenge, a twoway ANOVA revealed a significant treatment effect $\left[F_{(1,29)}=13.8\right.$; $p=0.001]$. As indicated by a post hoc test, locomotion of the AMPHsensitized mice was significantly enhanced by the AMPH challenge for both prenatal treatments (saline, $p \leq 0.05$; and LPS, $p \leq 0.01$; Fig. 3B). The total time in grooming behavior after the AMPH challenge presented a significant pre-treatment $\left[F_{(1,22)}=6.58 ; p=0.01\right]$ and interaction $\left[F_{(1,27)}=5.84 ; p=0.02\right]$ effects, as indicated by a twoway ANOVA (Fig. 3D). The grooming was marked increased in the LPS-saline group $(p<0.05)$ based on Bonferroni post hoc test.

\subsubsection{D1 receptor protein level}

All of the protein expression analyses were performed by normalizing the densitometric values for each experiment to those obtained from the Sal-Sal group (control) from each brain region, which were defined as an optical density of $100 \%$. The other measurements were expressed as percentages of the Sal-Sal group, with positive percentages indicating $\mathrm{D} 1 \mathrm{R}$ up-regulation and negative percentages indicating down-regulation.

No statistical differences were found in the optical density of bands from the frontal cortical tissue among the different experimental groups $(p>0.05)$. In the striatum, however, D1R protein level showed significant variations among groups $\left[F_{(3,8)}=5.86\right.$; $p<0.05$ ], as depicted in Fig. 4A. The D1 receptor protein level was increased in the LPS-saline group $(p<0.05)$ based on Dunnett's post hoc test. Moreover, D1R protein level in the striatum correlated strongly with the time spent in grooming behavior during AMPH challenge $(r=0.98, p<0.01$; Fig. 4B). 

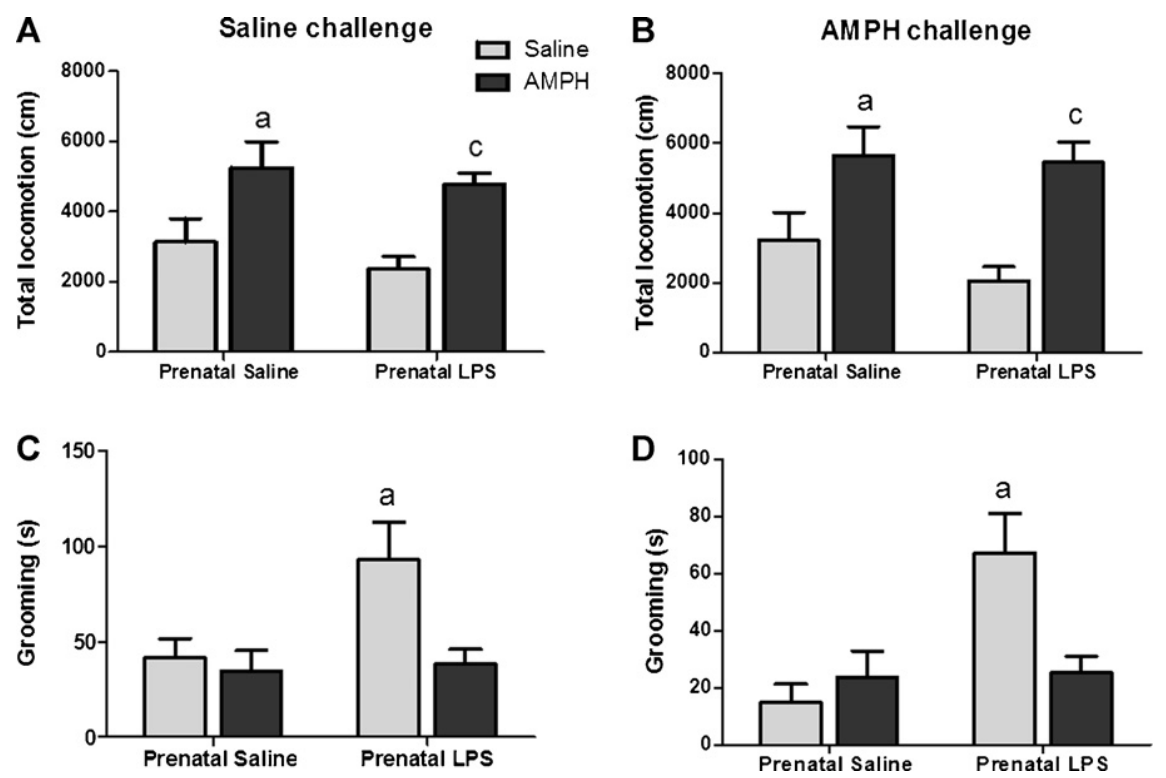

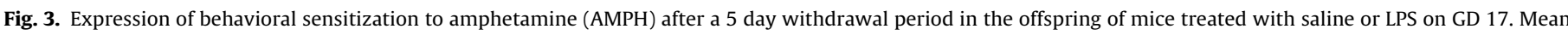

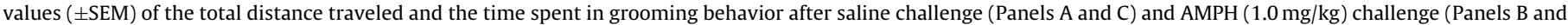
D) on days 15 and 17 , respectively. ${ }^{a}$ Different from the Sal group treated chronically with saline, ${ }^{c}$ different from the LPS group treated chronically with saline.

A

\section{D1R}

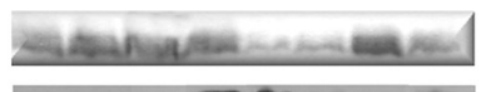

Beta-actin
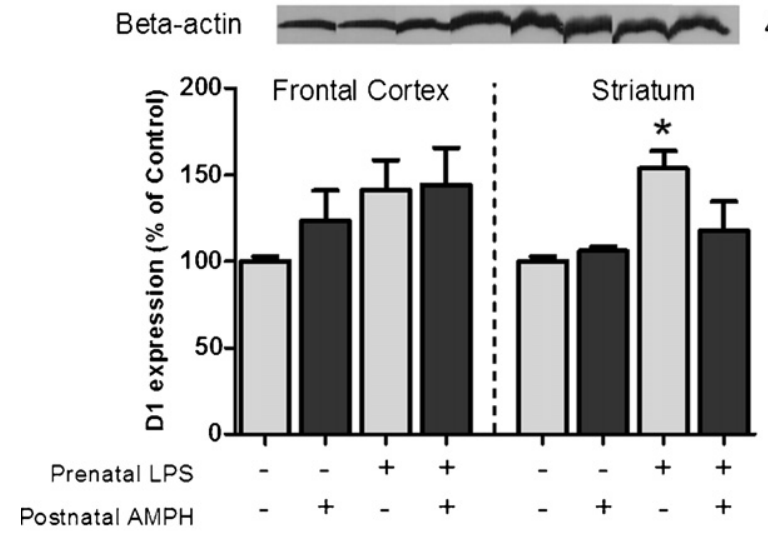

B

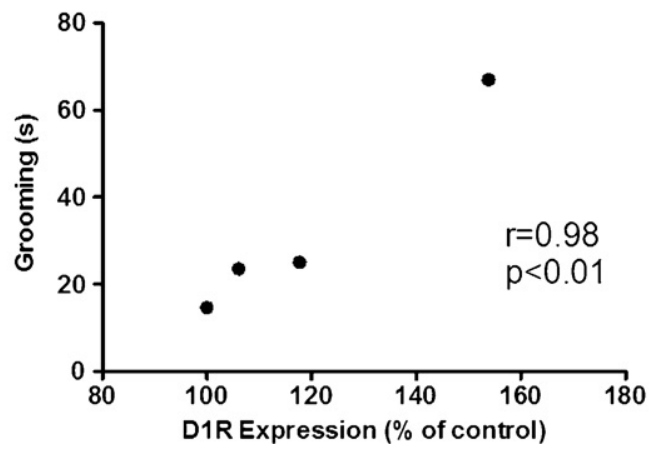

Fig.4. Expression of the D1 dopaminergic receptor in the frontal cortex and striatum of offspring of mothers treated with saline or LPS on GD 17. D1 protein expression in the striatum is up-regulated in animals receiving LPS during pregnancy and saline during the development phase, whereas no differences were found in the frontal cortex (Panel A). The protein levels of D1R in the striatum correlate closely with the increase of grooming behavior on the AMPH challenge (Panel B). The values are expressed as mean \pm SEM. ${ }^{*}$ Different from the Sal-Sal group.

\section{Discussion}

In the present study, we report that exposure to LPS during late gestation affects the developing brain dopaminergic system in a specific manner. On one hand, the locomotor response induced by a stimulant dose of AMPH is enhanced in the offspring of LPStreated dams. On the other hand, the emergence of dopaminergic and behavioral disturbances provoked by maternal immune activation were not observed in the behavioral sensitization paradigm, which is a model of addictive behavior. In this sense, the current data indicate that disturbances in the maternal cytokine balance during specific stages of fetal development modulate the dopaminergic and behavioral outcomes in the adult offspring.

Emerging literature from epidemiologic, clinical, and preclinical investigations has brought attention to the association between maternal infection and the emergence of psychiatric disorders. For example, the occurrence of infections during pregnancy with Influenza, Toxoplasma gondii, Rubella and Herpes Simplex Virus Type 2 is believed to increase the risk of schizophrenia in children [for review, see 35]. Although the mechanisms underlying this epidemiological relationship remain unclear, the maternal cytokine-associated inflammatory response to infection is considered a crucial link, as the identity of the pathogen seems irrelevant. Given the complexity of schizophrenia, an approach to the development of relevant animal models relies on focusing on specific signs or symptoms associated with schizophrenia, rather than mimicking the entire syndrome. In such cases, specific observations that have been identified in schizophrenic patients provide a focus of study in experimental animals.

It is worth noting that many studies using animal models have attempted to correlate the emergence of dopaminergic disturbances induced by maternal immune activation to symptoms of schizophrenia, such as impaired sensorimotor gating [12,36,37], deficits in social interaction [13] and working memory [38], and enhanced behavioral sensitivity to acute treatment with the indirect DA receptor agonist AMPH and the NMDA-receptor antagonist MK-801 [11,12].

In this sense, our results are in agreement with previously published studies demonstrating that prenatal exposure to pro-inflammatory cytokines enhances the offspring's locomotor response to acute AMPH treatment, an indicator of increased 
dopaminergic neurotransmission in the mesolimbic pathway $[11,12]$. In fact, it has been demonstrated that this outcome could be prevented by early antipsychotic treatment, which is a wellestablished treatment for schizophrenic patients [39].

Nevertheless, it is worth noting that the majority of studies have focused on Polyl:C exposure on GD 9 to evaluate this specific outcome. In this sense, the main feature of our study is that the stimulating effect is elicited even when the immune insult is LPS and applied on GD 17, demonstrating that the emergence of altered DA transmission is evidently independent of the gestation window of immune activation. In addition, early/middle pregnancy (GD 9) and late pregnancy (GD 17) in the mouse roughly correspond to the middle/end of the first trimester and to the middle of the second trimester of human pregnancy, respectively, with respect to developmental biology and the percentage of the gestational time in mice and humans.

The acute psychopharmacological actions of AMPH have been relatively well characterized. In particular, the ability to produce psychomotor activation and reward are thought to be primarily due to their capability to increase DA neurotransmission through the stimulation of DA release by presynaptic vesicles. The acute administration of psychostimulants, such as AMPH, elicits a typical dose-effect curve in rodents: whereas low doses stimulate locomotor and exploratory behavior, higher doses produce compulsive and stereotyped behaviors (such as licking and gnawing), with no increase or even a reduction in locomotion and exploration. The locomotor stimulation has been classically attributed to the psychostimulant-induced DA release in the ventral striatum, whereas compulsive and highly stereotyped behavior is related to DA release within the dorsal striatum [40]. Nevertheless, it is important to stress that the enhancement of the locomotor stimulant effect of AMPH only took place in mice treated with the highest dose $(5.0 \mathrm{mg} / \mathrm{kg})$, as the lowest dose $(2.5 \mathrm{mg} / \mathrm{kg})$ did not show the stimulant effect in saline-treated offspring in our experimental conditions. This discrepancy with the results of previous studies may be due to differences in the strain of mice used herein, which can account for distinct resistance to DA stimulation.

In light of the fact that maternal immune activation promotes enhanced acute AMPH-induced DA release within the mesolimbic pathway and consequentially increased locomotion, we questioned whether this enhancing property would be evident in a paradigm of repeated exposure, such as behavioral sensitization. In this sense, low doses of psychostimulants evoke or exacerbate psychotic symptoms among schizophrenic patients [41], and drugs used to treat both idiopathic and psychostimulant-induced psychosis act primarily as DA receptor antagonists [42]. In light of these shared characteristics, investigators have suggested that sensitization to psychostimulants may also be a useful animal model of schizophrenia [43].

As reviewed by Vanderschuren and Kalivas [44], behavioral sensitization to psychostimulants has two distinct stages according to drug-elicited behavior and neuroadaptations within dopaminergic pathways. Notably, the development phase is characterized by a progressive and persistent increase in locomotor activity after repeated drug administration and is correlated with an increased firing rate in the ventral tegmental area (VTA), and synaptic DA concentration in the nucleus accumbens is then increased. As a consequence, after a withdrawal period, increases in the expression and activity of the DA transporter and vesicular monoamine transporter may contribute to the enhanced release of DA during the expression phase (drug re-exposure). In response to DA overflow through the synapse, up-regulation of postsynaptic D1 receptors within the ventral striatum is also reported. In summary, the VTA plays an important role in the development of behavioral sensitization, while the NAcc is mainly related to its expression.
Although much of the research regarding sensitization to psychostimulants is focused on mesolimbic dopaminergic transmission, the emerging role of the mesocortical DA system, particularly in the medial prefrontal cortex, has gained particular attention [45]. Yet, it has been shown that a challenge with druginducing sensitization yields a marked increase in the DA levels within the dorsal and ventral striatum than in animals receiving the drug for the first time $[46,47]$ or in animals exposed to the same drug but in a different environment [48-50].

In this sense, although mice treated with a repeated low dose of AMPH injection presented progressively increased locomotion during the development phase, both prenatal treatments produced similar motor stimulation in our experimental conditions, indicating that maternal treatment with LPS did not affect the offspring's drug-induced locomotion in the behavioral sensitization paradigm. Nevertheless, our results indicate that LPS-treated mice elicits behavioral sensitization earlier than the Sal group. Additionally, the expression of behavioral sensitization after drug re-exposure (AMPH challenge) was evident in AMPH-sensitized mice regardless of prenatal treatment, demonstrating that prenatal exposure to LPS did not intensify the expression of the offspring's behavioral sensitization.

Despite the fact that acute motor stimulation is enhanced in the offspring exposed to inflammatory stimuli, which is suggestive of increased dopaminergic transmission within the mesolimbic pathway, it seems intriguing that this susceptibility did not occur in the behavioral sensitization paradigm. However, it is essential to remember that the neuroadaptation inherent to behavioral sensitization is a much more complex process and involves extensive changes in expression of DA-related genes and proteins, such as the DA receptors and DA transporter.

This result contrasts with previous findings in which early-life factors are directly involved in the propensity of adult drug addiction. On one hand, insults during specific developmental stages (i.e., the perinatal period), such as stress [51], cocaine [52] and lead [53] exposure, high fat diet [54], and local inflammation [55], are known to alter the development of behavioral sensitization to psychostimulants. On the other hand, the exact mechanism by which this alteration arises is still unknown. These two main hypotheses have been proposed to identify factors involved on dopaminergic modulation in response to maternal immune activation, maternal hypoferremia and fetal hypoxia [55-57].

Furthermore, our results pointed to the occurrence of contextual conditioned behavior during saline challenge, regardless of prenatal treatment. Notably, animals who received chronic AMPH injection throughout the 10 days of the development phase exhibited increased locomotion even when they received saline after the withdrawal period, showing that the pairing drug $\times$ open field was sufficient to increase a drug-elicited behavior even in a drugfree condition. Because a distinct context is repetitively paired with the drug, it is often believed that contextual sensitized effects are modulated by Pavlovian conditioning processes [58,59]. To that end, the set of contextual cues acquires the ability to produce conditioned drug-like effects (i.e., enhanced dopaminergic transmission and consequently increased locomotion), which add progressively onto the continuous pharmacological action of the drug as a consequence of repeated administration during the development phase. This phenomenon has been described for many drugs that have specific patterned behavioral effects, including AMPH, apomorphine, cocaine, methamphetamine, morphine, and ethanol [58,60-62].

Regarding the D1 receptor, immunoblotting of the striatum revealed an up-regulation of the D1 receptor protein levels in the offspring exposed to LPS during pregnancy (LPS-Sal), which in turn was down-regulated by AMPH-induced behavioral sensitization (LPS-AMPH). Curiously, despite the absence of D1 up-regulation 
in AMPH-sensitized mice, which was an expected finding based on previous molecular studies, our data from experiment 2 corroborate our behavioral results from experiment 1 . In this sense, the LPS-exposed offspring seems much more prone to up-regulation of dopaminergic receptors and consequently to stimulant effects of acute AMPH administration mostly due to up-regulation of the D1 receptor within the mesolimbic pathway. Moreover, the immunoblotting revealed three bands, representing the different isoforms of D1R detected in all groups. The different isoforms may correspond to the different levels of post translational modifications of D1 such as glycosylation, palmitoylation and/or phosphorylation. Indeed, these post translational processes are involving in the anchoring of the $\mathrm{D} 1 \mathrm{R}$ at the plasma membrane [63]. As we have shown in the western blotting, the total amount of D1R protein are increased in the striatum of the LPS saline group, but decreased after repeated AMPH treatment. However, it seems that the two highest band corresponding to the partially and fully glycosylate forms of D1R are more evident in the striatum of LPS saline group than in the saline-treated group, meaning that there is more D1R at the plasma membrane in the LPS-Sal group. Notwithstanding, the necessity for an autoradiographic study to determine the binding between DA and its receptors, as well as immunolocalization of these receptors, is currently acknowledged.

In addition, grooming behavior during the expression phase was found dramatically increased in the LPS-exposed offspring which were not submitted to chronic AMPH treatment, indicating a marked correlation between D1R expression and stereotyped behavior. Curiously, both the D1R receptor expression and grooming behavior were prevented by previous chronic AMPH administration in the LPS-AMPH group, probably due to activation of negative feedback of dopaminergic receptors provoked by continuous AMPH-induced DA release. In this way, a hyper sensibility of the post synaptic neurons of the striatum may enhance the grooming response via the thalamo-cortico-thalamic pathway.

It was already shown that acute LPS administration can dramatically decrease DA turnover within the first hours [64]. Nevertheless, the present study provides additional evidence that DA function can be programmed by immune activation during the perinatal period as well, particularly during gestation, and has a relevant impact upon developmental neuropsychiatric research since its consequences lasts until adulthood and correlates with psychotic-like behaviors, such as enhanced susceptibility to psychostimulants and increased stereotyped behavior.

In conclusion, our findings indicate that maternal immune activation in late gestation enhances the locomotor response to acute AMPH challenge and increases grooming behavior in adult male mice offspring. However, neither development nor expression of locomotor sensitization to AMPH was affected by prenatal treatment with LPS. Additionally, up-regulation of the D1 receptor in the striatum was found in offspring of mothers exposed to LPS, which was significantly correlated with stereotyped behavior. Our results indicate that maternal immune activation elicits distinct outcomes upon development of dopaminergic pathways, as locomotor responses were increased in response to acute challenge but not to chronic treatment with AMPH.

\section{Author contributions}

$\mathrm{AZ}$ and JPN conceived and designed the experiments. AZ and GM performed the experiments. AZ analyzed the data. JPN and GM contributed reagents, materials, and analysis tools. AZ, GM and JPN wrote the paper.

\section{Funding}

This work was supported by grants from the CNPq and FAPESP (Thematic Awards \#09/51886-3 to JPN, \#09/51998-6 to AZ).

\section{Competing interests}

The authors have declared that no competing interests exist.

\section{Acknowledgments}

We would like to thank the staff of our animal facility for the care of the mice used in this study. We would also like to express our cordial thanks to Sandra Campos Rodrigues, Alison Ribeiro, Marcelo Meira Santos Lima and Karina Possa Abrahão for assistance during the project.

\section{References}

[1] Arndt TL, Stodgell CJ, Rodier PM. The teratology of autism. Int J Dev Neurosci 2005;23:189-99.

[2] Brown AS, Begg MD, Gravenstein S, Schaefer CA, Wyatt RJ, Bresnahan M, et al. Serologic evidence of prenatal influenza in the etiology of schizophrenia. Arch Gen Psychiatry 2004;61:774-80.

[3] Meyer U, Feldon J, Fatemi SH. In vivo rodent models for the experimental investigation of prenatal immune activation effects in neurodevelopmental brain disorders. Neurosci Biobehav Rev 2009;33:1061-79.

[4] Patterson PH. Immune involvement in schizophrenia and autism: etiology, pathology and animal models. Behav Brain Res 2009;204:313-21.

[5] Alexopoulou L, Holt AC, Medzhitov R, Flavell RA. Recognition of doublestranded RNA and activation of NF-kappaB by Toll-like receptor 3. Nature 2001;413:732-8.

[6] Triantafilou M, Triantafilou K. Lipopolysaccharide recognition: CD14, TLRs and the LPS-activation cluster. Trends Immunol 2002;23:301-4.

[7] Fortier ME, Joober R, Luheshi GN, Boksa P. Maternal exposure to bacterial endotoxin during pregnancy enhances amphetamine-induced locomotion and startle responses in adult rat offspring. J Psychiatr Res 2004;38:335-45.

[8] Meyer U, Nyffeler M, Engler A, Urwyler A, Schedlowski M, Knuesel I, et al. The time of prenatal immune challenge determines the specificity of inflammationmediated brain and behavioral pathology. J Neurosci 2006;26:4752-62.

[9] Takeuchi O, Akira S. Recognition of viruses by innate immunity. Immunol Rev 2007;220:214-24.

[10] Borrell J, Vela JM, Arevalo-Martin A, Molina-Holgado E, Guaza C. Prenatal immune challenge disrupts sensorimotor gating in adult rats. Implications for the etiopathogenesis of schizophrenia. Neuropsychopharmacology 2002;26:204-15.

[11] Meyer U, Nyffeler M, Schwendener S, Knuesel I, Yee BK, Feldon J. Relative prenatal and postnatal maternal contributions to schizophrenia-related neurochemical dysfunction after in utero immune challenge. Neuropsychopharmacology 2008;33:441-56.

[12] Meyer U, Nyffeler M, Yee BK, Knuesel I, Feldon J. Adult brain and behavioral pathological markers of prenatal immune challenge during early/middle and late fetal development in mice. Brain Behav Immun 2008;22:469-86.

[13] Kirsten TB, Taricano M, Maiorka PC, Palermo-Neto J, Bernardi MM. Prenatal lipopolysaccharide reduces social behavior in male offspring. Neuroimmunomodulation 2010;17:240-51.

[14] Kirsten TB, Taricano M, Florio JC, Palermo-Neto J, Bernardi MM. Prenatal lipopolysaccharide reduces motor activity after an immune challenge in adult male offspring. Behav Brain Res 2010;211:77-82.

[15] Vuillermot S, Weber L, Feldon J, Meyer U. A longitudinal examination of the neurodevelopmental impact of prenatal immune activation in mice reveals primary defects in dopaminergic development relevant to schizophrenia. J Neurosci 2010;30:1270-87.

[16] Castall B, Marsden CD, Naylor RJ, Pycock CJ. Stereotyped behaviour patterns and hyperactivity induced by amphetamine and apomorphine after discrete 6 hydroxydopamine lesions of extrapyramidal and mesolimbic nuclei. Brain Res 1977;123:89-111.

[17] Porrino LJ, Lucignani G, Dow-Edwards D, Sokoloff L. Correlation of dosedependent effects of acute amphetamine administration on behavior and local cerebral metabolism in rats. Brain Res 1984;307:311-20.

[18] Laruelle M, Abi-Dargham A. Dopamine as the wind of the psychotic fire: new evidence from brain imaging studies. J Psychopharmacol 1999;13:358-71.

[19] Laruelle M, Abi-Dargham A, Gil R, Kegeles L, Innis R. Increased dopamine transmission in schizophrenia: relationship to illness phases. Biol Psychiatry 1999;46:56-72.

[20] Laruelle M, Abi-Dargham A, van Dyck CH, Gil R, D’Souza CD, Erdos J, et al. Single photon emission computerized tomography imaging of amphetamine-induced dopamine release in drug-free schizophrenic subjects. Proc Natl Acad Sci USA 1996;93:9235-40. 
[21] Pierce RC, Kalivas PW. A circuitry model of the expression of behavioral sensitization to amphetamine-like psychostimulants. Brain Res Brain Res Rev 1997;25:192-216.

[22] Robinson TE, Becker JB. Enduring changes in brain and behavior produced by chronic amphetamine administration: a review and evaluation of animal models of amphetamine psychosis. Brain Res 1986;396:157-98.

[23] Post RM, Rose H. Increasing effects of repetitive cocaine administration in the rat. Nature 1976;260:731-2.

[24] Segal DS, Mandell AJ. Long-term administration of D-amphetamine: progressive augmentation of motor activity and stereotypy. Pharmacol Biochem Behav 1974;2:249-55.

[25] Masur J, Oliveira de Souza ML, Zwicker AP. The excitatory effect of ethanol: absence in rats, no tolerance and increased sensitivity in mice. Pharmacol Biochem Behav 1986;24:1225-8.

[26] Babbini M, Davis WM. Time-dose relationships for locomotor activity effects of morphine after acute or repeated treatment. Br J Pharmacol 1972;46:213-24.

[27] Domino EF. Nicotine induced behavioral locomotor sensitization. Prog Neuropsychopharmacol Biol Psychiatry 2001;25:59-71.

[28] Robinson TE, Berridge KC. The neural basis of drug craving: an incentivesensitization theory of addiction. Brain Res Brain Res Rev 1993;18:247-91.

[29] Robinson TE, Berridge KC. Review. The incentive sensitization theory of addiction: some current issues. Philos Trans R Soc Lond B Biol Sci 2008;363:3137-46.

[30] Sanchis-Segura C, Spanagel R. Behavioural assessment of drug reinforcement and addictive features in rodents: an overview. Addict Biol 2006;11:2-38.

[31] Golan H, Stilman M, Lev V, Huleihel M. Normal aging of offspring mice of mothers with induced inflammation during pregnancy. Neuroscience 2006;141:1909-18.

[32] Golan HM, Lev V, Hallak M, Sorokin Y, Huleihel M. Specific neurodevelopmental damage in mice offspring following maternal inflammation during pregnancy. Neuropharmacology 2005;48:903-17.

[33] Hava G, Vered L, Yael M, Mordechai H, Mahoud H. Alterations in behavior in adult offspring mice following maternal inflammation during pregnancy. Dev Psychobiol 2006;48:162-8.

[34] Kameda SR, Fukushiro DF, Trombin TF, Procopio-Souza R, Patti CL, Hollais AW, et al. Adolescent mice are more vulnerable than adults to single injectioninduced behavioral sensitization to amphetamine. Pharmacol Biochem Behav 2011;98:320-4.

[35] Brown AS, Derkits EJ. Prenatal infection and schizophrenia: a review of epidemiologic and translational studies. Am J Psychiatry 2010;167:261-80.

[36] Fortier ME, Luheshi GN, Boksa P. Effects of prenatal infection on prepulse inhibition in the rat depend on the nature of the infectious agent and the stage of pregnancy. Behav Brain Res 2007;181:270-7.

[37] Romero E, Guaza C, Castellano B, Borrell J. Ontogeny of sensorimotor gating and immune impairment induced by prenatal immune challenge in rats: implications for the etiopathology of schizophrenia. Mol Psychiatry 2010;15:372-83.

[38] Meyer U, Knuesel I, Nyffeler M, Feldon J. Chronic clozapine treatment improves prenatal infection-induced working memory deficits without influencing adult hippocampal neurogenesis. Psychopharmacology (Berl) 2010;208:531-43.

[39] Meyer U, Spoerri E, Yee BK, Schwarz MJ, Feldon J. Evaluating early preventive antipsychotic and antidepressant drug treatment in an infectionbased neurodevelopmental mouse model of schizophrenia. Schizophr Bull 2008;36:607-23.

[40] Kelly PH, Seviour PW, Iversen SD. Amphetamine and apomorphine responses in the rat following 6-OHDA lesions of the nucleus accumbens septi and corpus striatum. Brain Res 1975;94:507-22.

[41] Lieberman JA, Kinon BJ, Loebel AD. Dopaminergic mechanisms in idiopathic and drug-induced psychoses. Schizophr Bull 1990;16:97-110.

[42] Snyder SH. Amphetamine psychosis: a model schizophrenia mediated by catecholamines. Am J Psychiatry 1973;130:61-7.

[43] Kalivas PW, Sorg BA, Hooks MS. The pharmacology and neural circuitry of sensitization to psychostimulants. Behav Pharmacol 1993;4:315-34.

[44] Vanderschuren LJ, Kalivas PW. Alterations in dopaminergic and glutamatergic transmission in the induction and expression of behavioral sensitization: a critical review of preclinical studies. Psychopharmacology (Berl) 2000;151:99-120.
[45] Steketee JD. Neurotransmitter systems of the medial prefrontal cortex: potential role in sensitization to psychostimulants. Brain Res Brain Res Rev 2003;41:203-28.

[46] Paulson PE, Robinson TE. Amphetamine-induced time-dependent sensitization of dopamine neurotransmission in the dorsal and ventral striatum: a microdialysis study in behaving rats. Synapse 1995;19:56-65.

[47] Robinson TE, Jurson PA, Bennett JA, Bentgen KM. Persistent sensitization of dopamine neurotransmission in ventral striatum (nucleus accumbens) produced by prior experience with (+)-amphetamine: a microdialysis study in freely moving rats. Brain Res 1988;462:211-22.

[48] Burechailo L, Martin-Iverson MT. Behavioral sensitization to cocaine, but not cocaine-conditioned behavior, is associated with increased dopamine occupation of its receptors in the nucleus accumbens. Behav Neurosci 1996;110:1388-96.

[49] Fontana D, Post RM, Weiss SR, Pert A. The role of D1 and D2 dopamine receptors in the acquisition and expression of cocaine-induced conditioned increases in locomotor behavior. Behav Pharmacol 1993;4:375-87.

[50] Fontana DJ, Post RM, Pert A. Conditioned increases in mesolimbic dopamine overflow by stimuli associated with cocaine. Brain Res 1993;629: 31-9.

[51] Kabbaj M, Isgor C, Watson SJ, Akil H. Stress during adolescence alters behavioral sensitization to amphetamine. Neuroscience 2002;113:395-400.

[52] Glatt SJ, Bolanos CA, Trksak GH, Crowder-Dupont C, Jackson D. Prenatal cocaine exposure alters behavioral and neurochemical sensitization to amphetamine in adult rats. Neuropharmacology 2000;39:599-610.

[53] Clifford PS, Hart N, Thompson J, Buckman S, Wellman PJ, Bratton GR, et al. Prenatal lead exposure enhances methamphetamine sensitization in rats. Pharmacol Biochem Behav 2009;93:165-9.

[54] Naef L, Srivastava L, Gratton A, Hendrickson H, Owens SM, Walker CD. Maternal high fat diet during the perinatal period alters mesocorticolimbic dopamine in the adult rat offspring: reduction in the behavioral responses to repeated amphetamine administration. Psychopharmacology (Berl) 2008;197: 83-94.

[55] Aguilar-Valles A, Flores C, Luheshi GN. Prenatal inflammation-induced hypoferremia alters dopamine function in the adult offspring in rat: relevance for schizophrenia. PLoS ONE 2010;5:e10967.

[56] Girard S, Kadhim H, Beaudet N, Sarret P, Sebire G. Developmental motor deficits induced by combined fetal exposure to lipopolysaccharide and early neonata hypoxia/ischemia: a novel animal model for cerebral palsy in very premature infants. Neuroscience 2009;158:673-82.

[57] Prandota J. Possible pathomechanisms of sudden infant death syndrome: key role of chronic hypoxia, infection/inflammation states, cytokine irregularities, and metabolic trauma in genetically predisposed infants. Am J Ther 2004;11:517-46.

[58] Crombag HS, Badiani A, Maren S, Robinson TE. The role of contextual versus discrete drug-associated cues in promoting the induction of psychomotor sensitization to intravenous amphetamine. Behav Brain Res 2000;116:1-22.

[59] Tirelli E, Terry P. Amphetamine-induced conditioned activity and sensitization: the role of habituation to the test context and the involvement of Pavlovian processes. Behav Pharmacol 1998;9:409-19.

[60] Ahmed SH, Oberling P, Di Scala G, Sandner G. Amphetamine-induced conditioned activity does not result from a failure of rats to habituate to novelty. Psychopharmacology (Berl) 1996;123:325-32.

[61] Stewart J, Badiani A. Tolerance and sensitization to the behavioral effects of drugs. Behav Pharmacol 1993;4:289-312.

[62] Tirelli E, Heidbreder C. Conditioning of and contextual sensitization to apomorphine-induced climbing in mice: evidence against the habituation hypothesis. Behav Neurosci 1999;113:368-76.

[63] Free RB, Hazelwood LA, Cabrera DM, Spalding HN, Namkung Y, Rankin ML, et al. $\mathrm{D} 1$ and $\mathrm{D} 2$ dopamine receptor expression is regulated by direct interaction with the chaperone protein calnexin. J Biol Chem 2007;282:21285-300.

[64] Zager A, Andersen ML, Lima MM, Reksidler AB, Machado RB, Tufik S. Modulation of sickness behavior by sleep: the role of neurochemical and neuroinflammatory pathways in mice. Eur Neuropsychopharmacol 2009;19: 589-602. 
APÊNDICE B 


\section{Maternal immune activation increases corticosterone response to acute stress without affecting hypothalamic neurotransmission and sleep pattern in male mice offspring}

Adriano Zager ${ }^{1}$, Monica Levy Andersen², Sergio Tufik², João Palermo-Neto ${ }^{1}$

1 Neuroimmunomodulation research group, Departmento de Patologia, Faculdade de Medicina Veterinária e Zootecnia, Universidade de São Paulo, São Paulo, Brazil.

2 Departamento de Psicobiologia, Universidade Federal de São Paulo (UNIFESP-EPM), São Paulo, Brazil.

Running head: Impact of prenatal LPS on stress-induced response of adult offspring

Corresponding author:

Adriano Zager

Department of Pathology, School of Veterinary Medicine, University of Sao Paulo Av. Prof. Dr. Orlando Marques de Paiva, 87

05508270 - Cidade Universitária

São Paulo/SP - Brazil

Phone \# (55-11) 3091-7941

Fax \# (55-11) 3091-7682

E-mail address: adrianozager@hotmail.com 


\section{Abstract}

Early life experiences are homeostatic determinants for adult organisms. We evaluated the impact of prenatal immune activation during late gestation on neuro-immuneendocrine function of adult offspring, and its interaction with acute stress. Pregnant mice received saline or lipopolysaccharide (LPS) on gestational day 17. Adult male offspring were assigned to control or restraint stress condition. We analyzed plasmatic corticosterone and catecholamines levels, neurotransmitter content on hypothalamus, striatum and frontal cortex, and sleep-wake cycle after acute restraint stress. Offspring from LPS-treated dams have increased baseline norepinephrine levels and potentiated corticosterone secretion after acute stressor, with no effect on hypothalamic neurotransmitter content or sleep response. The offspring of challenged dams showed impairment in the stress-induced serotonergic and dopaminergic alterations in striatum and frontal cortex. The data demonstrate a distinction between the plasmatic levels of corticosterone in response to acute stress and hypothalamic neurotransmitter content and sleep pattern. We provide new evidence into the influence of immune activation during late gestation on the neuroendocrine homeostasis of offspring.

Key words: Prenatal LPS; HPA axis; sympathoadrenal system; corticosterone; norepinephrine; neurotransmission; sleep pattern 


\section{Introduction}

The occurrence of maternal infection during pregnancy is considered an environmental risk factor for the emergence of many neurochemical disorders in later life, including dopaminergic disturbances and increased incidence of autism and schizophrenia [1-3]. Our lab has recently shown that prenatal immune stimulation with lipopolysaccharide (LPS) has significant impacts on behavior and neurochemistry in later life. For instance, impairment of playing behavior (in infants) and social interactions (in adults) when an immune insult is applied during early/mid gestation [4] and enhancement of amphetamineinduced locomotor stimulation and stereotyped behavior when an insult is applied during late gestation [5] have been observed.

In addition, the offspring of challenged dams are often reported to have disrupted dopaminergic and serotonergic transmission, as indicated by differences in neurotransmitter content and synthesis [6,7], expression of receptors and behavioral impairments $[1,5,8]$. However, it is important to stress that it is not only brain functions that are influenced by maternal immune responses but also the homeostasis of the endocrine system. It has already been shown that activation of the maternal immune system during mid-gestation elicits increased levels of the stress hormones ACTH and corticosterone in the offspring under baseline conditions, although no differences were found after novelty stress [9].

Based on previous findings, we can infer that elevated levels of cytokines play a major role during the development of different critical systems in the fetus, such as the hypothalamic-pituitary-adrenal (HPA) axis and the sympathoadrenal system. However, this hypothesis remains unexplored with regard to an immune challenge occurring during late gestation, a phase in which organogenesis is complete and the changes that arise from 
immune activation are restricted. Thus, the aim of the present study was to provide a comprehensive investigation of the impact of prenatal immune activation by LPS during late gestation on neuro-immune-endocrine function in adult offspring, as well as the interaction of such activation with acute stress in adulthood. Specifically, plasmatic corticosterone and catecholamines, neurotransmitter content and sleep-wake cycle were analyzed. 


\section{Methods}

Animals

Pregnant albino Swiss mice from our own colony, weighing 45-60 g each, were used (gestational day [GD] 0: presence of vaginal plug). Dams were housed in pairs in standard polypropylene cages at a controlled room temperature $(22 \pm 2 \circ \mathrm{C})$ and humidity level (65$70 \%$ ), with artificial lighting (12 h light/12 h dark cycle), and with free access to Nuvilab® rodent chow (Nuvital company, São Paulo, Brazil) and filtered water. Sterilized and residuefree wood shavings were used as animal bedding. The animals used in this study were maintained in accordance with the guidelines of the Committee on Care and Use of Laboratory Animal Resources of the School of Veterinary Medicine, University of São Paulo (protocol \# 1683/2009, FMVZ-USP).

\section{Drugs}

LPS derived from Escherichia coli serotype 0127:B8 (Sigma, St. Louis, MO, USA) was freshly dissolved in $0.9 \%$ sterile saline and was administered intraperitoneally (i.p.) to pregnant mice at a dose of $120 \mu \mathrm{g} / \mathrm{kg}$ on GD 17 ( $4 \mu \mathrm{g} / \mathrm{animal})$. The dose and gestational period were chosen based on previous studies in which maternal inflammation is achieved without inducing preterm delivery or influencing offspring growth or sensory-motor reflex development [5,10-12].

These dams were allowed to give birth and nurture their offspring normally and an average of 12 litters per treatment was used to obtain the male offspring. No cross-fostering was performed, since cross-fostering, per se, alters the behavioral and corticosterone responses to LPS [13] 


\section{Restraint stress}

The acute stressor used was restraint stress $(10 \times 3 \mathrm{~cm}$ ventilated Plexiglas tubes) for 2 hours. A preliminary temporal study performed in our laboratory showed that acute restraint stress causes an immediate, marked increase in plasma corticosterone levels, which return to baseline levels within a few hours, characterizing an appropriate model of acute stress. All the stress procedures were performed between 8:00-10:00 AM to prevent any circadian variability.

\section{Experimental procedure}

Experiment 1: Collection of blood from the submandibular vein and Corticosterone assay

On the day of the experiment, blood from the submandibular vein under baseline condition was collected from adult male offspring (90 days old) from both prenatal treatment groups ( $\mathrm{N}=7 /$ group). Afterwards, all mice were placed in the restraint apparatus for 2 hours. Immediately after the end of the procedure, mice were again subjected to the collection of blood from the submandibular vein under an acute stress condition. Aliquots of blood were placed in vacuum tubes containing liquid EDTA and were centrifuged at $4^{\circ} \mathrm{C}$ at $1500 \mathrm{~g}$ for 15 minutes. Plasma was frozen at $-80^{\circ} \mathrm{C}$ until analysis.

Plasma corticosterone levels were assayed by a commercial double-antibody radioimmunoassay method specifically designed and validated for rats and mice (MP Biomedicals, USA). The sensitivity of the assay was $0.25 \mathrm{ng} / \mathrm{ml}$. Plasmatic norepinephrine and epinephrine levels were assayed by ELISA (LDN Diagnostika, Germany), according to the manufacturer's instructions. 


\section{Experiment 2: Brain collection and monoamine assays}

On the day of the experiment, adult male offspring (90 days old; $N=10 /$ group) were submitted or not to acute restraint stress as described above, and immediately after the procedure, they were decapitated in an adjacent room, and their brains were dissected. These procedures were performed twice analyzing half of sample size each time. The isolation and collection of brain samples were performed using traditional manual microdissection methods, using information from Paxinos and Franklin [14] for guidance. In addition, all isolated tissues were weighed, ensuring homogeneity. By adopting these procedures, we believe we have reached a high control standard without the contamination of other brain areas. The frontal cortex, hypothalamus, and striatum were dissected and stored at $-80^{\circ} \mathrm{C}$ until analysis.

The brain regions samples from the male offspring were individually homogenized by sonication in $500 \mu \mathrm{L}$ of extraction solution $(0.1 \mathrm{M}$ perchloric acid containing $0.4 \mathrm{mM}$ sodium metabisulfite and $0.2 \mathrm{mM}$ EDTA). The homogenates were centrifuged at $20000 \mathrm{~g}$ for 10 minutes, filtered through a $0.22 \mu \mathrm{m}$ membrane and stored at $-80^{\circ} \mathrm{C}$ until analysis. Precipitates were dissolved in $0.1 \mathrm{~N} \mathrm{NaOH}$ and the protein levels were assessed (Bicinchoninic acid method, Pierce Chemical, USA).

Supernatants were subjected to fast isocratic separation through a C18 High performance liquid chromatography (HPLC) reverse-phase column system (Spheri-5, C18, ODS, $5 \mu \mathrm{m}, 25 \mathrm{~cm} \times 4.6 \mathrm{~mm}$ column; linked to a NewGuard Cartridge Column, RP-18, 7 $\mu \mathrm{m}$ pre-column; PerkinElmer Brownlee Columns, USA) and were electrochemically detected using an amperometric detector (L-ECD-6A, Shimadzu, Japan) by oxidation on a glass carbon electrode at $+850 \mathrm{mV}$ relative to an $\mathrm{Ag}-\mathrm{AgCl}$ reference electrode. The mobile phase consisted of the following components diluted in double-distilled water: $0.163 \mathrm{M}$ citric acid, $0.06 \mathrm{M}$ sodium phosphate (dibasic anhydrous), $0.69 \mathrm{mM}$ octyl sodium sulfate, $12 \mathrm{mM}$ 
EDTA, 4\% acetonitrile, 1.7\% tetrahydrofuran, and sufficient orthophosphoric acid to bring the $\mathrm{pH}$ to 2.85. The mobile phase was filtered through a $0.2-\mu \mathrm{m}$ membrane, degassed under vacuum, and delivered at a flow rate of $1.24 \mathrm{ml} /$ minutes. Each sample was analyzed in duplicate for concentrations of norepinephrine (NE), dopamine (DA), serotonin (5-HT), and their non-conjugated metabolites, such as 3,4-dihydroxyphenilacetic acid (DOPAC), homovanilic acid (HVA), and 5-hydroxyindoleacetic acid (5-HIAA). Analyte recovery was determined by adding a fixed concentration of dihydroxybenzylamine (DHBA) as an internal standard prior to tissue homogenization [15]. All standards and salts were purchased from Sigma (St. Louis, USA), and the solvents (HPLC grade) were purchased from JT Baker (USA).

\section{Experiment 3: Sleep pattern during stress recovery}

Implantation of electrodes and recording

Different groups of mice had their electrocorticographic (ECoG) and electromyographic (EMG) activities simultaneously recorded, thus permitting assessment of the sleep-wake cycle during normal conditions (baseline) and recovery from acute restraint stress. Anesthesia was induced by i.p. administration of ketamine $(70-80 \mathrm{mg} / \mathrm{kg})$ and xylazine $(9 \mathrm{mg} / \mathrm{kg})$. Two pairs of electrodes (steel screws) were implanted in the frontoparietal medial derivation (one pair on each side of the skull) for ECoG recording. One additional pair of nickel-chrome electrodes was implanted in the dorsal muscle of the mouse's neck for EMG recording. The electrodes were soldered to a connector, which was fixed to the animal's cranium with acrylic dental cement. After surgery, mice were given antibiotic (veterinary pentabiotic ${ }^{\circledR}, 0.5 \mathrm{ml} / \mathrm{kg}$, i.m.) and diclofenac ( $25 \mathrm{mg} / \mathrm{ml}$, i.p.), and mice were allowed to recover from surgery for 2 weeks. 
After the recovery period following surgery, the adult male offspring (90 days old; $n=8-9 /$ group) were subjected to undisturbed baseline sleep recording for 48 hours. On the day of the experiment, the mice were removed from the recording apparatus and were submitted to acute restraint stress for 2 hours, followed by undisturbed sleep recording for 48 hours using Somnologica software (EMBLA Medical digital polygraph, Reykjavik, Iceland).

The sleep pattern was visually and manually scored in 10-second segments by a single blinded researcher, thus ensuring consistency of the data. The following sleep parameters were considered: total sleep time (percentage of sleep time during the recording), slow wave sleep (SWS, percentage of all periods of deep sleep during the recording), and REM sleep (percentage of all periods of REM sleep during the recording). SWS was classified as an EEG voltage of 20-30 $\mu \mathrm{V}$ (usually 200-400 $\mu \mathrm{V}$, peak to peak) and low frequency activity (delta waves, $1-4 \mathrm{~Hz}$ ). REM sleep was classified as an EEG voltage below $20 \mu \mathrm{V}$, with high and regular theta activity $(6-10 \mathrm{~Hz})$, especially in the fronto-parietal medial EEG derivation, and with muscle atonia in the EMG recording.

\section{Statistical analysis}

The data were tested for normality using the Kolmogorov-Smirnov test. Parametric data were analyzed by two-way analysis of variance (ANOVA) followed by Bonferroni's test and non-parametric data were analyzed by Kruskal-Wallis, followed by Dunn's multiple comparison test. The results are expressed as the mean \pm SEM and the level of statistical significance was set at $p \leq 0.05$. 


\section{Results}

\section{Experiment 1: Plasma Corticosterone Levels}

Two-way ANOVA showed an effect of prenatal treatment $[F(1,9)=4.86, p=0.05]$, stressful

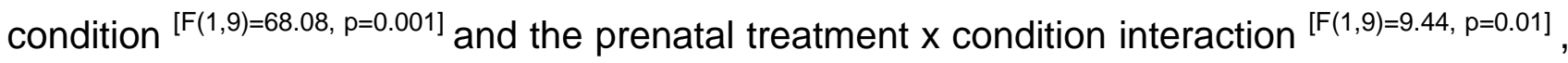
on the plasma corticosterone levels before and after acute stress. The Bonferroni post hoc test revealed a significant increase in plasma corticosterone levels after acute stress following both prenatal treatments, saline $(p \leq 0.05)$ and LPS $(p \leq 0.001)$, when compared to baseline levels. However, there were significantly higher levels of corticosterone after acute stress in the offspring pre-treated with LPS when compared to the Sal group under the same condition ( $p \leq 0.01)$, as illustrated in Figure $1 \mathrm{~A}$.

Regarding plasmatic norepinephrine levels, Two-way ANOVA showed an effect of prenatal treatment $[F(1,8)=52.72, p=0.001]$, stressful condition $[F(1,8)=75.15, p=0.001]$ and the prenatal treatment $x$ condition interaction ${ }^{[F(1,8)=33.93, p=0.001]}$. The Bonferroni post hoc test revealed a significant increase in baseline norepinephrine levels in the offspring of dams treated with LPS, compared to Sal group under the same condition ( $p \leq 0.001$ ), as illustrated in Figure $1 \mathrm{~B}$.

The two-way ANOVA showed no significant difference between groups in plasmatic epinephrine levels, as shown by figure $1 \mathrm{C}$.

\section{Experiment 2: Monoamine content within brain regions}

The Krukal-Wallis test evidenced significant differences on serotonin turnover in striatum ( $p \leq 0.01)$ and frontal cortex ( $p \leq 0.001)$, as well as in dopamine turnover in frontal cortex $(p \leq 0.01)$ (Table 1). Dunn's multiple comparison test showed that stressed animals from Sal group have increased serotonin turnover in striatum ( $p \leq 0.05)$ and dopamine turnover in frontal cortex $(p \leq 0.05)$, compared to baseline condition. On the other hand, the 
serotonin turnover in frontal cortex is increased in stressed animals from the LPS group ( $p \leq$ 0.05), when compared to basal condition.

Experiment 3: Sleep pattern

A two-way ANOVA showed an effect of time on the percentage of total sleep time $[F(14,168)=14.51, p=0.001]$, slow-wave sleep ${ }^{[F(14,168)=14.76, p=0.001]}$ and REM sleep ${ }^{[F(14,168)=11.98, p=0.001]}$ of offspring from dams treated with either saline or LPS during late gestation. However, the post hoc Bonferroni test showed no significant difference between the prenatal treatments in all of the parameters (Figure 2). 


\section{Discussion}

Our results show that maternal immune activation during late pregnancy induces specific changes in fetal development that may affect the sympathoadrenal response of the offspring, even into adulthood. The male offspring of LPS-treated dams showed increased circulating norepinephrine levels under baseline condition and potentiated corticosterone release in response to acute stressor, in turn, neither hypothalamic neurotransmission nor sleep pattern were affected.

In addition to raising the levels of circulating inflammatory cytokines, maternal immune activation during pregnancy may also be considered a stressor stimulus because LPS activates the HPA axis in the mother. Thus, it is essential to examine the function of the HPA axis in the offspring, even into adulthood. In this context, our data shows that, although baseline levels of corticosterone were similar, animals born of dams exposed to LPS showed potentiation of corticosterone release in response to acute restraint stressor. Interestingly, this is only evident immediately after the stress stimulus, given that the difference between prenatal treatments disappears 1 hour after the withdrawal of the restraint apparatus (data not shown).

A pioneering study showed that offspring of dams immune-stimulated with human erythrocytes or LPS administration showed hyperactivity of the HPA axis, including increased release of $\mathrm{ACTH}$ and corticosterone under baseline conditions; however, no differences were found after novelty stress. However, this manipulation also caused a reduction in the expression of glucocorticoid receptors (GR) in the hippocampus of the offspring in adulthood, indicating impairment in the HPA axis negative feedback [9]. Recently, it was shown that treatment with LPS during early/middle gestation increases the offspring's HPA axis response to maternal isolation stress on P21 and to 30 minutes restraint stress on P90, based on increased corticosterone release [16]. 
The plasmatic catecholamines levels in our experiment 1 point out to increased activity of the sympathoadrenal system in the experimental group, as indicated by enhanced baseline norepinephrine. However, the increased norepinephrine response was reversed after acute stress, probably due to negative feedback mechanism. In this context, chromaphin cells present in the adrenal medulla also release epinephrine directly into the circulation in response to sympathetic activation. However, our data showed that prenatal immune activation does not impact plasmatic epinephrine levels before and after acute stress. In addition, we cannot ruled out the participation of direct sympathetic innervation of adrenal glands in this phenomenon without electrophysiological studies.

Several neurochemical changes have been reported in studies that involve the paradigm of maternal immune activation. In this sense, altered neurotransmission and expression of dopaminergic, serotonergic and noradrenergic receptors in the CNS of animals exposed to immune stimulation during pregnancy have been observed $[17,18]$. In contrast to previous studies, our results show that neither maternal immune activation nor acute stress were capable of affecting neurotransmission within the hypothalamus. It was recently shown that restraint stress effects on neurotransmitter content and turnover depend on strain of mice analyzed [19].

The other brain areas analyzed here showed significant differences, particularly on serotonin and dopamine turnover, which is widely regarded as a more representative measurement of serotonergic and dopaminergic system alterations. On one hand, both the serotonin turnover (5-HIAA/5-HT) in striatum and dopamine turnover (HVA/DA) in frontal cortex were increased in Sal group after acute stress, a mechanism that is impaired in experimental group. On the other hand, the serotonin turnover in frontal cortex is increased after acute stress in the LPS group, possibly due to attenuated serotonin turnover in nonstressed animals. 
The changes observed in striatal serotonin turnover are particular relevant regarding habituation to predictable stressors. The striatum receives serotonergic innervation from both the median and dorsal raphe nucleus, which regulate dopamine release and may influence the development of reward, addiction and stress-induced behavioral alterations [20]. Serotonergic turnover alterations consequently augment the activity of serotonin receptors, such as 5-HT2C receptors that are highly expressed in the striatum where they regulate the tonic inhibition of dopamine release in the mesolimbic, nigrostriatal and mesocortical pathways $[21,22]$. Our data showed increased striatal serotonergic turnover following acute stress in saline-treated offspring, a set of homeostatic response that is dysfunctional in the offspring from LPS-treated dams.

The reciprocal innervation between the medial pre-frontal cortex (mPFC), striatum and limbic structures is implicated in the development of habituation to predictable chronic stressors. In this context, the serotonergic tone on dopaminergic projections to the cortex seems to be attenuated in the experimental group. The present findings seem to be consistent with other research which found that transection of mPFC projections may enhance the sympathoadrenal system activity without affecting the HPA axis activity [23].

It is important to stress that there are a number of hormones and peptides which are produced and released in response to stress that were not analyzed, and could play a role mediating the phenomenon presented here. In this context, vasopressin is secreted by posterior pituitary during acute stress response and modulates, in conjunction with corticotropin releasing factor (CRF), the release of corticosteroids by the adrenal gland in response to stress. Oxytocin is another hormone secreted from the same site as vasopressin, and counter-acts the effects of corticosteroids. Additionally, prolactin is also secreted during acute stress response, and its plasma levels increases even before corticosterone [24]. 
The percentages of the total sleep, slow wave sleep and REM sleep times were not altered by prenatal LPS alone or in combination with restraint stress. Although acute stress reduced sleep time right after the stressor, we did not observe any differences between the prenatal treatments. Nonetheless, it seems that changes in offspring resulting from maternal immune activation were not sufficient to cause disturbances in the hypothalamic neurochemical response and sleep pattern of these animals, or alternatively, may indicate the occurrence of some compensatory mechanism.

It is important to stress that most studies that report alterations in the neurotransmission of the offspring were performed after applying the immune insult during early/middle gestation, including those studies from our lab $[6,25]$. In contrast, recent studies revealed that late, but not early/middle gestational immune challenge impact fetal brain development in a specific manner, reducing the expression of NMDA receptors in hippocampus and potentiating the locomotor response to NMDA-receptor blockade by MK801, as well as increasing cytokine response and caspase-3 signaling $[18,26]$. Therefore, we hypothesize that alterations induced by immune activation during late gestation in our experiment are related to sympathetic tonus and endocrine response, with no detectable effect upon hypothalamic neurotransmission or sleep patterns.

It is worth noting that our results indicate a distinction between the peripheral corticosterone release and hypothalamic neurotransmitter content in response to acute stress, suggesting that pathways other than HPA axis might also be involved in this phenomenon. Notwithstanding, the increased circulating norepinephrine levels of experimental group supports the hypothesis of enhanced sympathoadrenal response which, in turn, could lead to increased corticosterone secretion after acute stress.

In summary, our results demonstrate that maternal immune activation on the 17th gestational day enhances sympathoadrenal activity and potentiates corticosterone release 
after acute stress by adult male offspring. Interestingly, the new insight herein is that this phenomenon occurs without affecting hypothalamic neurotransmitter content or sleep-wake cycle. Thus, our study provides additional evidences on how the neuro-immune-endocrine homeostasis of adult offspring is affected by immune activation during the prenatal period, particularly late gestation. 


\section{Acknowledgements}

The authors would also like to express their gratitude to Ricardo Borges Machado for the HPLC analysis and to Waldermaks Leite for the assistance during the project.

This work was supported by grants from the AFIP, CNPq and FAPESP (Thematic Awards \#09/51886-3 to JPN, \#09/51998-6 to AZ, \#98/14303 to ST).

\section{Competing interests}

The authors have declared that no competing interests exist. 


\section{Figures}
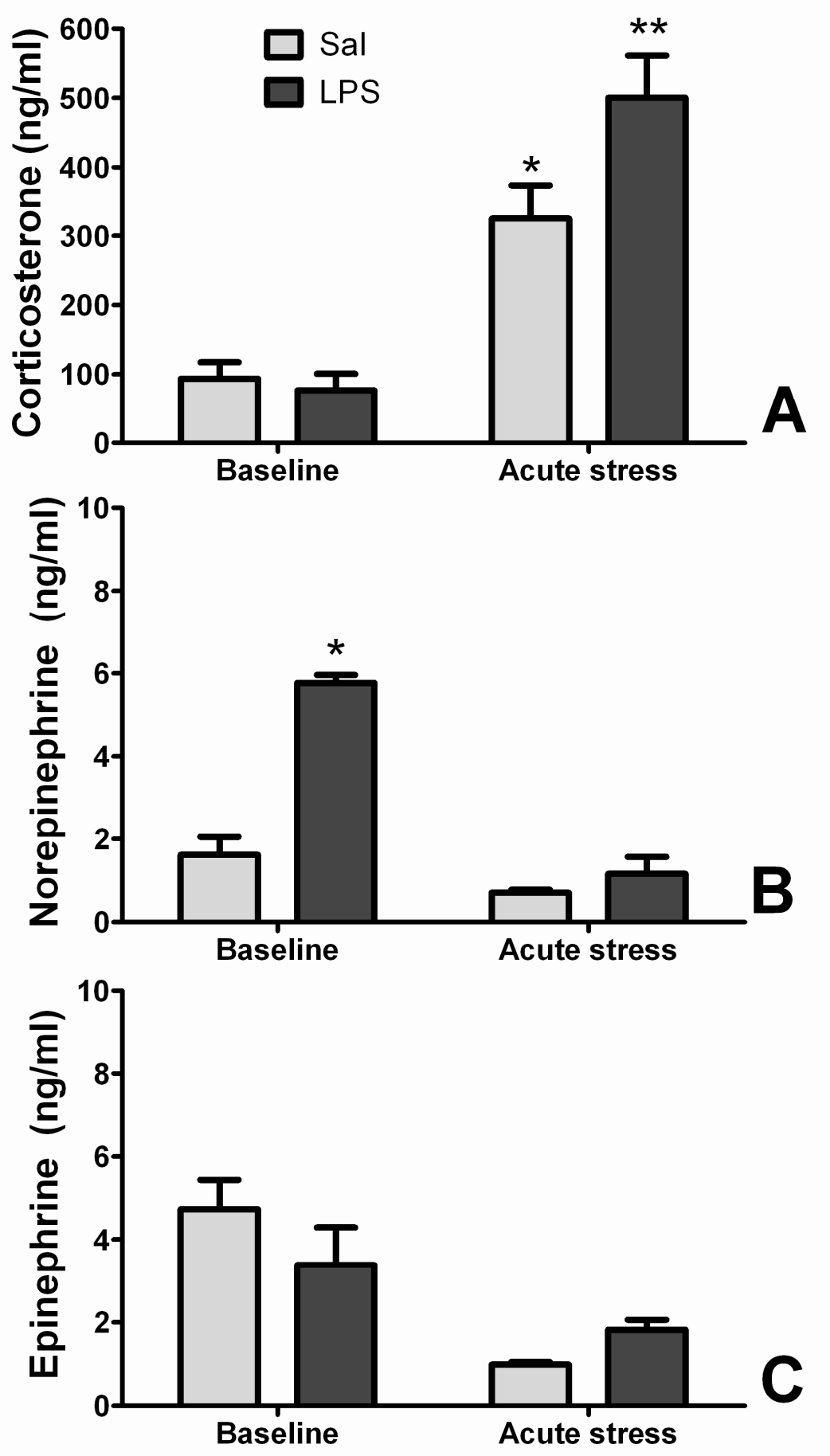

Figure 1. Plasmatic corticosterone and catecholamines response after acute stress in adult offspring of dams treated with saline or LPS on GD 17. Mean values ( \pm SEM) of plasmatic corticosterone (A), norepinephrine $(B)$ and epinephrine $(C)$ before and after acute restraint stress ( $N=7 /$ group). * different from baseline of saline (Sal) group; ** different from baseline of LPS group and from stressed Sal group. 

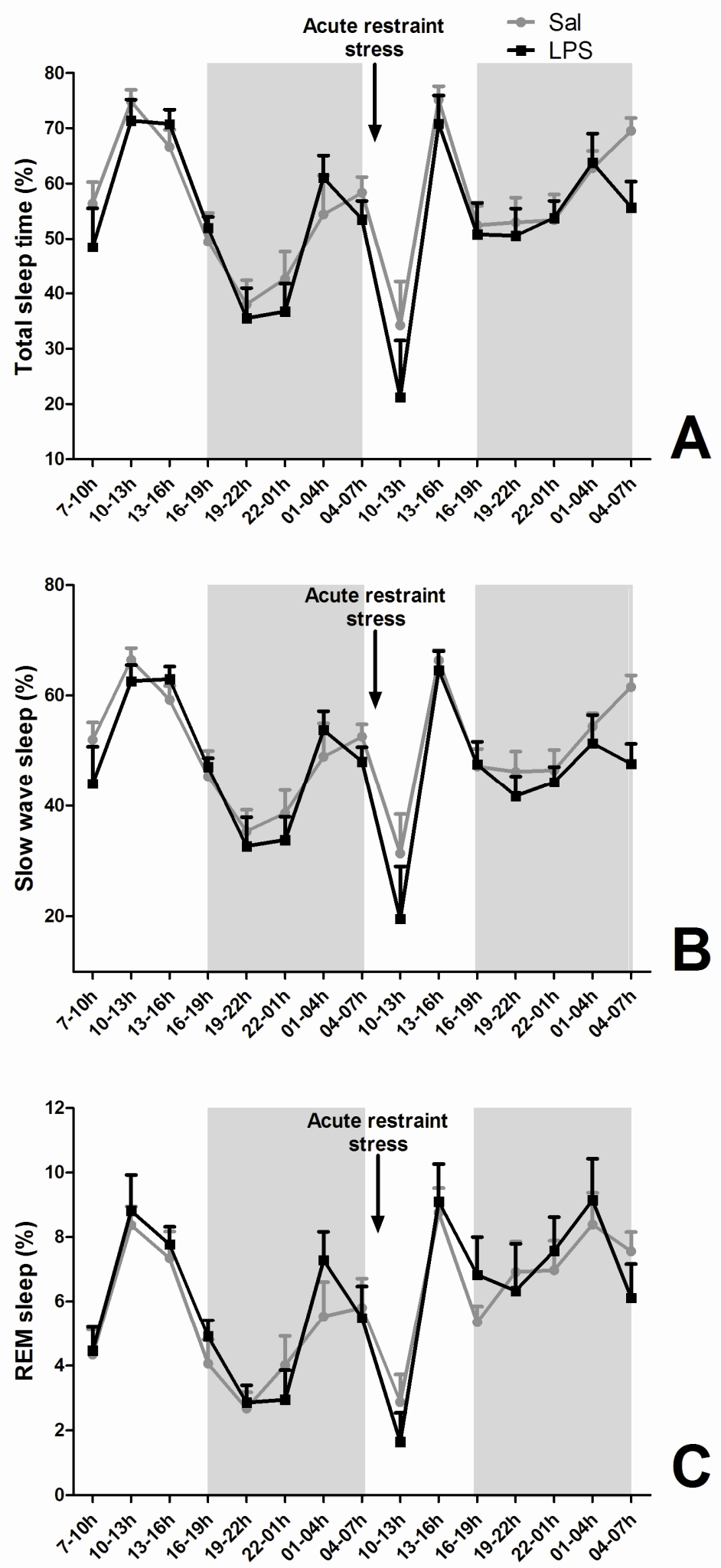

Figure 2. Sleep pattern of offspring from dams treated with saline or LPS on GD 17 exposed to acute stress in adult life. Percentage of total sleep time (Panel A), slow wave sleep (panel B), and REM sleep (Panel C) during the baseline period and after acute restraint stress ( $n=8-9 /$ group). Gray area denotes dark period. The values are expressed as mean \pm SEM. 
Table 1. Impact of maternal immune activation and/or acute adult stress on neurotransmitter content and turnover in brain areas.

\begin{tabular}{|c|c|c|c|c|}
\hline \multirow[b]{2}{*}{ Hypothalamus } & \multicolumn{4}{|c|}{ Groups } \\
\hline & Sal-no stress & Sal-acute stress & LPS-no stress & LPS-acute stress \\
\hline Norepinephrine (ng/mg prot) & $7.16 \pm 2.08$ & $4.95 \pm 0.88$ & $8.18 \pm 1.75$ & $8.04 \pm 1.39$ \\
\hline Dopamine (ng/mg prot) & $2.34 \pm 1.20$ & $1.55 \pm 0.18$ & $2.13 \pm 0.61$ & $1.87 \pm 0.30$ \\
\hline Dopamine turnover (HVA/DA) & $1.81 \pm 0.43$ & $2.04 \pm 0.25$ & $1.86 \pm 0.60$ & $1.65 \pm 0.19$ \\
\hline $\begin{array}{l}\text { Dopamine turnover } \\
\text { (DOPAC/DA) }\end{array}$ & $3.76 \pm 0.77$ & $4.04 \pm 0.41$ & $2.78 \pm 0.63$ & $3.15 \pm 0.26$ \\
\hline 5-HT (ng/mg prot) & $1.57 \pm 0.72$ & $0.85 \pm 0.18$ & $2.32 \pm 1.64$ & $0.87 \pm 0.21$ \\
\hline 5-HT turnover (5-HIAA/5-HT) & $12.19 \pm 4.10$ & $13.84 \pm 2.81$ & $15.35 \pm 6.67$ & $12.61 \pm 2.92$ \\
\hline \multicolumn{5}{|l|}{ Striatum } \\
\hline Norepinephrine (ng/mg prot) & $2.29 \pm 0.41$ & $2.04 \pm 0.19$ & $2.55 \pm 0.24$ & $2.26 \pm 0.24$ \\
\hline Dopamine (ng/mg prot) & $50.76 \pm 2.54$ & $53.48 \pm 3.43$ & $50.39 \pm 2.55$ & $49.77 \pm 4.73$ \\
\hline Dopamine turnover (HVA/DA) & $0.16 \pm 0.01$ & $0.18 \pm 0.01$ & $0.16 \pm 0.01$ & $0.18 \pm 0.01$ \\
\hline $\begin{array}{l}\text { Dopamine turnover } \\
\text { (DOPAC/DA) }\end{array}$ & $0.32 \pm 0.03$ & $0.26 \pm 0.03$ & $0.28 \pm 0.02$ & $0.29 \pm 0.03$ \\
\hline 5-HT (ng/mg prot) & $6.61 \pm 0.50$ & $6.16 \pm 0.54$ & $7.56 \pm 0.73$ & $6.52 \pm 0.65$ \\
\hline 5-HT turnover (5-HIAA/5-HT) & $0.61 \pm 0.04$ & $0.87 \pm 0.05$ * & $0.67 \pm 0.07$ & $0.78 \pm 0.04$ \\
\hline \multicolumn{5}{|l|}{ Frontal Cortex } \\
\hline Norepinephrine (ng/mg prot) & $3.36 \pm 0.76$ & $2.55 \pm 0.65$ & $3.19 \pm 0.74$ & $2.04 \pm 0.50$ \\
\hline Dopamine (ng/mg prot) & $2.93 \pm 0.31$ & $1.59 \pm 0.26$ & $2.29 \pm 0.25$ & $2.10 \pm 0.41$ \\
\hline Dopamine turnover (HVA/DA) & $3.13 \pm 0.67$ & $6.77 \pm 1.09$ * & $3.42 \pm 0.43$ & $5.02 \pm 0.97$ \\
\hline $\begin{array}{l}\text { Dopamine turnover } \\
\text { (DOPAC/DA) }\end{array}$ & $2.88 \pm 0.47$ & $5.03 \pm 0.90$ & $2.60 \pm 0.41$ & $5.00 \pm 1.21$ \\
\hline 5-HT (ng/mg prot) & $1.41 \pm 0.34$ & $1.95 \pm 0.40$ & $2.28 \pm 0.28$ & $1.46 \pm 0.24$ \\
\hline 5-HT turnover (5-HIAA/5-HT) & $8.02 \pm 1.66$ & $10.61 \pm 3.52$ & $4.29 \pm 0.39$ & $10.43 \pm 1.24$ * \\
\hline
\end{tabular}

Mean values $( \pm$ SEM) of neurotransmitter concentrations and turnover ratios in the hypothalamus, striatum and frontal cortex of the offspring from dams treated with saline or LPS on GD 17 ( $n=10 /$ group). * different from respective baseline condition. 


\section{References}

1 Kirsten TB, Chaves-Kirsten GP, Chaible LM, Silva AC, Martins DO, Britto LR, Dagli ML, Torrao AS, Palermo-Neto J, Bernardi MM: Hypoactivity of the central dopaminergic system and autistic-like behavior induced by a single early prenatal exposure to lipopolysaccharide. J Neurosci Res 2012;90:1903-1912.

2 Malkova NV, Yu CZ, Hsiao EY, Moore MJ, Patterson PH: Maternal immune activation yields offspring displaying mouse versions of the three core symptoms of autism. Brain Behav Immun 2012;26:607-616.

3 Brown AS, Patterson PH: Maternal infection and schizophrenia: Implications for prevention. Schizophr Bull 2011;37:284-290.

4 Kirsten TB, Taricano M, Maiorka PC, Palermo-Neto J, Bernardi MM: Prenatal lipopolysaccharide reduces social behavior in male offspring. Neuroimmunomodulation 2010;17:240-251.

5 Zager A, Mennecier G, Palermo-Neto J: Maternal immune activation in late gestation enhances locomotor response to acute but not chronic amphetamine treatment in male mice offspring: Role of the d1 receptor. Behav Brain Res 2012;232:30-36.

6 Kirsten TB, Taricano M, Florio JC, Palermo-Neto J, Bernardi MM: Prenatal lipopolysaccharide reduces motor activity after an immune challenge in adult male offspring. Behav Brain Res 2010;211:77-82.

7 Winter C, Djodari-Irani A, Sohr R, Morgenstern R, Feldon J, Juckel G, Meyer U: Prenatal immune activation leads to multiple changes in basal neurotransmitter levels in the adult brain: Implications for brain disorders of neurodevelopmental origin such as schizophrenia. Int J Neuropsychopharmacol 2009;12:513-524.

8 Fortier ME, Joober R, Luheshi GN, Boksa P: Maternal exposure to bacterial endotoxin during pregnancy enhances amphetamine-induced locomotion and startle responses in adult rat offspring. J Psychiatr Res 2004;38:335-345.

9 Reul JM, Stec I, Wiegers GJ, Labeur MS, Linthorst AC, Arzt E, Holsboer F: Prenatal immune challenge alters the hypothalamic-pituitary-adrenocortical axis in adult rats. J Clin Invest 1994;93:2600-2607.

10 Golan HM, Lev V, Hallak M, Sorokin Y, Huleihel M: Specific neurodevelopmental damage in mice offspring following maternal inflammation during pregnancy. Neuropharmacology 2005;48:903-917.

11 Golan H, Stilman M, Lev V, Huleihel M: Normal aging of offspring mice of mothers with induced inflammation during pregnancy. Neuroscience 2006;141:1909-1918.

12 Hava G, Vered L, Yael M, Mordechai H, Mahoud H: Alterations in behavior in adult offspring mice following maternal inflammation during pregnancy. Dev Psychobiol 2006;48:162-168.

13 Gomez-Serrano M, Tonelli L, Listwak S, Sternberg E, Riley AL: Effects of cross fostering on open-field behavior, acoustic startle, lipopolysaccharide-induced corticosterone release, and body weight in lewis and fischer rats. Behav Genet 2001;31:427-436.

14 Paxinos G, Franklin K: The mouse brain in stereotaxic coordinates New York, Academic Press, 2001.

15 Machado RB, Tufik S, Suchecki D: Chronic stress during paradoxical sleep deprivation increases paradoxical sleep rebound: Association with prolactin plasma levels and brain serotonin content. Psychoneuroendocrinology 2008 
16 Lin YL, Lin SY, Wang S: Prenatal lipopolysaccharide exposure increases anxiety-like behaviors and enhances stress-induced corticosterone responses in adult rats. Brain Behav Immun 2012;26:459-468.

17 Wang S, Yan JY, Lo YK, Carvey PM, Ling Z: Dopaminergic and serotoninergic deficiencies in young adult rats prenatally exposed to the bacterial lipopolysaccharide. Brain Res 2009;1265:196-204.

18 Meyer U, Nyffeler M, Yee BK, Knuesel I, Feldon J: Adult brain and behavioral pathological markers of prenatal immune challenge during early/middle and late fetal development in mice. Brain Behav Immun 2008;22:469-486.

19 Browne CA, Clarke G, Dinan TG, Cryan JF: Differential stress-induced alterations in tryptophan hydroxylase activity and serotonin turnover in two inbred mouse strains. Neuropharmacology 2011;60:683-691.

20 Alex KD, Pehek EA: Pharmacologic mechanisms of serotonergic regulation of dopamine neurotransmission. Pharmacol Ther 2007;113:296-320.

21 De Deurwaerdere P, Navailles S, Berg KA, Clarke WP, Spampinato U: Constitutive activity of the serotonin2c receptor inhibits in vivo dopamine release in the rat striatum and nucleus accumbens. J Neurosci 2004;24:3235-3241.

22 Di Giovanni G, Di Matteo V, La Grutta V, Esposito E: M-chlorophenylpiperazine excites non-dopaminergic neurons in the rat substantia nigra and ventral tegmental area by activating serotonin-2c receptors. Neuroscience 2001;103:111-116.

23 Ondicova K, Kvetnansky R, Mravec B: Medial prefrontal cortex transection enhanced stress-induced activation of sympathoadrenal system in rats. Endocr Regul 2012;46:129136.

24 Papathanassoglou ED, Giannakopoulou M, Mpouzika M, Bozas E, Karabinis A: Potential effects of stress in critical illness through the role of stress neuropeptides. Nurs Crit Care 2010;15:204-216.

25 Kirsten TB, Chaves GP, Taricano M, Martins DO, Florio JC, Britto LR, Torrao AS, Palermo-Neto J, Bernardi MM: Prenatal lps exposure reduces olfactory perception in neonatal and adult rats. Physiol Behav 2011;104:417-422.

26 Meyer U, Nyffeler M, Engler A, Urwyler A, Schedlowski M, Knuesel I, Yee BK, Feldon J: The time of prenatal immune challenge determines the specificity of inflammationmediated brain and behavioral pathology. J Neurosci 2006;26:4752-4762. 
APÊNDICE C 


\title{
Increased cell-mediated immunity in male mice offspring exposed to maternal immune activation during late gestation
}

\author{
Adriano Zager, Milena Lobão Pinheiro, Viviane Ferraz-de-Paula, Alison Ribeiro, João \\ Palermo-Neto
}

Neuroimmunomodulation Research Group, Department of Pathology, School of Veterinary Medicine, University of Sao Paulo, Sao Paulo, Brazil.

Running head: Impact of prenatal LPS on Th1 immunity of adult offspring

\section{Corresponding author:}

Adriano Zager

Department of Pathology, School of Veterinary Medicine, University of Sao Paulo Av. Prof. Dr. Orlando Marques de Paiva, 87

05508270 - Cidade Universitária

São Paulo/SP - Brazil

Phone \# (55-11) 3091-7941

Fax \# (55-11) 3091-7682

E-mail address: adrianozager@hotmail.com 


\section{Abstract}

Early life experiences, particularly during the gestational period, are homeostatic determinants for an individual's brain development. However, recent data suggest that the immune response of the offspring is also affected by events during the gestational period. Here, we evaluated the impact of prenatal immune activation on the innate and adaptive immune responses of adult offspring. Pregnant Swiss mice received saline or lipopolysaccharide (LPS) on gestational day 17. In adulthood, male offspring were analyzed using 2 experimental techniques: in vitro analysis of cytokine production and immune cell activity, and development of the delayed-type hypersensitivity (DTH) responses of ovalbumin-sensitized mice. We analyzed Th1/Th2/Th17 cytokine production in vitro, neutrophil and dendritic cell function, and the DTH response. Offspring from LPS-treated dams displayed increased cell-mediated immunity as indicated by increased IL-12 production by cultured antigen-presenting cells and an enhanced DTH response as well as impaired production of the regulatory cytokine IL-10. This study provides new insights regarding the influence of immune activation during late gestation on the immunological homeostasis of offspring, particularly on Th1 immunity.

Key words: Prenatal LPS; Th1/Th2/Th17 cytokines; Th1 immunity; delayed-type hypersensitivity; neutrophils; dendritic cell. 


\section{Introduction}

The occurrence of maternal infection during pregnancy is considered an environmental risk factor for the emergence of many disorders in later life including autism [1, 2], schizophrenia [3], anxiety [4] and depression [5]. Studies from our lab have recently shown that prenatal immune stimulation with lipopolysaccharide (LPS) has significant impacts on behavior and neurochemistry in later life in animal models $[6,7]$. Briefly, LPS is recognized by toll-like receptor (TLR) 2 and 4 [8] on immune cells and stimulates the release of inflammatory cytokines (interleukin (IL)-1ß, IL-6 and tumor necrosis factor (TNF)a), which, in turn, affect placental function and fetal development.

Despite the recent body of evidence indicating that brain abnormalities in the offspring may be a consequence of maternal immune activation, the influence of this maternal phenomenon on immune function is still poorly understood. It should be noted that both animal experiments concerning prenatal inflammation and clinical studies have indicated immune dysregulation in autistic subjects, including defects in regulatory $T$ cells [9] and increased IL-17 production [10], supporting the hypothesis of a close relationship between prenatal immune activation, adult immune dysfunction and the emergence of psychiatric disorders.

Changes induced by prenatal immune activation seem to indicate the delayed development of innate immunity and increased serum concentrations of IL-2, IL-6 and TNF$\alpha$ in offspring [11]. Recently, it has been shown that prenatal immune activation induced by the viral mimetic polyriboinosinic-polyribocytidylic acid (Polyl:C) induces preferential development of Th17 cells in offspring [12, 13], demonstrating that maturation and polarization of the adaptive immune system may be influenced by the gestational environment. 
Based on previous findings, we infer that elevated levels of maternal cytokines play a major role during the development of different critical systems in the fetus such as the peripheral immune system. Thus, the aim of the present study was to investigate the impact of prenatal immune activation induced by LPS during late gestation on the immune function of adult offspring. Specifically, cytokine production by cultured splenocytes, neutrophil and dendritic cell activity, and delayed-type hypersensitivity responses were analyzed.

\section{Methods}

\subsection{Animals}

Pregnant albino Swiss mice from our colony, weighing 45-60 g each, were used in this study (gestational day [GD] 0: presence of a vaginal plug). Dams were housed in pairs in standard polypropylene cages at a controlled temperature $(22 \pm 2 \circ \mathrm{C})$ and humidity level (65-70\%) with artificial lighting (12 h light/12 h dark cycle) in a non-SPF environment with free access to Nuvilab® rodent chow (Nuvital company, São Paulo, Brazil) and filtered water. Sterilized and residue-free wood shavings were used as animal bedding, and experiments were performed according to Ethical Committee of the School of Veterinary Medicine, University of São Paulo (protocol \# 1683/2009, FMVZ-USP).

\subsection{Prenatal treatment}

LPS derived from Escherichia coli serotype 0127:B8 (Sigma, St. Louis, MO, USA) was freshly dissolved in $0.9 \%$ sterile saline and administered intraperitoneally (i.p.) to pregnant mice at a dose of $120 \mu \mathrm{g} / \mathrm{kg}$ on gestational day (GD) 17. This dose and gestational period were chosen based on previous studies in which maternal inflammation was achieved without inducing preterm delivery or influencing offspring growth or sensorymotor reflex development [7, 14-16]. In addition, GD 17 in mice is equivalent to week 20 of 
pregnancy in humans, a period during which the pluripotent stem cells migrate and proliferate in the fetal bone marrow, which controls hematopoiesis that was initially regulated by the fetal liver, spleen and thymus [17].

These dams were allowed to give birth and nurture their offspring normally and an average of 7 litters per treatment were used to obtain male offspring for the study. No cross-fostering was performed because cross-fostering per se alters the behavioral and corticosterone responses to LPS [18]. After weaning on postnatal day 21, the pups were distributed into different groups based on their prenatal treatment. No more than one pup from the same litter was paced into the same cage or same group.

Nevertheless, our LPS treatment did not influence the number of pups per litter, the physical or reflexological development of the offspring, or the maternal behavior (data not shown). When necessary, the litters were standardized to a maximum of 8 pups per dam. The animals were weighed once a week from birth to weaning and again before the experiments, with no differences observed between prenatal treatments at any time points.

\subsection{Experimental procedure}

\subsubsection{Experiment 1: Blood and tissue collection}

On the day of the experiment, 70 -day-old animals ( $n=10 /$ group) were decapitated, and an aliquot of blood from each mouse was placed into a tube containing liquid heparin for neutrophil activity analysis. Spleens were surgically removed and analyzed following the culture procedures described below. These procedures were performed twice with an analysis of half of the samples each time to reach a total of 10 animals per group. 


\subsubsection{Oxidative Burst and Phagocytosis by Circulating Neutrophils}

Briefly, $100 \mu \mathrm{L}$ of whole blood $\left(2 \times 10^{5}\right.$ cells $\left./ 100 \mu \mathrm{L}\right)$ was mixed with $200 \mu \mathrm{L}$ of dichlorofluorescin (DCFH $0.3 \mathrm{mM}$ ) in phosphate-buffered saline (PBS) and $100 \mu \mathrm{L}$ of either SAPI (Propidium iodide-labeled S. aureus, $2.4 \times 10^{9}$ bacteria/ml) or phorbol myristate acetate $(\mathrm{PMA} / 100 \mathrm{ng})$ in different tubes. Samples were incubated at $37^{\circ} \mathrm{C}$ for 30 minutes. Phagocytosis reactions were stopped by adding $2 \mathrm{ml}$ of cold EDTA solution (3 mM). After centrifugation (250 $\mathrm{g}$ for 10 minutes), the erythrocytes were lysed with $0.2 \% \mathrm{NaCl}(2 \mathrm{ml}$ per tube) for $20 \mathrm{~s}$. Immediately thereafter, a $1.6 \%$ sterile $\mathrm{NaCl}$ solution $(2 \mathrm{ml})$ was added to restore isotonicity. These procedures were repeated twice for complete erythrocyte lysis. Samples were then centrifuged (250 $g$ for 10 minutes), and the cell pellets were resuspended in $200 \mu \mathrm{L}$ of cold PBS.

The samples were then analyzed by flow cytometry (FACS Calibur, BD Biosciences, USA), collecting 5000 events in the gate being analyzed. For the acquisition and analysis of the results, we used the CellQuest Pro (BD Biosciences) and FlowJo (Tree Star) software programs. Direct measurements of the green-channel (DCFH) and red-channel (SAPI) mean fluorescence levels were recorded to indicate oxidative burst and phagocytosis, respectively, as described elsewhere [19]. Quantification of oxidative burst was estimated as the geometric mean of the DCFH fluorescence/cell. The intensity of phagocytosis was expressed as the geometric mean of the SAPI fluorescence that was ingested by the neutrophils. Percent phagocytosis (percent of neutrophils ingesting bacteria) was expressed by the number of neutrophils with red fluorescence divided by the total number of cells, multiplied by 100 .

\subsubsection{Spleen cell culture}


Each spleen was collected, mechanically dissociated and homogenized in $5 \mathrm{ml}$ of sterile RPMI-1640. This suspension was centrifuged at $450 \mathrm{~g}$ for 5 minutes and resuspended in $9 \mathrm{ml}$ of sterile ammonium chloride to lyse erythrocytes, following which the solution was centrifuged again. The cells were then resuspended in $5 \mathrm{ml}$ of complete RPMI medium containing $5 \%$ fetal calf serum and incubated in sterile 6 -well plates at $37^{\circ} \mathrm{C}(5 \%$ $\mathrm{CO}_{2}$ ) for two hours.

Non-adherent cells (lymphocytes) and adherent cells (antigen-presenting cells APCs) were then separated, adjusted to a concentration of $1 \times 10^{6} \mathrm{celll} / \mathrm{ml}$ and incubated in RPMI (5\% FCS) for 24 hours in the presence of different stimuli. Non-adherent cells were stimulated with concanavalin-A (Con-A, $10 \mu \mathrm{g} / \mathrm{ml}$ ), while the adherent cells were stimulated with LPS $(1 \mu \mathrm{g} / \mathrm{ml})$ or LPS plus IFN- $\gamma(50 \mathrm{U} / \mathrm{ml})$. After 24 hours of incubation, cultured cells were collected and centrifuged at $450 \mathrm{~g}$ for 5 minutes and the supernatants were then frozen at $-80^{\circ} \mathrm{C}$ until the analysis.

\subsubsection{Quantification of cytokines by ELISA}

Culture supernatants were analyzed for the concentrations of IL-2, IL-4, IL-6, IFN- $\gamma$, TNF, IL-17 and IL-10 by flow cytometry using the Cytometric Bead Array (CBA) Th1/Th2/Th17 kit (BD Biosciences, USA) according to the manufacturer's instructions. Additionally, the IL-12 analysis was performed by ELISA (ElisaMax Biolegend, CA, USA) according to the manufacturer's instructions.

\subsubsection{Phenotyping of dendritic cells}

Adherent cells stimulated with LPS or LPS+IFN- $\gamma$ were resuspended and centrifuged at $450 \mathrm{~g}$ for 5 minutes. The remaining cells were labeled with the following antibodies: CD80-PE, CD86-FITC, IA ${ }^{\mathrm{b}}$-PE and CD11c-FITC (BD Pharmingen, USA). After incubation 
for 60 minutes at room temperature in the dark, cells were washed twice in PBS (100 $\mu /$ tube) and resuspended in $150 \mu \mathrm{L}$ of PBS. Then, the samples were analyzed by flow cytometry (FACS Calibur, BD Biosciences, USA), collecting 5000 events for the analysis gate. For the acquisition and analysis of the results, we used CellQuest Pro (BD Biosciences) and FlowJo (Tree Star). Due to differences in flow cytometer compensation between experiments, all of the results were normalized to percentages relative to the control group (Saline) for presentation and interpretation.

\subsubsection{Experiment 2: Delayed-Type Hypersensitivity (DTH)}

Another set of twenty 70 -day-old male mice ( $n=10 /$ group) were used to induce a DTH response to ovalbumin (OVA grade V, Sigma-Aldrich®, Inc., St. Louis, MO, USA) by employing a protocol described elsewhere [20]. Briefly, animals were injected with $50 \mu \mathrm{g}$ of OVA emulsified in $100 \mu \mathrm{L}$ of Complete Freund's adjuvant (CFA, Sigma-Aldrich ${ }^{\circledR}$ ) subcutaneously (s.c.) at the base of the tail. Seven days later, the animals were challenged s.c. in the left hind paw with $20 \mu \mathrm{L}$ of a $4 \%$ heat-aggregated OVA solution in saline. Paw thickness was measured at 1, 4, 6, 24 and 48 hours after challenge. The net increase in paw thickness was calculated by subtracting the initial thickness.

\subsection{Statistical analysis}

The data were tested for normality using the Kolmogorov-Smirnov test. Parametric data were analyzed with an unpaired Student's t-test or a repeated measures ANOVA followed by Bonferroni's test and non-parametric data were analyzed with a Mann-Whitney U-test. The results are expressed as the mean \pm SEM and the level of statistical significance was set at $p \leq 0.05$. 


\section{Results}

\section{Experiment 1:}

3.1 Evaluation of oxidative burst and phagocytosis by circulating neutrophils

The t-tests indicated no significant differences in the percentages of phagocytosis, baseline oxidative burst or oxidative burst induced by PMA and SAPI of neutrophils between the two groups of offspring. The Mann-Whitney test indicated no significant difference in the intensity of phagocytosis between the two groups as shown in table 1.

\subsection{Cytokine production by cultured, stimulated splenocytes}

Non-adherent cells

T-tests indicated no significant effects of prenatal treatment with LPS on the concentrations of IL-2, IL-4, IL-6, IFN- $\gamma$, TNF, IL-17 or IL-10 produced in cultures of nonadherent cells from the spleens of the offspring as shown in table 1.

\section{Adherent cells}

As shown in Figure $1 \mathrm{~A}$ and $1 \mathrm{~B}$, t-tests showed no significant effects of prenatal LPS treatment on concentrations of IL-6 or TNF produced in cultures of adherent cells from the spleens of the offspring.

As shown in Figure 1C, the t-test indicated a significant reduction in the concentration of IL-10 produced in cultures of adherent cells stimulated with LPS from the offspring of LPS-challenged dams $(p \leq 0.05)$.

A t-test revealed a significant increase in $\mathrm{IL}-12$ levels produced by adherent splenocytes stimulated with LPS and IFN from the offspring of dams pre-treated with LPS compared to the saline-treated group $(p \leq 0.01)$. Figure 1D illustrates these findings. 


\subsection{Dendritic cell phenotyping}

As shown by t-tests, adherent cells in cultures stimulated with both LPS and LPS+IFN-y did not any show differences between offspring groups with regard to the mean fluorescence intensities (MFI) of the IA ${ }^{\mathrm{b}}$ (MHC II), CD80 and CD86 markers or in the $\mathrm{CD} 80^{+} \mathrm{CD} 6^{+}$cells. The Mann-Whitney test indicated that there were no significant differences between the groups with regard to $C D 11 \mathrm{c}^{+} I \mathrm{~A}^{\mathrm{b+}}$ cells as shown in table 1 .

\subsection{Experiment 2: DTH}

As depicted in figure 2, a two-way ANOVA indicated effects of prenatal treatment $[F(1,56)=4.05, p=0.05]$, time ${ }^{[F(4,56)=60.21, p=0.001]}$ and the prenatal treatment $x$ time interaction $[F(4,56)=2.53, p=0.05]$ on the increase in paw thickness during the development of $D T H$. The Bonferroni post hoc test revealed a significant increase in paw thickness in the offspring of LPS-treated dams at $6 \mathrm{~h}(1.19 \pm 0.118 \mathrm{~mm}$ Sal vs. $1.458 \pm 0.057 \mathrm{~mm}$ LPS $), 24 \mathrm{~h}$ $(0.718 \pm 0.081 \mathrm{~mm}$ Sal vs. $0.981 \pm 0.037 \mathrm{~mm}$ LPS $)$ and $48 \mathrm{~h}(0.464 \pm 0.085 \mathrm{~mm}$ Sal vs. $0.701 \pm 0.054 \mathrm{~mm}$ LPS) post challenge when compared to the saline group $(p \leq 0.05)$.

\section{Discussion}

Our results show that maternal immune activation during late pregnancy induces specific changes in the development of the fetus that may affect the immunity of the male offspring even into adulthood. Our findings indicate that maternal immune activation on GD 17 has significant effects on the immune function of male offspring, such as a disturbed cytokine balance and an increased DTH response.

It should be noted that the GD 17 in mice is equivalent to week 20 of pregnancy in humans, a period during which the fetal bone marrow becomes the primary hematopoietic site, which persists throughout postnatal life. The establishment of the bone marrow 
hematopoietic microenvironment is a process that requires the migration of stem cells, the calcification of the cartilaginous skeletal elements, and remodeling of ossified tissue, and this microenvironment is essential for normal postnatal leukocyte production [17, 21]. In addition, the LPS dose used in this study was capable of inducing a moderate immune stimulation, increasing IL-6 in both the maternal spleen and the fetal brain [14] without requiring higher doses used in other studies [22] that could induce fetal toxicity.

Curiously, our results indicate that prenatal immune activation has no effect on neutrophil activity as measured by all of the analyzed parameters such as production of reactive oxygen species (oxidative burst) and phagocytosis of $S$. aureus, indicating that this manipulation has no impact on neutrophil-mediated innate immunity. However, other aspects of the innate immunity such as monocyte/macrophage activity were not analyzed here.

Our data show that the offspring of mothers treated with LPS have increased production of IL-12 by adherent spleen cells. IL-12 is a primary mediator of the innate immune system and is an essential inducer of cell-mediated immunity by stimulating IFN- $\gamma$ release and T cell differentiation to a Th1-type response [23]. This increased production of IL-12 leads to the hypothesis that maternal immune activation can modify the development of the immune system towards a Th1-biased response, which is mediated by the aforementioned cytokines. In addition, IL-10 production by adherent cells was attenuated in vitro when the offspring was previously exposed to maternal immune activation, suggesting that prenatal immune disturbances can affect the offsprings' regulatory cytokines as well.

However, cytokine production by stimulated lymphocytes was not different between prenatal treatment groups, possibly due to the greater data variability in the LPS group, despite a trend towards increased levels of IFN-gamma, IL-17 and IL-4. This finding indicates that lymphocytes are affected to a lesser extent than APCs, which produce 
abnormal levels of IL-10 and IL-12 and that lymphocytes may be less susceptible to in utero immune activation.

To determine whether the increase in IL-12 production has a functional consequence on adaptive immunity and whether this increase would reflect an exaggerated cell-mediated immune response, we submitted the offspring from the saline-treated and LPS-treated dams to a DTH challenge, in which the increase in paw thickness corresponds to an in vivo immune response in animals that had been previously sensitized [23]. The current experiment showed that paw swelling was increased in LPS-exposed offspring, indicating an enhancement of cellular infiltration or local edema and providing additional evidence for the overall increased Th1 response in immune-stimulated offspring.

One finding that supports our hypothesis of a disrupted Th1/Th2 balance in offspring from mothers with infection is the observation that offspring from immune-challenged dams have attenuated airway inflammation in response to experimentally induced asthma, which is a classical Th2 response model [24] that is known to be inhibited by Th1-type cytokines. This observation could be explained by the decreased production of IL-10 described in this study. However, it is important to stress that IL-10 has an important role as a regulatory cytokine and that other Th2 cytokines such as IL-5, IL-9 and IL-13 may be involved in this phenomenon.

Previous findings have demonstrated that the offspring of challenged dams have impairments in immunity that are characterized by a delay in the maturation of the immune response [11], increased cytokine production in vitro [25], and preferential polarization towards a Th17 response $[12,13]$. Along with our findings, these data may indicate that offspring from immune-stimulated dams may be more susceptible to autoimmune diseases later in life such as rheumatoid arthritis. 
With regard to dendritic cell function, the offspring of LPS-exposed dams did not demonstrate any differences in the frequency of $C D 11 C^{+} I A^{b+}$ or $C D 80^{+} C D 86^{+}$cells nor in the expression of co-stimulatory molecules on dendritic cells. While dendritic cells were the major focus of this study, it should also be acknowledged that macrophages are important mediators of innate and adaptive immunity and may have been responsible for the differences observed here.

\subsection{Conclusions}

In summary, our results demonstrate that maternal immune activation on the 17 th gestational day can affect the immune systems of male offspring, leading to the skewing of the cytokine balance towards a cell-mediated (Th1) immune response and promoting enhanced delayed-type hypersensitivity reactions. Thus, our study provides new insights into how the adaptive immune response of adult offspring is affected during the prenatal period, particularly late gestation, and opens new avenues of opportunities for pharmacological research and interventions. 


\section{Acknowledgements}

The authors would like to express their gratitude to Nicolle Queiroz for assistance with the CBA analysis.

\section{Author Contributions}

$A Z$ and JPN conceived of and designed the experiments. AZ, MLP, VFP and AR performed the experiments. AZ and MLP analyzed the data. JPN contributed reagents, materials, and analysis tools. AZ and JPN wrote the paper.

\section{Funding}

This work was supported by grants from the AFIP, CNPq and FAPESP (Thematic Awards \#09/51886-3 to JPN, \#09/51998-6 to AZ).

\section{Competing interests}

The authors have declared that no competing interests exist. 


\section{Figures}
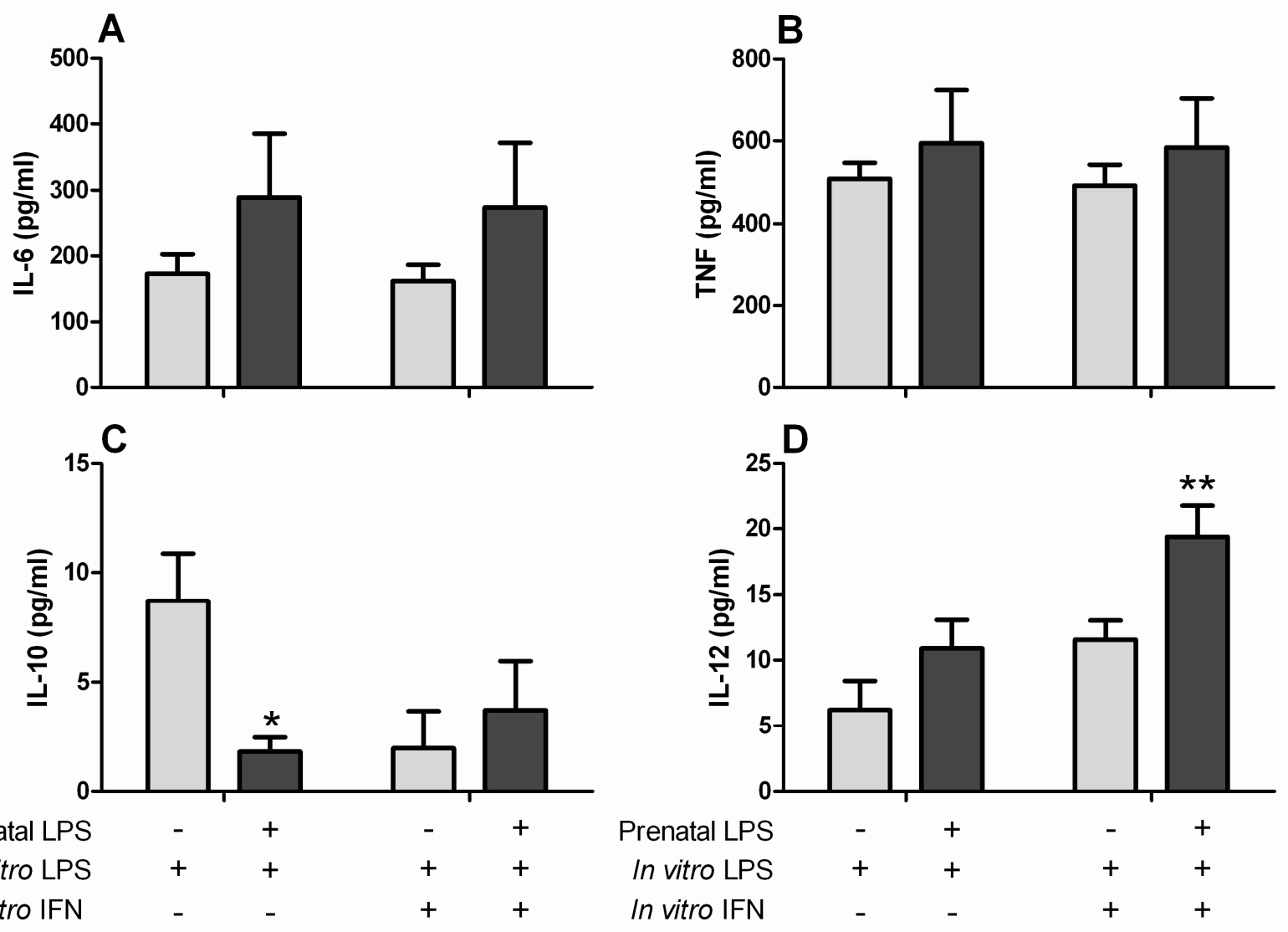

Figure 1. Cytokine production by cultured adherent splenocytes from the offspring of dams treated with saline or LPS on GD 17. Adherent cells (APCs) were isolated from the spleens of adult male offspring from dams treated with saline or LPS on GD 17, and then, these cells were incubated for 24 hours in the presence of LPS or LPS plus IFN (n=10/group). Mean values ( \pm SEM) of IL-6 (A), TNF (B), IL-10 (C) and IL12 (D) produced by stimulated, adherent cells. ${ }^{*} p \leq 0.05$ vs. Sal group, ${ }^{* *} p \leq 0.01$ vs. Sal group. 


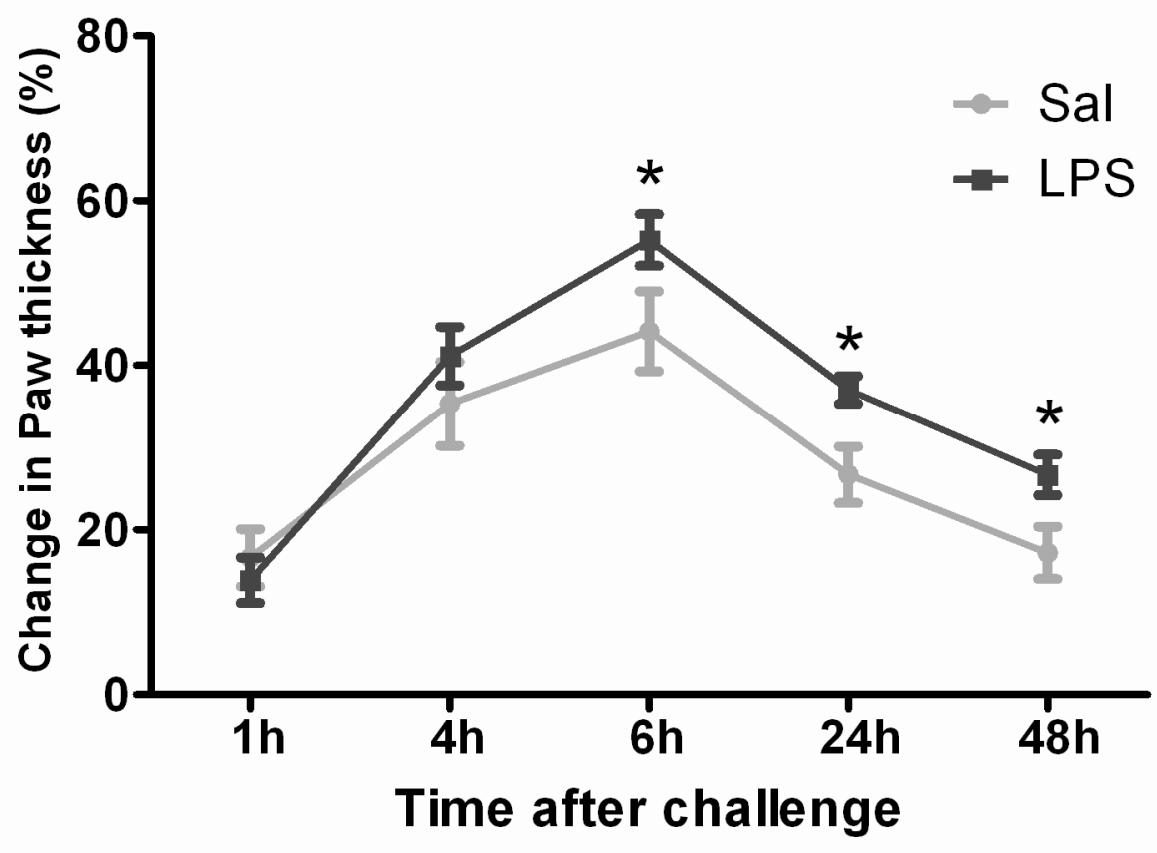

Figure 2. Effect of maternal immune activation on the development of delayed-type hypersensitivity (DTH) in OVA-sensitized offspring mice. Mean values ( \pm SEM) of paw thickness increases (\%) at 1, 4, 6 , 24 and $48 \mathrm{~h}$ after challenge with OVA during a DTH response ( $n=10$ /group). " $p \leq 0.05$ vs. Sal group at the same time point. 
Table 1. Effect of maternal immune activation on adult offsprings' immune cell activity.

\begin{tabular}{ccc}
\hline & \multicolumn{2}{c}{ Prenatal treatment } \\
\cline { 2 - 3 } & Saline & LPS \\
\hline Neutrophils & $90.3 \pm 1.3$ & $89.5 \pm 2.1$ \\
\% phagocytosis & $589.6 \pm 237.0$ & $809.7 \pm 321.4$ \\
Intensity of phagocytosis & $35.7 \pm 4.4$ & $27.3 \pm 4.8$ \\
Baseline oxidative burst & $98.9 \pm 11.2$ & $104.1 \pm 9.8$ \\
Oxidative burst induced by PMA & $166.5 \pm 21.8$ & $214.7 \pm 21.0$ \\
Oxidative burst induced by SAPI & & \\
\hline Non-adherent cells & $125.4 \pm 35.4$ & $111.3 \pm 21.3$ \\
IL-2 $(\mathrm{pg} / \mathrm{ml})$ & $1.3 \pm 0.12$ & $2.4 \pm 1.9$ \\
IL-4 $(\mathrm{pg} / \mathrm{ml})$ & $45.7 \pm 8.8$ & $71.7 \pm 23.4$ \\
IL-6 $(\mathrm{pg} / \mathrm{ml})$ & $43.4 \pm 18.4$ & $84.0 \pm 39.6$ \\
IFN- $\gamma(\mathrm{pg} / \mathrm{ml})$ & $173.1 \pm 36.7$ & $192.6 \pm 22.9$ \\
TNF $(\mathrm{pg} / \mathrm{ml})$ & $2.3 \pm 0.9$ & $4.1 \pm 2.2$ \\
IL-17 $(\mathrm{pg} / \mathrm{ml})$ & $3.3 \pm 1.2$ & $2.2 \pm 1.4$ \\
IL-10 $(\mathrm{pg} / \mathrm{ml})$ & & \\
CD11c+lAb+ & $100 \pm 1.8$ & $105.9 \pm 9.3$ \\
CD80+CD86+ & $100 \pm 1.8$ & $83.9 \pm 5.5$ \\
IAb & $100 \pm 0.8$ & $101.9 \pm 5.5$ \\
CD80 & $100 \pm 1.5$ & $111.7 \pm 5.2$ \\
CD86 & $100 \pm 0.8$ & $110.9 \pm 4.9$ \\
\hline Adherent cells & & \\
\hline
\end{tabular}

Mean values ( \pm SEM) of phagocytic activity and oxidative burst of peripheral neutrophils, cytokine production by non-adherent cells, and expression of the markers CD11c, IA ${ }^{\mathrm{b}}, \mathrm{CD} 80$ and CD86 (\% relative to control) by adherent cells from the male offspring of dams treated with saline or LPS on GD 17 ( $n=10 /$ group). PMA: phorbol myristate acetate, SAPI: propidium iodide-labeled S. aureus. 


\section{References}

[1] Kirsten TB, Chaves-Kirsten GP, Chaible LM, Silva AC, Martins DO, Britto LR, Dagli ML, Torrao AS, Palermo-Neto J, Bernardi MM. Hypoactivity of the central dopaminergic system and autistic-like behavior induced by a single early prenatal exposure to lipopolysaccharide. J Neurosci Res 2012;90:1903-12.

[2] Malkova NV, Yu CZ, Hsiao EY, Moore MJ, Patterson PH. Maternal immune activation yields offspring displaying mouse versions of the three core symptoms of autism. Brain Behav Immun 2012;26:607-16.

[3] Brown AS, Patterson PH. Maternal infection and schizophrenia: implications for prevention. Schizophr Bull 2011;37:284-90.

[4] Lin YL, Lin SY, Wang S. Prenatal lipopolysaccharide exposure increases anxiety-like behaviors and enhances stress-induced corticosterone responses in adult rats. Brain Behav Immun 2012;26:459-68.

[5] Enayati M, Solati J, Hosseini MH, Shahi HR, Saki G, Salari AA. Maternal infection during late pregnancy increases anxiety- and depression-like behaviors with increasing age in male offspring. Brain Res Bull 2012;87:295-302.

[6] Kirsten TB, Taricano M, Maiorka PC, Palermo-Neto J, Bernardi MM. Prenatal lipopolysaccharide reduces social behavior in male offspring. Neuroimmunomodulation 2010;17:240-51.

[7] Zager A, Mennecier G, Palermo-Neto J. Maternal immune activation in late gestation enhances locomotor response to acute but not chronic amphetamine treatment in male mice offspring: Role of the D1 receptor. Behav Brain Res 2012;232:30-6.

[8] Triantafilou M, Triantafilou K. Lipopolysaccharide recognition: CD14, TLRs and the LPSactivation cluster. Trends Immunol 2002;23:301-4.

[9] Hsiao EY, McBride SW, Chow J, Mazmanian SK, Patterson PH. Modeling an autism risk factor in mice leads to permanent immune dysregulation. Proc Natl Acad Sci U S A 2012;109:12776-81.

[10] Al-Ayadhi LY, Mostafa GA. Elevated serum levels of interleukin-17A in children with autism. J Neuroinflammation 2012;9:158.

[11] Hodyl NA, Krivanek KM, Lawrence E, Clifton VL, Hodgson DM. Prenatal exposure to a pro-inflammatory stimulus causes delays in the development of the innate immune response to LPS in the offspring. J Neuroimmunol 2007;190:61-71.

[12] Mandal M, Marzouk AC, Donnelly R, Ponzio NM. Maternal immune stimulation during pregnancy affects adaptive immunity in offspring to promote development of TH17 cells. Brain Behav Immunity 2010;25:863-71.

[13] Mandal M, Marzouk AC, Donnelly R, Ponzio NM. Preferential development of Th17 cells in offspring of immunostimulated pregnant mice. J Reprod Immunol 2010;87:97-100.

[14] Golan HM, Lev V, Hallak M, Sorokin Y, Huleihel M. Specific neurodevelopmental damage in mice offspring following maternal inflammation during pregnancy. Neuropharmacology 2005;48:903-17.

[15] Golan H, Stilman M, Lev V, Huleihel M. Normal aging of offspring mice of mothers with induced inflammation during pregnancy. Neuroscience 2006;141:1909-18.

[16] Hava G, Vered L, Yael M, Mordechai H, Mahoud H. Alterations in behavior in adult offspring mice following maternal inflammation during pregnancy. Dev Psychobiol 2006;48:162-8.

[17] Holladay SD, Smialowicz RJ. Development of the murine and human immune system: differential effects of immunotoxicants depend on time of exposure. Environ Health Perspect 2000;108 Suppl 3:463-73. 
[18] Gomez-Serrano M, Tonelli L, Listwak S, Sternberg E, Riley AL. Effects of cross fostering on open-field behavior, acoustic startle, lipopolysaccharide-induced corticosterone release, and body weight in Lewis and Fischer rats. Behav Genet 2001;31:427-36.

[19] Hasui M, Hirabayashi Y, Kobayashi Y. Simultaneous measurement by flow cytometry of phagocytosis and hydrogen peroxide production of neutrophils in whole blood. $\mathrm{J}$ Immunol Methods 1989;117:53-8.

[20] Ribeiro A, Ferraz-de-Paula V, Pinheiro ML, Sakai M, Costa-Pinto FA, Palermo-Neto J. Anandamide prior to sensitization increases cell-mediated immunity in mice. Int Immunopharmacol 2010;10:431-9.

[21] Landreth KS. Critical windows in development of the rodent immune system. Hum Exp Toxicol 2002;21:493-8.

[22] Chlodzinska N, Gajerska M, Bartkowska K, Turlejski K, Djavadian RL. Lipopolysaccharide injected to pregnant mice affects behavior of their offspring in adulthood. Acta Neurobiol Exp (Wars) 2011;71:519-27.

[23] Abbas AK, Lichtman AH, Pillai S. Cellular and molecular immunology. 6th ed: Saunders Elsevier; 2007.

[24] Kirsten TB, de Oliveira BP, de Oliveira AP, Kieling K, de Lima WT, Palermo-Neto J, Bernardi MM. Single early prenatal lipopolysaccharide exposure prevents subsequent airway inflammation response in an experimental model of asthma. Life Sci 2011;89:15-9.

[25] Basta-Kaim A, Szczesny E, Leskiewicz M, Glombik K, Slusarczyk J, Budziszewska B, Regulska M, Kubera M, Nowak W, Wedzony K, Lason W. Maternal immune activation leads to age-related behavioral and immunological changes in male rat offspring - the effect of antipsychotic drugs. Pharmacol Rep 2012;64:1400-10. 